\title{
Rain, Rain, Go Away: 195 Potential Exclusion-Restriction Violations for Studies Using Weather as an Instrumental Variable
}

\author{
Jonathan Mellon
}

2023-04-19

\begin{abstract}
Instrumental variable (IV) analysis assumes the instrument only affects the dependent variable via its relationship with the independent variable. Other possible causal routes from the IV to the dependent variable are exclusion-restriction violations and invalidate the instrument. Weather has been widely used as an instrument in social science to predict many different variables. The use of weather to instrument different independent variables represents strong prima facie evidence of exclusion violations for all weather-IV studies. A review of 289 studies reveals 195 variables previously linked to weather: all representing potential exclusion violations. Using sensitivity analysis, I show that the magnitude of many of these violations is sufficient to overturn numerous existing IV results. I conclude with practical steps to systematically review existing literature to identify and quantify possible exclusion violations when using IV designs.
\end{abstract}

\section{Introduction $^{1}$}

Endogeneity is a pervasive challenge for social scientists. The causal relationship between $X_{1}$ and $Y$ cannot be estimated simply by observing their relationship (first DAG in table 1) as most variables share unmeasured confounders $U$ (second row). One strategy is to use an instrumental variable (IV) $W$ that causally affects $X_{1}$ but is uncorrelated with the

\footnotetext{
${ }^{1}$ Thanks to Tom Pepinsky, Jack Bailey, Chris Prosser, Carlos Cinelli, the University of Manchester Democracy and Elections Group, the Trade, Environment, Development and Energy Research Group at the University of Birmingham, and the McGill Department of Economics for feedback on drafts of this paper. The views expressed herein are those of the author and do not reflect the position of the United States Military Academy, the Department of the Army, or the Department of Defense.
} 
error term. $W$ 's ability to manipulate $X_{1}$ independently of $U$ allows for consistent causal estimation of the relationship between $X_{1}$ and $Y$ using techniques like two-stage least squares (2SLS) subject to identifying assumptions.

IV estimation assumes that $W$ affects $Y$ only through $X_{1}$ (the exclusion restriction) as shown in table 1's third row. ${ }^{23}$ However, this assumption is violated if another pathway between $W$ and $Y$ exists such via $X_{j}$ in the fourth row of table 1 . If we assume that any alternative pathway between $W$ and $Y$ is mediated by at least one variable, the exclusion restriction can be restated as the claim that no variable $X_{j}$ exists that is both caused by $W$ and which causes $Y$ (and that $X_{1}$ does not fully mediate either link). The untestability ${ }^{4}$ of the exclusion restriction comes from the fact that there is no guarantee that we have enumerated all $X_{j}$ variables. If we had a definitive list of $X_{j}$ variables, the assumption would be testable provided we could establish the presence or absence of $X \rightarrow X_{j}$ and $X_{j} \rightarrow Y$ in each case.

Although we lack a complete list of $X_{j}$ variables, we can search for social science variables claimed to be caused by $W$. These variables are strong candidates for exclusion-restriction violations, as they usually only additionally require the existence of the $X_{j} \rightarrow Y$ relationship

\footnotetext{
${ }^{2}$ In practice, most IV studies also include a set of exogenous covariates $K$. While I describe unconditional IV estimation here, the same logic applies except that the various independence assumptions are conditional on $K$.

${ }^{3}$ I follow Angrist, Imbens, and Rubin (1996) in treating the exogeneity assumption separately to the exclusion restriction.

${ }^{4}$ Statistical techniques can detect exclusion-restriction violations but not confirm their absence. The Sargan-Hansen test applies when there are more instruments than instrumented variables by testing whether the residuals for the second-stage estimate (dropping one instrument at a time) correlate with the instruments (Kiviet 2020). The zero-first-stage test verifies that the treatment's reduced-form effect is zero in a sub-sample where the instrument should not affect $X_{1}$ (Kippersluis and Rietveld 2018).
} 


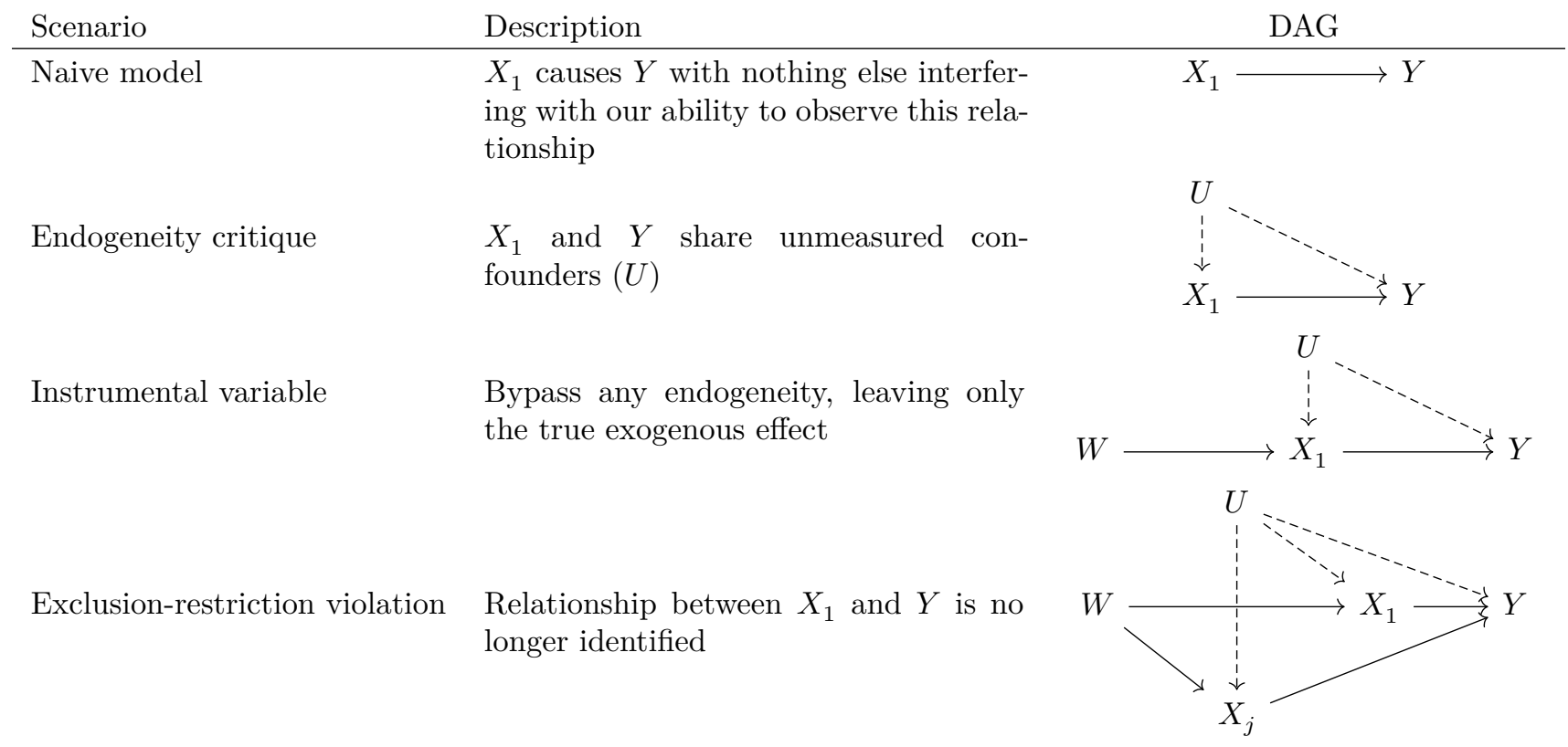

Table 1: DAGs illustrating Instrumental variables and endogeneity

(exceptions are described in table 2). Systematically searching for $W \rightarrow X_{j}$ links is an efficient approach to identify potential exclusion-restriction violations.

This approach turns the exclusion restriction from an untestable claim to a set of substantive claims about social science variables. It also includes a weaker, untestable claim that there are no undocumented $X_{j}$ variables violating the exclusion restriction.

I present a process to: 1) search for exclusion-restriction variables in existing literature, 2) assess and document exclusion-restriction violations, and 3) conduct sensitivity analysis to assess the impact of violations on results.

I apply this approach to a widely used instrument: the weather. The weather is appealing as a source of exogenous variation because it seems obvious that the weather is essentially random 
and only related to human outcomes through narrow causal paths. I examine whether the exclusion-restriction assumption is plausible for weather IVs.

Weather instruments are not without critics. Sarsons (2015) identifies likely exclusionrestriction violations in IV estimates of rainfall on economic growth, as rain predicts conflict even where incomes are unaffected and Horiuchi and Kang (2018) express concern that rainfall's effect on vote share is larger than can be explained by turnout alone. Gallen and Raymond (2019) raise exclusion-restriction concerns for rainfall and other overused IVs in economics. This paper goes beyond their analysis by examining studies in other social science fields, and quantifying the strength of exclusion-restriction violations using sensitivity analysis. Cooperman (2017) argue that rainfall suffers from spatial interdependence. Weather also has measurement problems (Dell, Jones, and Olken 2014; Schultz and Mankin 2019).

Rather than independently discovering violating routes from weather to outcomes, I use the IV literature itself to identify alternative causal pathways. I review 159 weather-IV studies and an additional 130 studies of the direct effect of weather. In total, I identify 195 variables that social scientists have linked to weather through many causal pathways. Consequently, this review challenges many weather-IV findings.

Any exclusion-restriction violation will bias an IV estimate, but small violations may be 
acceptable. I assess the severity of these violations by using the first-stage of IV estimates of weather on $X_{j}$ variables to conduct sensitivity analysis (Cinelli and Hazlett 2020a) on other weather IVs. This allows me to show how large a relationship would have to exist between an $X_{j}$ variable and a dependent variable to make an IV estimate insignificant. For some IV studies, $X_{j}$ would have to explain as little as $0.01 \%$ of variance in $Y$ to make the IV estimate of $X_{1}$ on $Y$ insignificant. However, in other cases, $X_{j}$ variables could not make the IV estimate insignificant, even if $X_{j}$ were perfectly correlated with $Y$. While both scenarios have exclusion-restriction violations, the sensitivity of the IV estimate in the former case should concern us more.

I demonstrate the process of assessing potential exclusion-restriction violations by examining which $X_{j}$ variables represent an exclusion-restriction violation for a weather-IV estimate of the effect of economic activity on civil conflict.

The paper proceeds as follows. First, I discuss the implications of one IV study using the same instrument as another. Second, I outline my approach to reviewing literature on an instrument, conducting sensitivity analysis, and assessing and documenting potential exclusion-restriction violations. Third, I show the review's results, the extent of exclusion violations for weather as an IV, and the sensitivity of IV results to these violations, including applying the full assessment method to a study examining the effect of economic activity on 
civil conflict. I conclude by discussing the implications of these results for social science IVs.

\section{What does another study using the instrument imply?}

What does another study using the same instrument for a different variable indicate? For

example, study 1 argues $W$ is an instrument for $X_{1}$ to predict an outcome $(Y)$ to avoid unobserved confounders $(U)$. Study j proposes that $W$ serves as an instrument for another variable $X_{j}$.

The simplest answer is that study j represents an exclusion-restriction violation where $X_{j}$ represents an alternate pathway from $W$ to $Y$ that does not include $X_{1}$ (shown in the fourth row of table 1). Other possibilities are presented in table 2, with each row displaying a DAG compatible with study 1 and study j's IV estimatethe new result and study 1's IV estimate. The DAG uses wavy red arrows to show causal links that must be absent for causal identification of study 1's IV estimate.

First, we can reject the claim that $W$ causes $X_{j}$ if the original claim was flawed or found in an inapplicable context (exception 1). For example, using prevailing winds $(W)$ to estimate the effect of grain shipments $\left(X_{j}\right)$ on 15 th century urbanization $(Y)$ is irrelevant to a study using $W$ to predict 21 st century pollution levels $\left(X_{1}\right)$.

If $X_{j}$ is part of $X_{1}$ (exception 2), it does not generally violation the exclusion restriction. 
Study 1 may use natural gas deposits $(W)$ to instrument pollution exposure's $\left(X_{1}\right)$ effect on mortality $(Y)$, while study $\mathrm{j}$ uses natural gas deposits to instrument sulfur dioxide exposure $\left(X_{j}\right)$. Sulfur dioxide exposure is part of pollution exposure, so this is not an exclusionrestriction violation for study 1 .

If $X_{1}$ is part of $X_{j}, X_{j}$ may not be an exclusion-restriction violation if no other part of $X_{j}(Q)$ is caused by $W$ and causes $Y$ (exception 3). For example, using elevation $(W)$ as an instrument for heart attacks $\left(X_{1}\right)$ would not necessarily be undermined by a claim that elevation causes health $\left(X_{j}\right)$, if the effect of elevation on health is solely due to its effect on heart attacks. If elevation affects another component of health $(Q)$ such as diabetes, $X_{j}$ would be an exclusion-restriction violation.

If $X_{j}$ is part of $Y$ (exception 4), it is not an exclusion-restriction violation unless $W$ directly affects $X_{j}$. Study 1 may use proximity to college $(W)$ as an instrument for education's $\left(X_{1}\right)$ effect on income $(Y)$, while study j uses proximity to college as an instrument for selfemployment income $\left(X_{j}\right)$. In this scenario, $X_{j}$ is not an exclusion-restriction violation for study 1 .

If $Y$ is part of $X_{j}$, it may not be an exclusion-restriction violation (exception 5). The key assumption is either that $W$ does not affect any part of $X_{j}$ apart from $Y$, or $Q$ does not affect 
$Y$. Reworking the previous example, study 1 uses proximity to college $(W)$ to instrument education's $\left(X_{1}\right)$ effect on self-employment income $(Y)$, and study j uses $W$ to instrument income $\left(X_{j}\right)$. Study j does not violate study 1's exclusion restriction provided that proximity to college does not influence self-employment income through income components unrelated to education. For instance, if self-employment income is crowded out by salary income earned from working at local colleges, it may constitute an exclusion-restriction violation.

Next, $X_{j}$ may mediate the effect of $X_{1}$ on $Y$ (exception 6). For example, drought $(W)$ may cause agricultural incomes $\left(X_{1}\right)$ to fall, leading to competition for resources $\left(X_{j}\right)$, ultimately resulting in violence $(Y)$. The existence of study $\mathrm{j}$ which uses droughts as an instrument for competition for resources does not necessarily invalidate study 1 which uses droughts as an instrument for agricultural income. However, study 1 must make a strong assumption: that there is no other causal pathway between droughts $(W)$ and competition for resources $\left(X_{j}\right)$ other than via agricultural income (indicated by the wavy red arrow on the DAG).

Another possibility is that $X_{j}$ does not cause $Y$ (exception 7). Suppose that study 1 uses military draft lottery number $(W)$ as an instrument for education's $\left(X_{1}\right)$ effect on income $(Y)$, while study $\mathrm{j}$ uses draft lottery number as an instrument for military service $\left(X_{j}\right)$. If military service does not affect earnings, then study $\mathrm{j}$ does not violate study 1's exclusion restriction. 
Finally, $X_{j}$ may mediate the effect of $W$ on $X_{1}$ (exception 8). For example, droughts $(W)$ may cause lower crop yield $\left(X_{j}\right)$, reducing agricultural income $\left(X_{1}\right)$, leading to violence $(Y)$. Study j's use of droughts as an instrument for crop yield does not automatically invalidate study 1's use of droughts as an instrument for agricultural income's effect on violence.

However, it requires an additional assumption: there are no other routes from crop yield $\left(X_{j}\right)$ to violence $(Y)$ other than through agricultural income (represented by the red wavy line). If an alternate pathway exists, such as via starvation or migration, this represents an exclusion-restriction violation and invalidates study 1's use of $W$ as an instrument for $X_{1}{ }^{5}$

\footnotetext{
${ }^{5}$ If a route from $W$ to $X_{1}$ that does not go via $X_{j}$ exists, $W$ can be a valid instrument by conditioning on $X_{j}$ and all confounders between $X_{j}$ and $Y$. Though technically valid, the assumptions stretch credulity.
} 
If none of these exceptions apply, then $X_{j}$ is an exclusion-restriction violation with the DAG shown in the fourth row of table 1.

In this scenario, Gallen and Raymond (2019) recommend conditioning on $X_{j}$ to recover the causal effect of $X_{1}$ on $Y$. However, this approach necessitates measuring all $X_{j}$ variables in the same dataset. Additionally, it requires that the DAG has the structure in figure 1 : that the unobserved confounders of $X_{1}$ and $Y\left(U_{1}\right)$ have no covariance with the unmeasured confounders of $X_{j}$ and $Y\left(U_{j}\right)$. In complex causal settings where IV is an attractive approach, making strong assumptions about unmeasured and even unknown variables is difficult to justify. If these assumptions are not met, $X_{j}$ is a collider for $U_{1}$ and $Y$ is an invalid control (Cinelli, Forney, and Pearl 2022). Conditioning on $X_{j}$ creates a backdoor path between $U_{1}$ and $W$ meaning the effect of $X_{1}$ on $Y$ is not causally identified (because it is confounded by $U_{1}$ ) and can be highly biased (Deuchert and Huber 2017). Since $X_{j}$ is an exclusion-restriction violation but cannot be conditioned on, there is no remaining way to identify study 1's IV estimate.

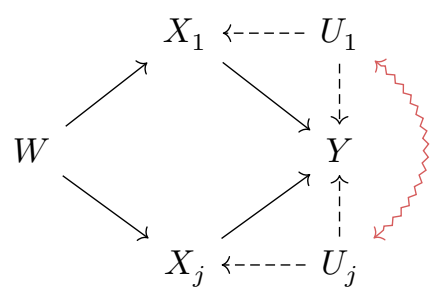

Figure 1: DAG showing a situation where conditioning on $X_{j}$ allows $W$ to be used as an instrument to estimate the causal effect of $X_{1}$ on $Y$. $\rightsquigarrow$ indicates causal links that must be absent. 


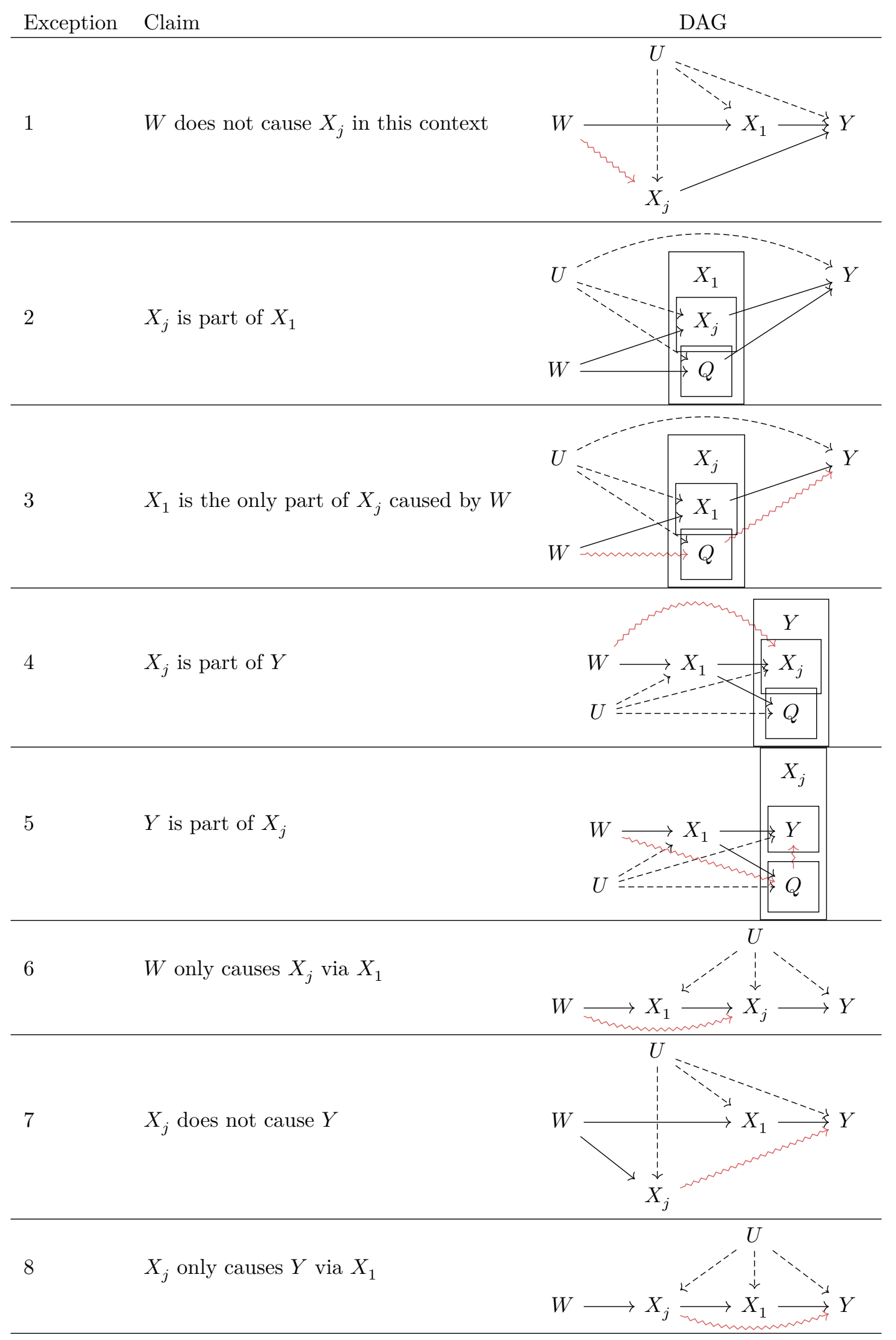

Table 2: Situations where $X_{j}$ is not an exclusion-restriction violation for an IV estimate of $X_{1}$ on $Y$ despite another study finding an effect of $W$ on $X_{j}$. $\leadsto$ indicates causal links that must be absent. Where there are multiple such links, at least one must be absent. A boxed variable inside a larger box indicates that the variable is a component of the variable represented by the larger box. 
This discussion has focused on identifying whether the estimate is strictly causally identified.

In practice, exclusion-restriction violations vary in magnitude, with corresponding levels of bias in the causal estimate. When the effect of $X_{j}$ on $Y$ is small, the overall bias may be minimal. Similarly, conditioning on $X_{j}$ may not dramatically bias the estimates when the effect of $U_{j}$ on $X_{j}$ and $Y$ is small enough, (Gallen and Raymond 2019). I address the magnitude of biases from exclusion-restriction violations using sensitivity analysis.

\section{Exclusion-Restriction Violation Assessment Methodology}

This section outlines a methodology for evaluating exclusion-restriction violations for an instrument based on existing literature. I explain the general methodology at each step and also provide detail on how I apply this methodology to the weather-IV example in this paper. This approach can be applied retrospectively to an existing IV claim or prospectively as part of new IV studies.

The methodology involves four steps. First, the literature is used to identify $X_{j}$ variables linked to study 1's instrument $W$. Second, potential exclusion-restriction variables are filtered for relevance using broad filters, such as country income level. Third, each $X_{j}$ variable is assessed using theory and literature to determine whether it falls under any of the excep-

tions in table 2 . Any remaining $X_{j}$ variables are likely to indicate an exclusion-restriction 
violation for study 1.

However, the violation's importance depends on the strength of the $W \rightarrow X_{j}$ and $X_{j} \rightarrow Y$

causal links. Thus, the fourth step examines the bias in study 1's estimate through sensitivity

analysis, using estimates of relationship strength from applicable literature.

\subsection{Weather example}

Weather IVs are widely used by social scientists, so provide a rich example for the exclusionrestriction methodology. I test the methodology in two ways in this paper. I test most of the stages of the process on as many weather-IV estimates as possible. This helps to understand how vulnerable a typical weather-IV estimate is to exclusion-restriction violations.

The exception-search stage is too intensive to perform on every IV estimate. I therefore, also show the full process on a single IV estimate of the effect of economic activity on civil conflict (using rainfall as an instrument). This relationship has been repeatedly studied using weather instruments (Miguel and Satyanath 2011; Jensen and Gleditsch 2009; Miguel, Satyanath, and Sergenti 2004), with various criticisms (Sarsons 2015; Ciccone 2011) leveled at those studies. I examine a study using subnational data for African countries (Hodler and Raschky 2014) with information available for sensitivity analysis. Hodler and Raschky (2014) find an effect of $-0.303(\mathrm{SE}=0.111)$ on conflict probability for a 1 -unit increase in 
the log of economic activity (measured using light intensity).

\subsection{Enumerate potential exclusion-restriction violations}

The method aims to identify as many potential exclusion-restriction violations (documented

causal links $W \rightarrow X_{j}$ ) for an IV study (study 1) as possible. The researcher enumerates

possible linkages between an instrument $W$ and variables that could affect humans $\left(X_{j}\right)$ by searching the literature about $W$ and examining what variables $W$ has been used to predict. IV studies which also use $W$ as an instrument are a particularly valuable source of $X_{j}$ variables because they make explicitly causal claims and often provide estimates that can be used in sensitivity analysis. Researchers should also search the literature for $X_{j}$ variables that are causally affected by closely related variables to $W$. For example, a researcher using elevation as an instrument should search for studies using variables such as air pressure or mountainous terrain as instruments or predictors. The researcher should also include any plausible $X_{j}$ variables they can think of that are not covered in the existing literature. Since a single exclusion restriction violation can undermine the IV strategy, researchers may choose to examine an initial batch of $X_{j}$ variables for their effect on study 1's estimate rather than attempting to fully enumerate all $X_{j}$ variables. If this initial batch does not reveal exclusionrestriction violations that cause unacceptable levels of bias, researchers should extend the literature search until they either find an unacceptable exclusion-restriction violation or have 
exhausted the literature.

\subsubsection{Application to weather IVs}

I apply the same method for enumerating potential exclusion-restriction variables to both

the broad analysis of weather-IV studies and the narrow economic activity $\rightarrow$ civil conflict

case. This literature review serves the dual purpose of identifying 1) the weather-IV studies

under examination for the broad analysis and 2) the potential exclusion-restriction variables

$\left(X_{j}\right)$ for those studies.

Although these studies use various weather phenomena as instruments, different weather

types are part of a complex causal network and are generally substantially correlated ${ }^{6}$ both

spatially $^{7}$ and longitudinally (Nicholls, Drosdowsky, and Lavery 1997). This means the causal

relationship rain $\rightarrow X_{j}$ implies some form of causal relationship between temperature and

$X_{j}$, and wind speed and $X_{j}$, although the strength of that relationship may be attenuated.

To generate potential exclusion-restriction variables for weather-IV studies, I reviewed the

first 500 results for the search term "weather "instrumental variable", on Google Scholar

(while the search returned 12,700 results in total, the results after 500 seemed largely off

topic). I also included the first 100 results from 'rain "instrumental variable", a few previ-

\footnotetext{
${ }^{6}$ These correlations do not account for measurement error. Correlations between different weather phenomena are not much lower than the correlations between different measurements of the same phenomenon (Auffhammer et al. 2013).

${ }^{7}$ Annual precipitation (2014 World Development Indicators) correlates with 2014 yearly-average temperature (World Bank Climate Knowledge Portal) at the country level at $\mathrm{r}=0.28$.
} 
ously identified studies, and relevant studies cited in other papers. This yielded 159 weatherIV studies, and 130 studies using weather as the independent variable of interest. These studies were primarily in economics, political science, and international development.

All studies were entered into a table (table B1) tracking the instrument, instrumented variable, and outcome variable. If a study contains more than one combination of these, I include a row for each combination. I also record the frequency of weather measurement, and IV, reduced-form, and first-stage estimates where available.

For analysis, I recoded the variables into coarser theoretical categories. For example, I coded GDP, household income, average income, economic growth, permanent income, income, agricultural income, growth, per-capita income, crop revenue per hectare, poverty, transitory income, agricultural growth, and farm financial performance as "income". Less coarse categories would better distinguish concepts but would increase the count of potential exclusion-restriction violations (since I enumerate $W \rightarrow X_{j}$ relationships but not $X_{j} \rightarrow Y$ relationships).

\subsection{Filter potential exclusion-restriction violations for relevance}

While the literature is a useful source of information about potential exclusion-restriction violations, not all existing $W \rightarrow X_{j}$ claims will be relevant to study 1's estimate. Because I 
only focus on whether the link exists at this stage, I do not need to worry about factors that

change the strength of the $W \rightarrow X_{j}$ link across contexts, but only factors that could make the link exist in the context of study $\mathrm{j}$ but not study 1 . If the enumeration step produced a large number of potential exclusion-restriction variables, it may be useful to apply heuristics to limit variables to those most likely to affect study 1 . The exact filters will depend on the study: political regime might be relevant for a voting behavior study, whereas economic development could be more relevant for a study of economic growth.

\subsubsection{Application to weather IVs}

I consider two factors that could lead a causal relationship between weather and $X_{j}$ to exist in one context but not another: 1) the temporal frequency of the weather variable and 2) the economic context of each study.

3.3.1.1 Temporal frequency Weather can be measured at different levels of temporal aggregation e.g. daily versus yearly rainfall variation. Shorter periods are generally relevant to longer periods but not the inverse. An effect of daily sunlight levels on happiness might generalize to an effect of yearly sunlight effects. However, it is less likely that an effect of yearly rainfall on income would generalize to daily variation in rainfall. Long-period weather-IV studies (differences on the order of years) are therefore vulnerable to exclusion-restriction 
violations from all other weather-IV studies. However, if short-term studies control for longterm weather, it should be possible to remove exclusion-restriction violations working via longer-term weather. For example, turnout weather-IV studies often control for the average weather on that date but this does not account for the correlation between election-day weather and weather patterns in the area over the past week or month, so fully controlling for other time periods is challenging.

I split the studies into short-term (weather measured monthly or more frequently) and longterm (weather measured less than monthly).

3.3.1.2 Economic development The relevance of exclusion-restriction variables may vary because the societies studied are different. Although societies vary along many dimensions, the most relevant factor for weather appears to be economic development. Poorer countries tend to have economies based on agriculture and raw-material extraction, while richer countries have more diversified economies. Consequently, the effects of weather may differ across these settings.

To mitigate this problem, I categorize the countries in each study based on the World Bank's current development levels. High and higher-middle income countries are grouped as high income, while lower-middle and lower income countries are grouped as low income. This 
compromises between only considering exclusion-restriction violations from identical contexts and allowing estimates from poor agricultural contexts to be relevant to high-income countries.

\subsection{Search for exceptions where $X_{j}$ is not a potential exclusion-restriction vio- lation}

Each $X_{j}$ variable is assessed using the steps in table 2 to assess 8 possible exceptions for why it may not be an exclusion-restriction violation. The subsequent step is only taken if the previous step fails to identify an exception. Literature searches and theoretical consideration should inform the decision at each stage. If an exception is found for $X_{j}$, the evidence and/or theory should be documented so readers can assess its validity.

If no exceptions apply, $X_{j}$ violates study 1's exclusion restriction.

\subsubsection{Application to weather IVs}

I do not attempt to search for exceptions for the broad set of weather IVs as this would require investigating 13,356 possible causal relationships (159 $Y$ variables and $84 X_{j}$ variables). However, an individual study would only need to assess $84 X_{j}$ variables for causal links to the $Y$ variable for that study.

To demonstrate this step, I apply the exception-search method to the IV estimate of economic activity's effect on civil conflict (Hodler and Raschky 2014). 


\subsection{Sensitivity Analysis}

The methodology so far aims to gather examples of exclusion-restriction violations for an IV

study (study 1). However, the presence of exclusion-restriction violations does not necessarily imply large biases in study 1's IV estimates. Instead, we must examine whether $X_{j}$ is a large enough violation of the exclusion-restriction assumption to alter the study 1's conclusions.

I assess the IV estimate's sensitivity by looking at the reduced-form (Cinelli and Hazlett 2020a), with an estimate being sensitive if the bias would make it non-significant or change the sign of the effect. While I focus on exclusion-restriction violations reducing an effect's magnitude, they could also arbitrarily increase its magnitude, depending on the sign of the $W \rightarrow X_{j}$ and $X_{j} \rightarrow Y$ relationships. I treat the $X_{j}$ variables as confounders, although this means the sensitivity analysis could be affected by post-treatment bias if $X_{j}$ and $Y$ share unmeasured confounders. Therefore, the sensitivity estimates indicate the likely level of bias but should not be considered the final substantive answer. The sensitivity analysis currently only applies to the IV regression reduced form in the case of a single instrument. However, multiple-instrument studies are not systematically less susceptible to exclusion-restriction violations.

The impact of an exclusion-restriction violation on an IV study's conclusions depends on two quantities: the partial $R^{2}$ of the relationship between the instrument $W$ and an exclusion- 
restriction variable $X_{j}\left(R_{X_{j} \sim W \mid K}^{2}\right)$, and the partial $R^{2}$ of the relationship between $X_{j}$ and the dependent variable $Y\left(R_{Y \sim X_{j} \mid W, K}^{2}\right)$, where $K$ is the set of exogenous predictors in the original study.

Based on a pair of partial- $R^{2}$ values for a particular $X_{j}$, I compute the bias of the coefficient (Cinelli and Hazlett 2020a) using the sensemakr package (Cinelli, Ferwerda, and Hazlett 2020) (where $n$ is the sample size and $p$ is the number of predictors):

$$
\text { bias }=S E \sqrt{\frac{R_{Y \sim X_{j} \mid W, K}^{2} R_{X_{j} \sim W \mid K}^{2}}{1-R_{X_{j} \sim W \mid K}^{2}}(n-p-1)}
$$

and the corrected standard error:

$$
S E_{\text {corrected }}=S E \sqrt{\frac{1-R_{Y \sim X_{j} \mid W, K}^{2}}{1-R_{X_{j} \sim W \mid K}^{2}} \cdot \frac{n-p-1}{n-p-2}}
$$

These are used to calculate a new central estimate and confidence interval which can be used to assess whether the revised estimate is unacceptably different from the original. In this paper, I consider an unacceptable change to be one that makes the result no longer significant with the same sign (or a change of equivalent magnitude in the same direction as the original effect). 
But how large are the relevant partial- $R^{2}$ values? These can be derived in various ways including with new data analysis or from studies which provide the estimates in this format. The IV literature provides useful estimates of $R_{X_{j} \sim W \mid K}^{2}$ through its first-stage estimates of the relationship between $W$ and various $X_{j}$ variables measured via F-statistics $\left(F_{X_{j}, W \mid K}\right){ }^{8}$

For study 1 , estimates of relationships between $W$ and the $X_{j}$ in other studies' (j) indicate the strength of possible exclusion-restriction violations.

If both partial- $R^{2}$ values are available, the revised estimate can be directly calculated. However, often one or both will be unavailable. If one partial- $R^{2}$ value is missing, it is possible to ask how large the other partial- $R^{2}$ value would need to be in order to change the original result unacceptably. If the second partial- $R^{2}$ would have to be huge to overturn a result, then the exclusion-restriction violation is unlikely to greatly change study 1's substantive conclusion. If the second partial- $R^{2}$ value could be minuscule yet still overturn the result, we should be wary of trusting study 1's conclusions.

If partial- $R^{2}$ values are unavailable, researchers can calculate pairs of values that needed to invalidate study 1's result and consider whether they can confidently rule out all of those

\footnotetext{
${ }^{8}$ The $R_{Y \sim X_{j} \mid K}^{2}$ for a model predicting $Y$ using a set of $q$ instruments $\left(X_{j}\right)$ and $p$ exogenous predictors $(K)$ is derived from the F-statistic $F_{Y, X_{j} \mid K}: R_{Y \sim X_{j} \mid K}^{2}=\frac{F_{Y, X_{j} \mid K} \cdot q}{(n-p-q)+q * F_{Y, X_{j} \mid K}}$, where $n$ is the number of observations. The degrees of freedom for the F-statistic are estimated from the available information about the number of observations, predictors, and instruments. Some studies likely accounted for clustering in their first-stage F-statistic but this information is rarely available, so I conservatively calculate degrees of freedom as $n-p-q$. Since the more robust approaches will return a smaller F-statistic, this assumption means I will tend to underestimate $R_{W \sim X_{j} \mid K}^{2}$ values and - consequently - the impact of exclusion-restriction violations. When researchers apply this technique they may want to consider calculating $R_{Y \sim X_{j} \mid K}^{2}$ from replication data for crucial $X_{j}$ variables to avoid these approximations.
} 
combinations.

\subsubsection{Filter fit statistics for transportability}

For a $R_{X_{j} \sim W \mid K}^{2}$ estimate from study $\mathrm{j}$ to be relevant to study 1 , three requirements must be met: 1) study 1 and j must use the same instrument, $\left.{ }^{9} 2\right)$ study 1 and j must model the same variance type (e.g. within-person), ${ }^{10}$ and 3) study 1 must not control for $X_{j}{ }^{11}$

\subsubsection{Application to weather IVs}

For the broad analysis of weather IVs, I am only able to examine reduced-form estimates that use single weather instruments and provide sufficient information to derive the reduced-form equation.

While all the studies I consider use some form of weather as an instrument, the exact variable used varies across studies (see table D1). Rainfall is the most common followed by temperature. Different weather types will not have the same strength of relationship to a particular

$X_{j}$. A study that demonstrates a strong link between rainfall and $X_{j}$ does not imply that $X_{j}$ is as strongly related to sunlight intensity or snowfall. I therefore only consider study j's $R_{X_{j} \sim W \mid K}^{2}$ estimate if it makes use of the same weather variable as study 1.

\footnotetext{
${ }^{9}$ This is a stricter standard than at the enumeration stage where only the presence of a causal link is required.

${ }^{10}$ Different variance types make it difficult to compare goodness-of-fit due to different DGMs, uneven sizes of geographical units, and different amounts of variance.

${ }^{11}$ Controlling for $X_{j}$ is inadvisable since it involves conditioning on a collider but would make the sensitivity analysis mischaracterize the bias. I therefore exclude first-stage estimates for $X_{j}$ variables controlled for in study 1. Other exogenous controls $(K)$ may affect partial- $R^{2}$ transferability but additional controls (beyond fixed effects) typically have a small effect on variance left to explain.
} 
The variance being modeled differs across weather studies (see table E1). For instance, some weather-IV studies use individual-level data at a single time point (between-person) while others use district-level data over time (within-subnational). The most common variance modeled is within-subnational . For instance, a yearly panel of US states with year and state fixed-effects. Within-person (or household) variation is the next most modeled form of variance: using person fixed-effects, lagged-dependent-variable, or first-differencing strategies. Studies that use within-unit variation often refer to the strategy as modeling the effect of weather shocks (because the effect of average weather is removed by unit fixed effects)

Few weather-IV estimates are excluded for controlling for other causal pathways. Of the $120 X_{j}$ variables with a $R_{X_{j} \sim W \mid K}^{2}$, only 39 are used as a control variable in one of the 63 reduced-form estimates. Income is the most commonly controlled exclusion-restriction variable, controlled for in $14 \%$ of IV estimates.

\section{Results}

\subsection{Enumerating potential exclusion-restriction violations for weather IVs}

In the assumed DAG in the third row of table 1, weather only affects the causal network through $X_{1}$. In reality, the literature review of 289 studies finds that weather enters the social science causal network through 124 different variables, and indirectly reaches 194 variables of 
interest to social scientists. Each of these variables represents a potential exclusion-restriction violation for the IV DAG (including the economic activity $\rightarrow$ civil conflict DAG). This is illustrated in figure 2 which shows the causal web for the most common weather type: rainfall. This is derived from 192 studies using rainfall and shows the wide variety of causal pathways the literature claims are linked to rain.

\subsection{Filter potential weather exclusion-restriction variables for relevance}

The overall weather DAG lists all potential exclusion-restriction violations from the literature, but scholars may prefer a narrower selection of relevant studies. Figure 3 displays causal links asserted in weather studies (of all weather types) by country income and temporal frequency. Few studies examine short-term weather variation in low-income countries, so only 11 variables are linked to weather including pirate attacks (Cook and Garrett 2013), COVID-19 (Shen, Cai, and Li 2020), exercise (Aral and Nicolaides 2017), and protest (Ritter and Conrad 2016).

The other time/income combinations show a large network of potential exclusion-restriction violations to consider. Short-term weather variation in high-income countries has 71 variables, long-term weather variation in low-income countries has 83 variables (this is the relevant set of $X_{j}$ variables for the economic activity $\rightarrow$ civil conflict example), and long-term variation in high-income countries has 122 variables. Most weather-IV studies have many 


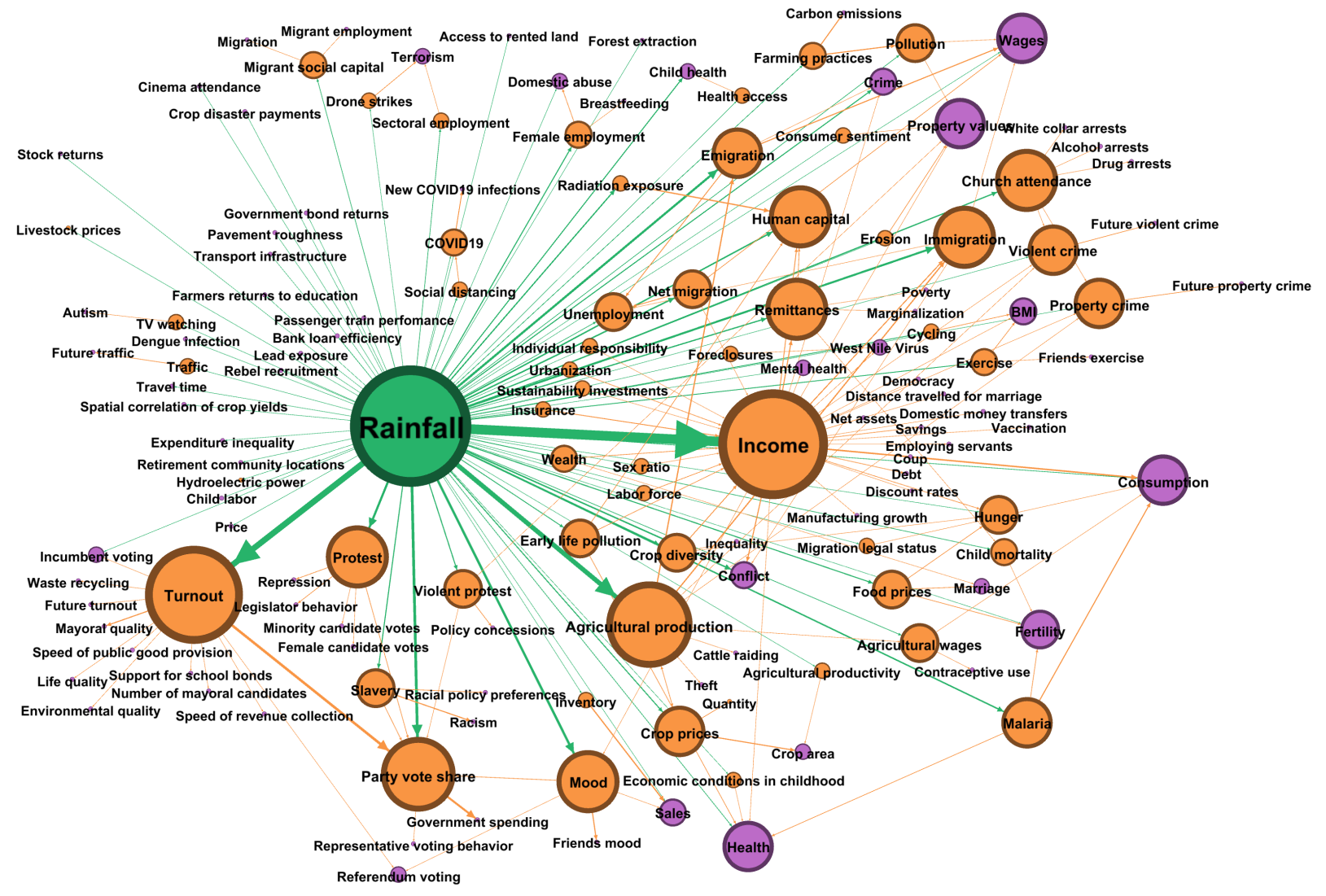

Figure 2: Causal web of rainfall from 192 papers. Nodes and ties sized proportional to the number of appearances in the literature. Colors: weather (green), instrumented variable (orange), and outcome (purple) 
relevant potential exclusion-restriction violations.

If all of these $W \rightarrow X_{j}$ relationships exist, the typical weather-IV study requires hundreds of additional identifying assumptions, which quickly becomes implausible.

\subsection{Which variables have been linked to weather?}

The DAGs reveal myriad potential exclusion-restriction violations, encompassing crucial social science variables.

Income is the most widely-instrumented variable in weather-IV studies of high-income and low-income countries. The link between weather and income is usually attributed to crop yield. But crop yield has also been proposed as a mechanism for weather effects on other $X_{j}$ variables such as food prices and food production for personal consumption (e.g. Kubik and May 2018). This means IV studies may attribute the effects of price levels, hunger, or malnutrition to income, thereby overestimating its effect.

Weather causally affects many variables unrelated to agriculture, but the relevance of these

variables will vary. Most researchers can assume "helicopter flying conditions" and "pirate attacks" are not possible exclusion-restriction violations. However, many causal pathways are widely relevant to social science outcomes.

The first causal pathway is mood. Several studies claim weather influences mood (e.g. Meier, 


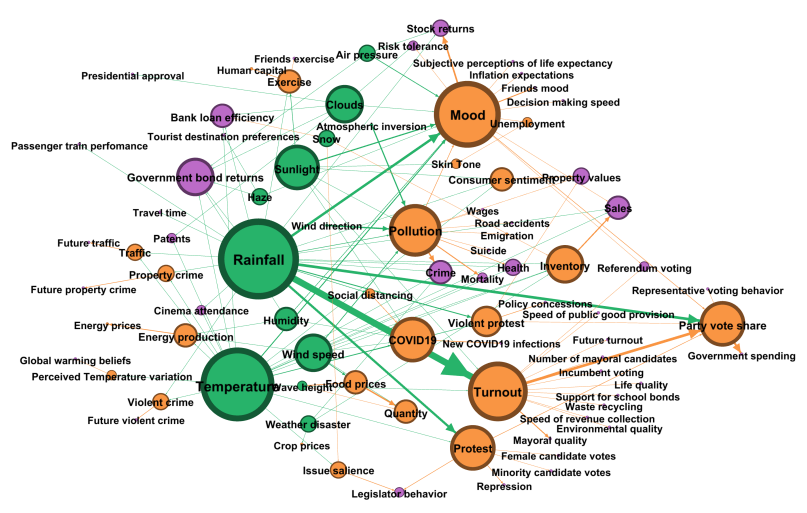

Low income countries/short-term

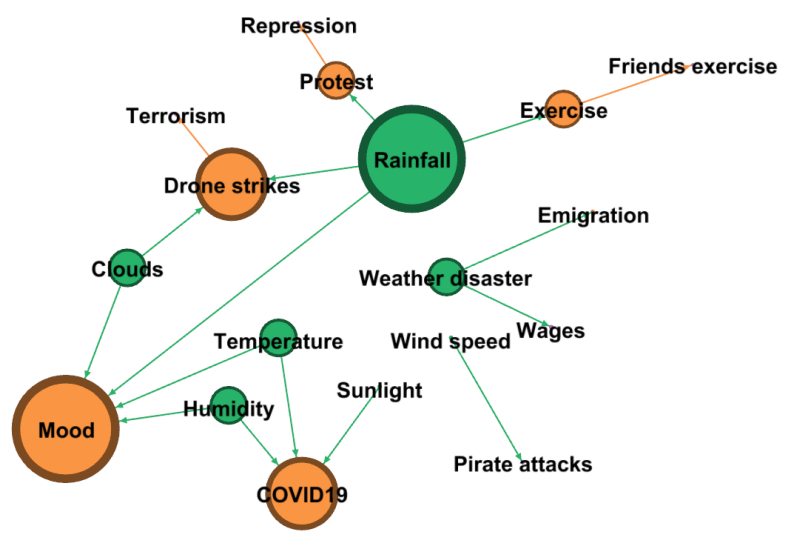

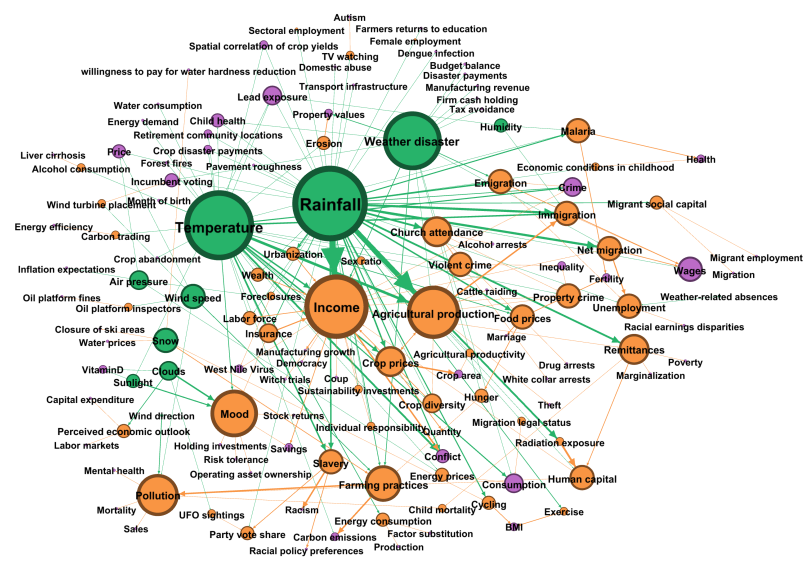

Low income countries/long-term

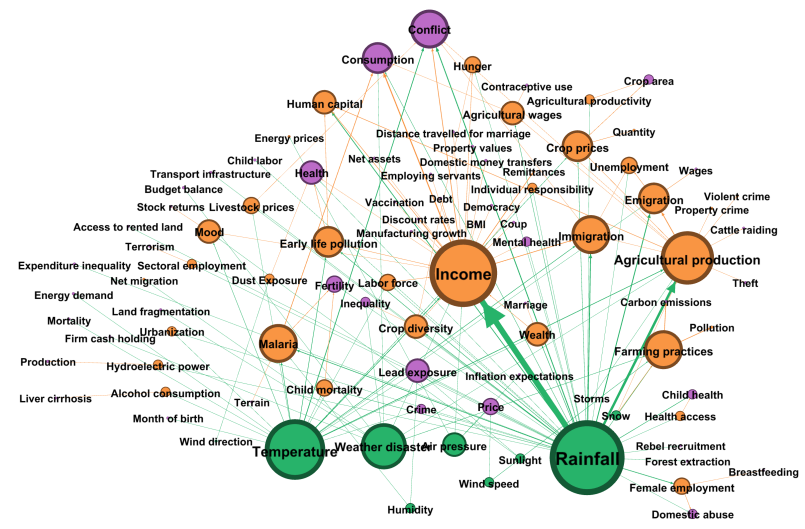

Figure 3: The causal webs of weather derived from 289 papers. Broken down by country income classification and temporal frequency. Size of nodes and ties are proportional to the number of appearances in the literature. Color key: weather (green), instrumented variable (orange), and outcome (purple) 
Schmid, and Stutzer 2019; Bassi 2019). In one weather-IV study, mood was linked to decisionmaking speed, investment decisions, inflation expectations, risk aversion, financial decisions, and perceived life expectancy (Guven and Hoxha 2015). Almost any social science variable could be causally influenced by at least one of these variables. Mood threatens both longterm and short-term weather-IV studies.

Another major causal route is pollution. Pollution has been instrumented by weather variables including wind speed (e.g. Peet 2020; Bondy, Roth, and Sager 2020), wind direction (e.g. Fan and Wang 2020), atmospheric inversions (Bondy, Roth, and Sager 2020; Sager 2019), and rainfall (e.g. Peet 2020). Pollution - in turn - has been linked to variables including crime (Bondy, Roth, and Sager 2020), mental health (Gu et al. 2020), mortality (Fan and Wang 2020), road accidents (Sager 2019), house prices (Fontenla, Goodwin, and Gonzalez 2019), cognition (Peet 2020), and mood (Zheng et al. 2019). Pollution threatens both long-term and short-term weather-IV studies.

Skin tone is another important variable. Katz et al. (2020) find that some people tan when exposed to sunlight while others do not. Using a weather-IV approach, they argue the gap in labor-market outcomes between those who do and do not tan widens during sunny periods.

This suggests that weather may impact social science outcomes through racial prejudice.

Skin tone could be an exclusion-restriction violation for long-term or short-term weather-IV 
studies.

Migration follows a similar pattern. Migration studies generally justify the use of weather as an IV by weather's effect on income, as lower incomes provide a push factor for emigrants and higher incomes are a pull factor for immigrants (e.g. Strobl and Valfort 2015). Even outside of low-income countries, there is evidence for non-economic links between migration patterns and weather, with Moretti (1998) finding good weather predicts the location of US retirement communities, and Rappaport (2007) finding the same pattern for US internalmigration more generally.

The next causal route is via the legacy of US slavery. Acharya, Blackwell, and Sen (2016) use cotton-growing climate (which includes weather variables) as an instrument for slavery. Slavery's legacy is therefore a potential exclusion-restriction violation for US IV studies using long-term weather.

There are hundreds of other variables including autism, government spending, drone strikes, UFO sightings, global warming beliefs, alcohol consumption, electricity demand, recycling, malaria, sex ratios, education, insurance, lead exposure, female labor force participation, witch trials, cinema attendance, child labor, birth month, cattle theft, democracy, urbanization, and bicycle usage. 


\subsection{Searching for exceptions where $X_{j}$ is not an exclusion-restriction violation}

I demonstrate how to identify potential exceptions for $X_{j}$ being an exclusion-restriction violation using an IV estimate of the causal effect of economic activity on civil conflict (Hodler and Raschky 2014).

Table 3 shows the 50 relevant $X_{j}$ variables other studies claim are caused by weather. The assumption column shows the outcome for the variables in the $X_{j}$ column. The justification and evidence for each categorization is shown in greater detail in table A1. My goal is not to advocate for these specific classifications, but to illustrate how the substantive assumptions behind the exclusion restriction can be shown explicitly to readers (who can decide whether they are convinced by the reasoning in table A1.

I categorize six variables as not being violations because the proposed $W \rightarrow X_{j}$ relationship does not apply to the current context (exception 1). For example, the claim that rainfall causes female labor force participation is based on studies of India (Chin 2012) and Vietnam (Thai and Myrskylä 2012), where rice-farming is considered women's work. Rice is a smaller part of African agriculture. I also reject $X_{j}$ variables where the claim is based on flawed work. For instance, the human capital and urbanization links to rainfall are based on a single cross-sectional working paper (Lagerlöf and Basher 2006) that used rainfall to instrument 
Table 3: IV identification assumptions for the causal effect of economic activity $\left(X_{1}\right)$ on civil conflict $(Y)$ for potential exclusion-restriction variables $\left(X_{j}\right)$ discovered to be related to a weather instrument $(W)$ in relevant literature. Remaining exclusion-restriction violations shown in bottom row.

\begin{tabular}{|c|c|c|}
\hline Exception & Assumption & $X_{j}$ \\
\hline 1 & $\begin{array}{l}W \text { does not cause } X_{j} \text { in this } \\
\text { context }\end{array}$ & $\begin{array}{l}\text { Female employment } \\
\text { Early life pollution } \\
\text { Individual Responsibility } \\
\text { Human capital } \\
\text { Urbanization } \\
\text { Month of birth }\end{array}$ \\
\hline 2 & $X_{j}$ is part of $X_{1}$ & $\begin{array}{l}\text { Agricultural productivity } \\
\text { Income } \\
\text { Agricultural production } \\
\text { Labor force } \\
\text { Wealth } \\
\text { Crop prices } \\
\text { Sectoral employment } \\
\text { Agricultural wages } \\
\text { Price } \\
\text { Consumption } \\
\text { Hydroelectric power } \\
\text { Unemployment } \\
\text { Energy demand }\end{array}$ \\
\hline 3 & $\begin{array}{l}X_{1} \text { is the only part of } X_{j} \text { caused } \\
\text { by } W\end{array}$ & \\
\hline 4 & $X_{j}$ is part of $Y$ & $\begin{array}{l}\text { Rebel recruitment } \\
\text { Crime }\end{array}$ \\
\hline 5 & $Y$ is part of $X_{j}$ & \\
\hline 6 & $W$ only causes $X_{j}$ via $X_{1}$ & $\begin{array}{l}\text { Forest extraction } \\
\text { Access to rented land } \\
\text { Expenditure inequality } \\
\text { Child Labor } \\
\text { Budget balance } \\
\text { Firm cash holding } \\
\text { Inflation expectations } \\
\text { Inequality } \\
\text { Livestock prices }\end{array}$ \\
\hline 7 & $X_{j}$ does not cause $Y$ & $\begin{array}{l}\text { Farming practices } \\
\text { Child mortality } \\
\text { Crop diversity } \\
\text { Child health } \\
\text { Fertility } \\
\text { Health } \\
\text { Dust Exposure } \\
\text { Mortality }\end{array}$ \\
\hline 8 & $X_{j}$ only causes $Y$ via $X_{1}$ & Energy prices \\
\hline None & $\begin{array}{l}X_{j} \text { is an exclusion-restriction } \\
\text { violation }\end{array}$ & $\begin{array}{l}\text { Immigration } \\
\text { Emigration } \\
\text { Health access } \\
\text { Mental health } \\
\text { Malaria } \\
\text { Lead exposure } \\
\text { Transport infrastructure } \\
\text { Hunger } \\
\text { Alcohol consumption } \\
\text { Mood } \\
\text { Land fragmentation }\end{array}$ \\
\hline
\end{tabular}


multiple different $X_{j}$ variables. The published version of that paper omits this analysis.

Next, $13 X_{j}$ variables are not considered exclusion-restriction violations because they are part of $X_{1}$ (exception 2). "Economic activity" is broad, so many other variables such as "crop production" and "income" can be considered components of it. Weather-IV studies with a narrower $X_{1}$ variable (such as crop income) would not be able to exclude as many $X_{j}$ variables at this stage.

Two variables are eliminated because $X_{j}$ is part of $Y$ (exception 4). Rebel recruitment can be reasonably treated as an inherent part of civil conflict rather than a separate process. Similarly, some scholars argue there is no strict boundary between crime and civil conflict (Collier 2000).

I eliminate nine cases where $X_{1}$ mediates the relationship between $W$ and $X_{j}$ and, crucially, where there is no reason to believe that $W$ has causal pathways to $X_{j}$ that do not run via $X_{1}$ (exception 6). I used the original studies linking $W$ and $X_{j}$ to establish whether multiple mechanisms were posited or only an economic activity mechanism. For instance, Ajefu and Abiona (2019) link weather shocks to child labor, but explicitly treat weather as a purely income-based shock meaning child labor falls under exception 6. Conversely, although weather's effect on emigration is often described as a response to income shocks 
(Kleemans and Magruder 2018; Pugatch and Yang 2011), others describe it as working via direct displacement such as Hurricane Maria's effect on Puerto Rican emigration (DeWaard, Johnson, and Whitaker 2020). This means emigration does not fall into this exception.

There are also situations where I assert that the $X_{j} \rightarrow Y$ relationship does not exist (exception 7). In each case, I search the literature for evidence of the relationship and consider plausible links not discussed in the literature. For example, no studies claim child mortality causes civil conflict in the near term, and it is difficult to imagine why this relationship would exist. Out of $20 X_{j}$ variables examined for causal links to civil conflict, 12 appear to cause civil conflict and 8 do not. This highlights that most endogenous social science variables are causally connected.

Finally, there were one cases where the causal effect of economic activity on civil conflict is fully mediated by economic activity (exception 8). For instance, Natalini, Bravo, and Newman (2020) only posit economic mechanisms for the link between energy prices and civil conflict.

No cases were found where $X_{1}$ is the only relevant part of $X_{j}$ (exception 3); or $Y$ is part of $X_{j}$ (exception 5).

This leaves $11 X_{j}$ variables which are likely exclusion-restriction violations for the effect 
of economic activity on civil conflict. These include malaria (which prolongs civil wars according to Bagozzi (2016)), emigration (which provides an exit option for participants and victims of conflict according to Peters and Miller (2022)), and hunger (which drives civil conflict independently of economic effects according to Koren and Bagozzi (2017)).

These exclusion-restriction violations imply the economic activity $\rightarrow$ civil conflict IV model is not causally identified. However, the extent of bias in the estimate depends on the strength of the $W \rightarrow X_{j}$ and $X_{j} \rightarrow Y$ causal links.

\subsubsection{Multiple pathways to the same dependent variable}

While I do not apply the full exception-search methodology to the broad set of weather-IV estimates, the literature review uncovered some sets of studies implying multiple pathways between weather and the same dependent variable.

10 weather-IV studies have crime as a dependent variable. However, the $X_{j}$ variables that crime is claimed to be causally influenced by include income (e.g. Mehlum, Miguel, and Torvik 2006), crop production (Papaioannou 2017), air quality (Bondy, Roth, and Sager 2020), church attendance (Moreno-Medina 2021), and immigration (Chalfin 2014), as well as directly through heat-induced aggression (Jacob, Lefgren, and Moretti 2007; Ranson 2014; Blakeslee and Fishman 2018). 
Party vote share is the dependent variable in 17 studies, with $X_{j}$ most commonly being turnout (Knack 1994; Kang 2019; Horiuchi and Kang 2018; Hansford and Gomez 2010; Gomez, Hansford, and Krause 2007; Artés 2014; Arnold and Freier 2016) (rain makes people less willing to go to the polls). However, other studies argue that election-day weather affects voters' mood (Duhaime and Moulton 2018; Bassi 2019) or risk tolerance (Bassi 2019), or that previous weather discouraged protest attendance (Wasow 2020; Madestam et al. 2013). Finally, 15 studies have conflict as a dependent variable, with income being the most common $X_{j}$ variable (Miguel and Satyanath 2011; Miguel, Satyanath, and Sergenti 2004; Jensen and Gleditsch 2009; Hsiang, Meng, and Cane 2011; Hodler and Raschky 2014). However, other conflict studies use weather to instrument agricultural production (Caruso, Petrarca, and Ricciuti 2016), water scarcity (Landis et al. 2017), livestock prices (Maystadt and Ecker 2014), and immigration (Bhavnani and Lacina 2015).

These examples demonstrate that some weather-IV studies have directly contradictory identifying assumptions. But even without directly observing $X_{j} \rightarrow Y$, the existence of $W \rightarrow X_{j}$ changes the IV strategy from only requiring claims about the narrow domain of weather, to making causal claims about the complex social world. 


\subsection{Sensitivity analysis of weather IVs}

The literature review contained 57 weather-IV estimates with reduced-form estimates or sufficient information to reverse-engineer the reduced-form. The literature also produced 120 first-stage estimates that I converted into $R_{X_{j} \sim W \mid K}^{2}$ values.

On average, I identified 35 potential exclusion-restriction violations per reduced-form equation (98 if dependent variables are included). However, on average, I only found a suitable $R_{X_{j} \sim W \mid K}^{2}$ estimate for four $X_{j}$ variables for each reduced-form equation and in 14 cases I found none. Importantly, the broad analysis of weather IVs has not searched for exclusionrestriction exceptions, so some of these apparent violations will fall into one of those exceptions. When applying this method to a particular IV claim, it would be important to include this step.

This means the sensitivity analysis covers only a small fraction of the potential exclusionrestriction violations documented in the literature, which is an unknown fraction of the true number of potential exclusion-restriction violations.

Figure 4 shows each reduced-form estimate's sensitivity (y-axis) to the $X_{j}$ variables with rel-

evant $R_{X_{j} \sim W \mid K}^{2}$ estimates. The shading and number indicate the strength of the $R_{Y \sim X_{j} \mid W, K}^{2}$ relationship required to make the $X_{1} \rightarrow Y$ IV estimate insignificant. Smaller values indicate 
that a weak $X_{j} \rightarrow Y$ relationship could make a study result insignificant. 
$\operatorname{Min} R_{Y \sim x_{j} \mid W, K}^{2}$ to make $\hat{\delta}$ not significantly different to 0

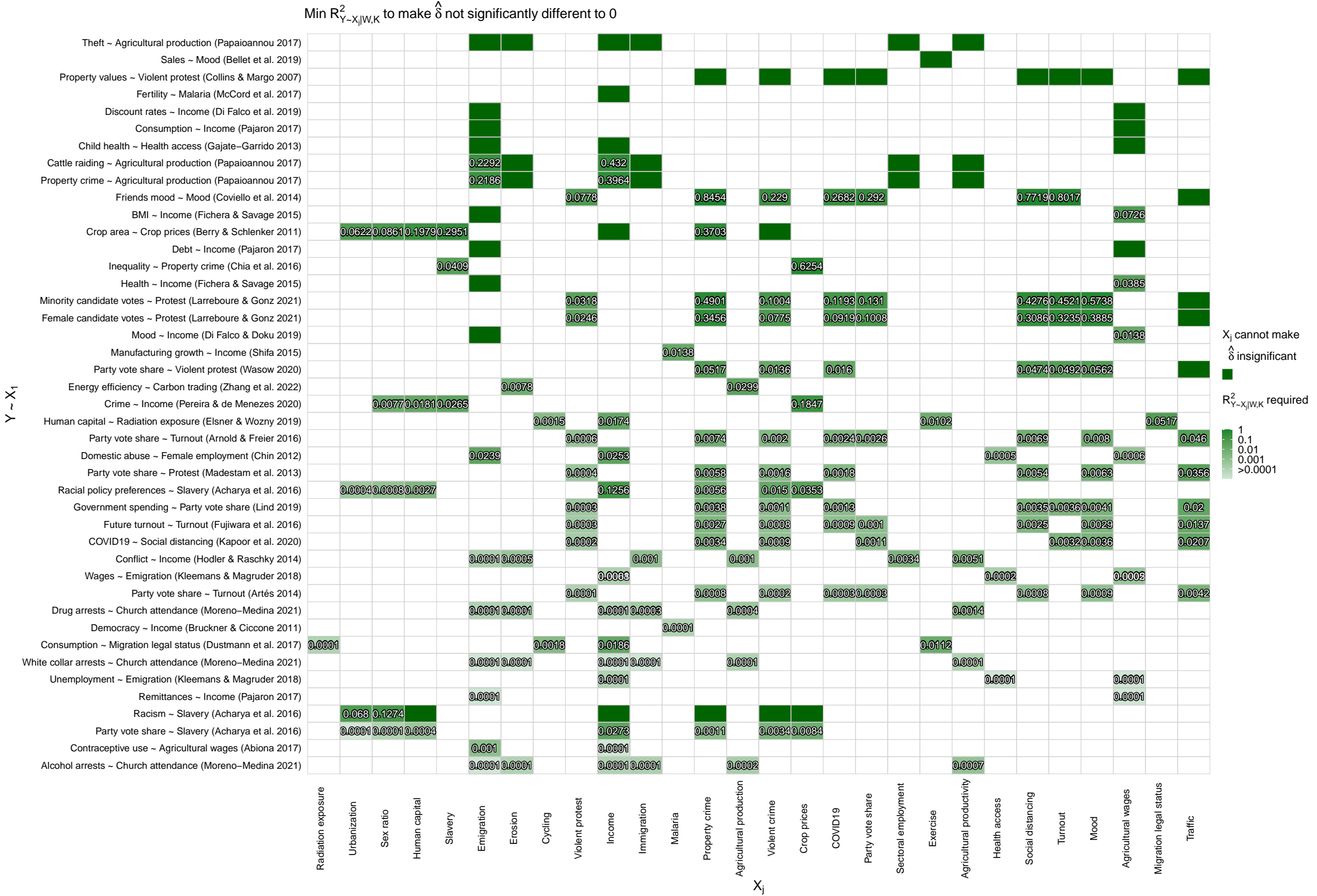

Figure 4: The minimum relationship between an exclusion-restriction violation variable, $X_{j}$, and dependent variable $Y\left(R_{Y \sim X_{j} \mid W, K}^{2}\right)$ required to make the IV relationship between $X_{1}$ and $Y(\hat{\delta})$ insignificant. Strength of required relationship indicated using shading on log-10 scale. Dark green shading indicates $X_{j}$ cannot make the relationship insignificant. Lowest $R_{Y \sim X_{j} \mid W, K}^{2}$ tested was 0.0001 .14 reduced-form equations without relevant $R_{X_{j} \sim W \mid K}^{2}$ estimates omitted. Fit statistics are filtered using the broad criteria and fit statistic criteria. 
Despite exclusion-restriction violations, some studies are likely robust to large relationships between $X_{j}$ and $Y$. For instance, Collins and Margo (2007) estimate the effect of violent protests on property prices using a rainfall instrument. In total, eight variables with relevant first-stage estimates could affect this estimate including property crime, violent crime, mood, and traffic. But none of these could make the result insignificant even if they were perfectly correlated with property prices. While many additional potential exclusion-restriction violations do not have first-stage estimates, the result appears relatively robust to exclusionrestriction violations.

Other studies require only small $X_{j} \rightarrow Y$ relationships. Moreno-Medina (2021) examines the effect of church attendance on various types of crime by using the number of weeks where it rained between 9am and 1pm on Sunday in a year as an instrument for church attendance. There are five relevant potential exclusion-restriction violations with first-stage fit statistics available: emigration, erosion, income, crop production, and agricultural productivity. For the weakest result (alcohol arrests), any of these variables would only need to explain $0.07 \%$ of variance in alcohol arrests to make the result insignificant. None of the paper's findings would require one of the exclusion-restriction variables to explain more than $0.14 \%$ of variance in a type of crime. While these variables are major drivers of crime, it is plausible that they could explain tiny fractions of a percent of variation in crime. Even though the instrumented 
variable in the paper is rain on Sundays, the tiny proportion of variance needed to make the results insignificant imply almost anything could overturn them.

A high proportion of studies have at least one potential exclusion-restriction variable that could easily make the result insignificant. Of the 43 reduced-form estimates with at least one exclusion-restriction estimate to test, 22 had at least one $X_{j}$ variable that would need to explain less than $1 \%$ of variance in $Y$ to make the result insignificant, and 19 have at least one $X_{j}$ variable that would need to explain less than $0.1 \%$ of variance in $Y$ to make the result insignificant. Only 8 were sufficiently robust that no relationship between $X_{j}$ and $Y$ could make the estimate insignificant.

Since most $X_{j}$ variables were not tested due to data limitations, these results represent a lower bound of weather-IV estimate sensitivity.

Figure 5 shows the strength of relationships required to make the IV estimate of economic activity on civil conflict insignificant. In order to believe the results are acceptably biased (defined as the coefficient and standard error not changing enough to make the result insignificant or increasing in magnitude by an equivalent amount), we must assume that each pair of partial- $R^{2}$ values is below the curve in figure 5 . If a reader finds this plausible for the 11 exclusion-restriction variables, then it is reasonable to believe the effect of economic 
activity on civil conflict. If both $R_{X_{j} \sim W \mid K}^{2}$ and $R_{Y \sim X_{j} \mid W, K}^{2}$ were around 0.0045 , the results would no longer be significant. A higher variance explained for one would reduce the size needed for the other.

I would personally be skeptical of basing an important empirical claim about the world on the assumption that none of the 11 exclusion-restriction variables lie above this curve. However, the important point is that readers can assess what they are required to believe to accept the result. ${ }^{12}$

As discussed in the earlier sensitivity analysis, transferring partial- $R^{2}$ values across contexts requires meeting several criteria. Of the 11 exclusion-restriction variables, only emigration has an $R_{X_{j} \sim W \mid K}^{2}$ value that meets these requirements: two relevant studies report a mean $R_{X_{j} \sim W \mid K}^{2}$ of 0.011 between rainfall and emigration (Corbi and Ferraz 2018; Badaoui, Strobl, and Walsh 2017). If this value applies to the economic activity $\rightarrow$ civil conflict estimate, emigration and conflict would only need an $R_{Y \sim X_{j} \mid W, K}^{2}$ of 0.001 to render the effect of economic activity on civil conflict insignificant. Even this figure should be treated carefully. While some studies link rainfall to emigration through mechanisms other than income, many studies argue income is a relevant pathway. Consequently, emigration may need to explain more variance to overturn the result.

\footnotetext{
${ }^{12}$ Since there are multiple exclusion-restriction violations that create unacceptable bias, I do not continue the exclusionrestriction variable search. However, if a researcher was willing to accept this level of bias, they would need to continue to enumerate $X_{j}$ variables from the literature to ensure that they had not missed important exclusion-restriction variables.
} 
No applicable $R_{X_{j} \sim W \mid K}^{2}$ values exist for rainfall's effect on malaria. However, the literature provides three first-stage estimates based on other variance types: between-person (Chang et al. 2014), within-country (McCord, Conley, and Sachs 2017), and between-subnational (Cutler et al. 2010), ranging from 0.0084 to 0.031. Even the smallest of these implies an $R_{Y \sim X_{j} \mid W, K}^{2}$ of 0.0021 would render the IV estimate insignificant.

Explicit sensitivity conditions allow readers to see what substantive claims required for an IV result to hold. Here, the effect of economic activity on civil conflict is sensitive to small effects of variables that the literature demonstrates are exclusion-restriction violations. However, studies with stronger estimates or less problematic instruments may require weaker assumptions to accept the IV results. By explicating and quantifying the conditions for strict identification and sensitivity readers can better assess the plausibility of IV claims.

\section{Conclusions}

Cunningham (2018) argues that a good instrument should have a "certain ridiculousness". Until the causal pathway is explained, the link between the instrument and outcome seems absurd. In a world where forest fires prevent Australians and Californians from leaving their homes for months, and 1-3 billion people are projected to be left outside of historicallyhabitable temperature ranges (Xu et al. 2020), the link between weather and the social 


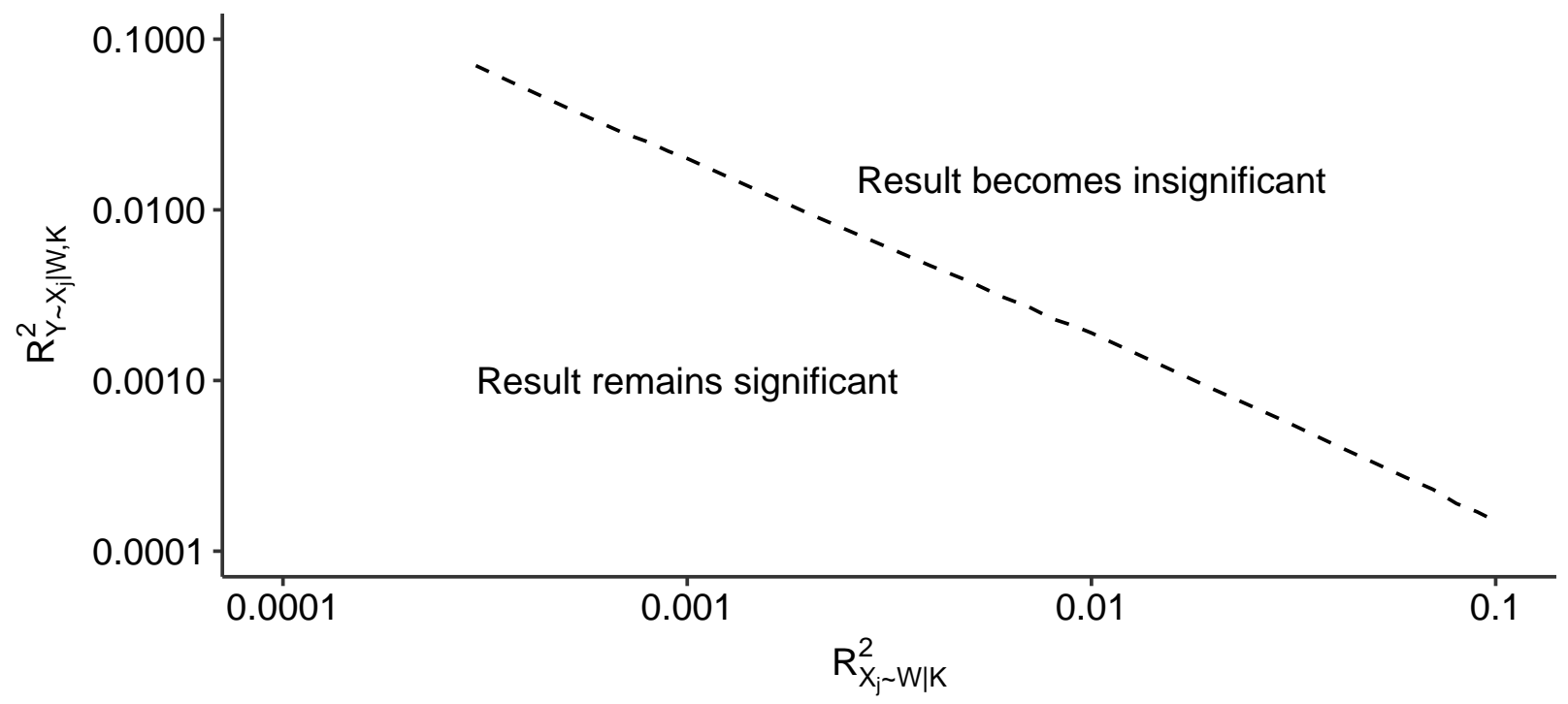

Figure 5: Combinations of $R_{Y \sim X_{j} \mid W, K}^{2}$ and $R_{X_{j} \sim W \mid K}^{2}$ that would make the effect of economic activity on conflict no longer significant. Pairs of values below the curve are insufficient to make the result insignificant. Pairs above the curve would make the result insignificant.

world is not absurd enough.

This paper shows that a widely used instrument is flawed because it systematically violates the exclusion-restriction assumption for most plausible applications. These findings suggest our standards for accepting instruments are overly lenient and atheoretical. The causal revolution in social science has revealed the wishful thinking underlying selection-on-observables. The same rigor must be applied to IV assumptions.

Nothing in this paper disproves particular empirical claims. Many weather-IV papers provide independent sources of evidence, and robustness checks (e.g. placebo tests) and some results will be true by chance. Nevertheless, my results suggest the underlying assumptions of weather-IVs are not strictly true, and many results are likely wrong. 
Evidence for widespread exclusion-restriction violations adds to growing evidence that IV regression studies are often poorly conducted. Brodeur, Cook, and Heyes (2020) found IV studies showed substantial evidence of p-hacking. Similarly, Lee et al. (2021) find the standard first-stage F-test used in IV regression is underpowered, and that over half of IV papers in the American Economic Review were no longer significant after accounting for this. Lal et al. (2021) find that most top political science IV articles make statistical errors, including inappropriate standard error and F-statistic calculations.

It is tempting to interpret instruments as being "used up" by multiple uses. However, it is important to distinguish the fact of whether an exclusion-restriction violation exists from our knowledge of that fact (which new research can change). This may seem unfair to authors who used the best available information, but the goal of this method is to assess empirical claims not to cast judgment on researchers.

While a scholar cannot know whether a new instrument will turn out to have exclusionrestriction violations, there are some classes of instruments where $W$ does not seem as likely to have multiple $X_{j}$ pathways. Random assignment to a treatment with partial compliance is unlikely to suffer from exclusion-restriction violations (e.g. winning a charter school lottery as an instrument for attending charter school (Angrist et al. 2017)). Narrow policy changes also seem less susceptible. For instance, Porzio, Rossi, and Santangelo (2022) instrument a 
cohort's average years of education with the school-leaving age when they were young.

By contrast, other widely used instruments (e.g. population density, historical splits in countries, lead exposure, colonialism, distance from anything) likely suffer from the problems described in this paper. Indeed, many of these instruments have faced criticism for similar reasons (Morck and Yeung 2011; Gallen and Raymond 2019).

This paper offers a way forwards for IV inference through a method for systematically finding and assessing exclusion-restriction violations from existing literature. This process unpacks the exclusion restriction into a series of substantive (and potentially testable) claims about the world. While we cannot prove the exclusion restriction, we can use the literature to identify and assess variables that have been linked to our instrument. This paper also demonstrates how sensitivity analysis (Cinelli and Hazlett 2020a, 2020b) can be used to quantify the strength of an exclusion-restriction violation required to overturn a result. This approach allows researchers to acknowledge violations of their identifying assumptions without having to abandon analysis that is not perfectly identified.

Avoiding contradictions in the literature is important beyond weather IVs. Typical nonexperimental social science models implicitly assume a sparse causal graph which is unrealistic given the volume of papers making causal claims. ${ }^{13}$ Unfortunately, this volume means

\footnotetext{
${ }^{13}$ Over 60,000 social science articles are published annually (see appendix C).
} 
constructing a realistic causal graph is likely beyond the means of individual social scientists.

Infrastructure to systematically record, dispute, and qualify the literature's causal claims could allow scientists to appropriately specify models with non-experimental data.

Causal knowledge in social science has few easy shortcuts. Apparently simple solutions such as IVs still rely on strong substantive claims about the world. To build cumulative knowledge, we must engage directly with the messy causal web of the social world. 


\section{References}

Acharya, Avidit, Matthew Blackwell, and Maya Sen. 2016. "The political legacy of American Slavery." Journal of Politics 78 (3): 621-41.

Ajefu, Joseph, and Olukorede Abiona. 2019. "Impact of Shocks on Labour and Schooling Outcomes and the Role of Public Work Programmes in Rural India." Journal of Development Studies 55 (6): 1140-57.

Angrist, Joshua, Peter Hull, Parag Pathak, and Christopher Walters. 2017. "Leveraging Lotteries for School Value-Added: Testing and Estimation." The Quarterly Journal of Economics 132 (2): 871-919.

Angrist, Joshua, Guido Imbens, and Donald Rubin. 1996. "Identification of Causal Effects Using Instrumental Variables." Journal of the American Statistical Association 91 (434): $444-55$.

Aral, Sinan, and Christos Nicolaides. 2017. "Exercise contagion in a global social network." Nature Communications 8 (1): 1-8.

Arnold, Felix, and Ronny Freier. 2016. "Only conservatives are voting in the rain: Evidence from German local and state elections." Electoral Studies 41: 216-21.

Artés, Joaquín. 2014. "The rain in Spain: Turnout and partisan voting in Spanish elections." European Journal of Political Economy 34: 126-41. 
Auffhammer, Maximilian, Solomon Hsiangy, Wolfram Schlenker, and Adam Sobelz. 2013. "Using weather data and climate model output in economic analyses of climate change." Review of Environmental Economics and Policy 7 (2): 181-98.

Badaoui, Eliane, Eric Strobl, and Frank Walsh. 2017. "The Impact of Internal Migration on Local Labour Markets in Thailand." Economic Development and Cultural Change.

Bagozzi, Benjamin. 2016. "On Malaria and the Duration of Civil War." Journal of Conflict Resolution 60 (5): 813-39.

Bassi, Anna. 2019. "Weather, Risk, and Voting: An Experimental Analysis of the Effect of Weather on Vote Choice." Journal of Experimental Political Science 6 (1): 17-32.

Bhavnani, Rikhil, and Bethany Lacina. 2015. "The Effects of Weather-Induced Migration on Sons of the Soil Riots in India." World Politics 67 (4): 760-94.

Blakeslee, David, and Ram Fishman. 2018. "Weather shocks, agriculture, and crime: Evidence from India." Journal of Human Resources 53 (3): 750-82.

Bondy, Malvina, Sefi Roth, and Lutz Sager. 2020. "Crime Is in the Air: The Contemporaneous Relationship between Air Pollution and Crime." Journal of the Association of Environmental and Resource Economists 7 (3): 555-85.

Brodeur, Abel, Nikolai Cook, and Anthony Heyes. 2020. "Methods Matter: p-Hacking and Publication Bias in Causal Analysis in Economics." American Economic Review 110 (11): 
$3634-60$.

Caruso, Raul, Ilaria Petrarca, and Roberto Ricciuti. 2016. "Climate change, rice crops, and violence: Evidence from Indonesia." Journal of Peace Research 53 (1): 66-83.

Chalfin, Aaron. 2014. "What is the contribution of Mexican immigration to U.S. crime rates? Evidence from rainfall shocks in Mexico." American Law and Economics Review $16(1): 220-68$.

Chang, Simon, Belton Fleisher, Seonghoon Kim, and Shi Liu. 2014. "Long-term health effects of malaria exposure around birth: Evidence from colonial Taiwan." Economic Development and Cultural Change 62 (3): 519-36.

Chin, Yoo. 2012. "Male backlash, bargaining, or exposure reduction? Women's working status and physical spousal violence in India." Journal of Population Economics 25 (1): $175-200$.

Ciccone, Antonio. 2011. "Economic shocks and civil conflict: A comment." American Economic Journal: Applied Economics 3 (4): 215-27.

Cinelli, Carlos, Jeremy Ferwerda, and Chad Hazlett. 2020. "Sensemakr: Sensitivity Analysis Tools for OLS in R and Stata." SSRN.

Cinelli, Carlos, Andrew Forney, and Judea Pearl. 2022. "A Crash Course in Good and Bad Controls." Sociological Methods \& Research, 1-34. 
Cinelli, Carlos, and Chad Hazlett. 2020a. "An Omitted Variable Bias Framework for Sensitivity Analysis of Instrumental Variables." Preprint.

—. 2020b. "Making sense of sensitivity: extending omitted variable bias." Journal of the Royal Statistical Society. Series B: Statistical Methodology 82 (1): 39-67.

Collier, Paul. 2000. "Rebellion as a Quasi-Criminal Activity." Journal of Conflict Resolution 44 (6): 839-53.

Collins, William, and Robert Margo. 2007. "The economic aftermath of the 1960s Riots in American Cities: Evidence from property values." Journal of Economic History 67 (4): $849-83$.

Cook, Duncan, and Sally Garrett. 2013. "Somali piracy and the monsoon." Weather, Climate, and Society 5 (4): 309-16.

Cooperman, Alicia. 2017. "Randomization inference with rainfall data: Using historical weather patterns for variance estimation." Political Analysis 25 (3): 277-88.

Corbi, Raphael, and Tiago Ferraz. 2018. "Rainfall, Internal Migration and Local Labor Markets in Brazil." Preprint.

Cunningham, Scott. 2018. Causal Inference: The Mixtape. tufte-latex.googlecode.com.

Cutler, David, Winnie Fung, Michael Kremer, Monica Singhal, and Tom Vogl. 2010. "Earlylife malaria exposure and adult outcomes: Evidence from malaria eradication in india." 
American Economic Journal: Applied Economics 2 (2): 72-94.

Dell, Melissa, Benjamin Jones, and Benjamin Olken. 2014. "What do we learn from the weather? The new climate-economy literature." Journal of Economic Literature 52 (3): 740-98.

Deuchert, Eva, and Martin Huber. 2017. "A Cautionary Tale About Control Variables in IV Estimation." Oxford Bulletin of Economics and Statistics 79 (3): 411-25.

DeWaard, Jack, Janna Johnson, and Stephan Whitaker. 2020. "Out-migration from and return migration to Puerto Rico after Hurricane Maria: evidence from the consumer credit panel." Population and Environment 42 (1): 28-42.

Duhaime, Erik, and Taylor Moulton. 2018. "Swingin' in the Rain: The Impact of Inclement Weather on Voting Behavior in U.S. Presidential Elections." SSRN.

Fan, Maoyong, and Yi Wang. 2020. "The impact of PM2.5 on mortality in older adults: Evidence from retirement of coal-fired power plants in the United States." Environmental Health: A Global Access Science Source 19 (1): 1-13.

Fontenla, Matías, M. Goodwin, and Fidel Gonzalez. 2019. "Pollution and the choice of where to work and live within Mexico City." Latin American Economic Review 28 (1). Gallen, Trevor, and Ben Raymond. 2019. "Broken instruments." Bureau of Labor Statistics. Gomez, Brad, Thomas Hansford, and George Krause. 2007. "The Republicans should pray 
for rain: Weather, turnout, and voting in U.S. presidential elections." Journal of Politics 69 (3): 649-63.

Gu, Hejun, Weiran Yan, Ehsan Elahi, and Yuxia Cao. 2020. "Air pollution risks human mental health: an implication of two-stages least squares estimation of interaction effects." Environmental Science and Pollution Research 27 (2): 2036-43.

Guven, Cahit, and Indrit Hoxha. 2015. "Rain or shine: Happiness and risk-taking." Quarterly Review of Economics and Finance 57: 1-10.

Hansford, Thomas, and Brad Gomez. 2010. "Estimating the electoral effects of voter turnout." American Political Science Review 104 (2): 268-88.

Hodler, Roland, and Paul Raschky. 2014. "Economic shocks and civil conflict at the regional level." Economics Letters 124 (3): 530-33.

Horiuchi, Yusaku, and Woo Kang. 2018. "Why Should the Republicans Pray for Rain? Electoral Consequences of Rainfall Revisited.” American Politics Research 46 (5): 86989.

Hsiang, Solomon, Kyle Meng, and Mark Cane. 2011. "Civil conflicts are associated with the global climate." Nature 476 (7361): 438-41.

Jacob, Brian, Lars Lefgren, and Enrico Moretti. 2007. "The dynamics of criminal behavior: Evidence from weather shocks." Journal of Human Resources 42 (3): 489-527. 
Jensen, Peter, and Kristian Gleditsch. 2009. "Rain, growth, and civil war: The importance of location." Defence and Peace Economics 20 (5): 359-72.

Kang, Woo. 2019. "Liberals should pray for rain: weather, opportunity costs of voting and electoral outcomes in South Korea." Political Science 71 (1): 61-78.

Katz, Tamar, Tali Regev, Shay Lavie, Haggai Porat, and Ronen Avraham. 2020. "Those who tan and those who don't: A natural experiment on colorism." PLoS ONE 15 (7): $1-14$.

Kippersluis, Hans van, and Cornelius Rietveld. 2018. "Beyond plausibly exogenous." Econometrics Journal 21 (3): 316-31.

Kiviet, Jan. 2020. "Testing the impossible: Identifying exclusion restrictions." Journal of Econometrics 218 (2): 294-316.

Kleemans, Marieke, and Jeremy Magruder. 2018. "Labour Market Responses To Immigration: Evidence From Internal Migration Driven By Weather Shocks." Economic Journal 128 (613): 2032-65.

Knack, Steve. 1994. "Does rain help the Republicans? Theory and evidence on turnout and the vote." Public Choice 79: 187-209.

Koren, Ore, and Benjamin Bagozzi. 2017. "Living off the land: The connection between cropland, food security, and violence against civilians." Journal of Peace Research 54 (3): 
$351-64$.

Kubik, Zaneta, and Julian May. 2018. "Weather shocks, food prices and food security: Evidence from South Africa." The 56th Annual Conference of the Agricultural Economics Association of South Africa, 42.

Lagerlöf, Nils-Petter, and Syed Basher. 2006. "Geography, population density, and percapita income gaps across US states and Canadian provinces.” Munich Personal RePEc Archive, no. 369.

Lal, Apoorva, Mackenzie Lockhart, Yiqing Xu, and Ziwen Zu. 2021. "How Much Should We Trust Instrumental Variable Estimates in Political Science? Practical Advice based on Over 60 Replicated Studies." SSRN.

Landis, Steven, Babak Rezaeedaryakenari, Yifan Zhang, Cameron Thies, and Ross Maciejewski. 2017. "Fording differences? Conditions mitigating water insecurity in the Niger River Basin." Political Geography 56: 77-90.

Lee, David, Justin McCrary, Marcelo Moreira, and Jack Porter. 2021. "Valid t-ratio Inference for IV." NBER Preprint.

Madestam, Andreas, Daniel Shoag, Stan Veuger, and David Yanagizawa-Drott. 2013. "Do Political Protests Matter? Evidence from the Tea Party Movement." Quarterly Journal of Economics, 1633-85. 
Maystadt, Jean, and Olivier Ecker. 2014. "Extreme weather and civil war: Does drought fuel conflict in Somalia through livestock price shocks?" American Journal of Agricultural Economics 96 (4): 1157-82.

McCord, Gordon, Dalton Conley, and Jeffrey Sachs. 2017. "Malaria ecology, child mortality \& fertility." Economics and Human Biology 24: 1-17.

Mehlum, Halvor, Edward Miguel, and Ragnar Torvik. 2006. "Poverty and crime in 19th Century Germany." Journal of Urban Economics 59 (3): 370-88.

Meier, Armando, Lukas Schmid, and Alois Stutzer. 2019. "Rain, emotions and voting for the status quo." European Economic Review 119: 434-51.

Miguel, Edward, and Shanker Satyanath. 2011. "Re-examining economic shocks and civil conflict." American Economic Journal: Applied Economics 3 (4): 228-32.

Miguel, Edward, Shanker Satyanath, and Ernest Sergenti. 2004. "Economic shocks and civil conflict: An instrumental variables approach." Journal of Political Economy 112 (4): $725-53$.

Morck, Randall, and Bernard Yeung. 2011. "Economies, history, and causation." Business History Review 85 (1): 39-63.

Moreno-Medina, Jonathan. 2021. "Sinning in the Rain: Weather Shocks, Church Attendance and Crime." The Review of Economics and Statistics, 1-46. 
Moretti, Enrico. 1998. "Social returns to education and human capital externalities: evidence from cities." Centre for Labour Economics Preprint.

Natalini, Davide, Giangiacomo Bravo, and Edward Newman. 2020. "Fuel riots: definition, evidence and policy implications for a new type of energy-related conflict." Energy Policy 147 (August 2019): 111885.

Nicholls, Neville, Wasyl Drosdowsky, and Beth Lavery. 1997. "Australian rainfall variability and change." Weather 52 (3): 66-72.

Papaioannou, Kostadis. 2017. “'Hunger makes a thief of any man': Poverty and crime in British colonial Asia." European Review of Economic History 21 (1): 1-28.

Peet, Evan. 2020. "Environment and Human Capital: The Effects of Early-Life Exposure to Pollutants in the Philippines." Environment and Development Economics, 1-25.

Peters, Margaret, and Michael Miller. 2022. "Emigration and Political Contestation." International Studies Quarterly 66 (1): 1-39.

Porzio, Tommaso, Federico Rossi, and Gabriella Santangelo. 2022. "The Human Side of Structural Transformation.” American Economic Review 112 (8): 2774-814.

Pugatch, Todd, and Dean Yang. 2011. "The Impact of Mexican Immigration on U.S. Labor Markets: Evidence from Migrant Flows Driven by Rainfall Shocks." SSRN.

Ranson, Matthew. 2014. "Crime, weather, and climate change." Journal of Environmental 
Economics and Management 67 (3): 274-302.

Rappaport, Jordan. 2007. "Moving to nice weather." Regional Science and Urban Economics $37(3): 375-98$.

Ritter, Emily, and Courtenay Conrad. 2016. "Preventing and Responding to Dissent: The Observational Challenges of Explaining Strategic Repression." American Political Science Review 110 (1): 85-99.

Sager, Lutz. 2019. "Estimating the effect of air pollution on road safety using atmospheric temperature inversions." Journal of Environmental Economics and Management 98 (251). Sarsons, Heather. 2015. "Rainfall and conflict: A cautionary tale." Journal of Development Economics 115: 62-72.

Schultz, Kenneth, and Justin Mankin. 2019. "Is Temperature Exogenous? The Impact of Civil Conflict on the Instrumental Climate Record in Sub-Saharan Africa." American Journal of Political Science 63 (4): 723-39.

Shen, Xinyi, Chenkai Cai, and Hui Li. 2020. "Quantifying socioeconomic activities and weather effects on the global spread of COVID-19 epidemic." Arxiv.

Strobl, Eric, and Marie Valfort. 2015. "The effect of weather-induced internal migration on local labor markets. Evidence from Uganda." World Bank Economic Review 29 (2): $385-412$. 
Thai, Thuan, and Mikko Myrskylä. 2012. "Rainfall shocks, parental behavior and breastfeeding: Evidence from rural Vietnam." Preprint.

Wasow, Omar. 2020. "Agenda Seeding: How 1960s Black Protests Moved Elites, Public Opinion and Voting." American Political Science Review, 638-59.

Xu, Chi, Timothy Kohler, Timothy Lenton, Jens Svenning, and Marten Scheffer. 2020. "Future of the human climate niche." PNAS 117 (21).

Zheng, Siqi, Jianghao Wang, Cong Sun, Xiaonan Zhang, and Matthew Kahn. 2019. "Air pollution lowers Chinese urbanites' expressed happiness on social media." Nature Human Behaviour 3 (3): 237-43. 


\section{Supplementary Information for Rain, Rain, Go Away: 195 Potential Exclusion-Restriction Violations for Studies Using Weather as an Instrumental Variable}

2023-04-19

\section{Appendix A: Evidence for assumptions in Income and Conflict Ex-}

\section{ample}

Table A1: Assumptions for the effect of economic activity $\left(X_{1}\right)$ on civil conflict $(Y)$ to be strictly causally identified related to potential exclusion restriction variables $\left(X_{j}\right)$ discovered to be related to weather in relevant literature.

\begin{tabular}{|c|c|c|c|}
\hline$X_{j}$ & Exception & Assumption & Evidence \\
\hline Female employment & 1 & $W$ does not cause $X_{j}$ & $\begin{array}{l}\text { Chin (2012) and Thai and Myrskylä (2012) both focus on } \\
\text { women harvesting rice which is less relevant to Africa. }\end{array}$ \\
\hline Early life pollution & 1 & $W$ does not cause $X_{j}$ & Doesn't happen on correct time frame. \\
\hline Individual & 1 & $W$ does not cause $X_{j}$ & Davis (2016) uses $n=89$ country cross-section (weak evidence) \\
\hline Responsibility & & & $\begin{array}{l}\text { and mechanism is a long-run values one rather than year to year } \\
\text { variation (not relevant). }\end{array}$ \\
\hline Human capital & 1 & $W$ does not cause $X_{j}$ & $\begin{array}{l}\text { Lagerlöf and Basher (2006) simultaneously instrument } \\
\text { population density, sex ratios, urbanization, and education using } \\
\text { rainfall. } 2007 \text { published version omitted these claims. }\end{array}$ \\
\hline Urbanization & 1 & $W$ does not cause $X_{j}$ & $\begin{array}{l}\text { Lagerlöf and Basher (2006) simultaneously instrument } \\
\text { population density, sex ratios, urbanization, and education using } \\
\text { rainfall. } 2007 \text { published version omitted these claims. }\end{array}$ \\
\hline Month of birth & 1 & $W$ does not cause $X_{j}$ & Less relevant in equatorial areas. \\
\hline
\end{tabular}




\begin{tabular}{|c|c|c|c|}
\hline Agricultural & 2 & $X_{j}$ is part of $X_{1}$ & Agricultural productivity is a core part of economic activity in \\
\hline productivity & & & this context. \\
\hline Income & 2 & $X_{j}$ is part of $X_{1}$ & Income is an indicator of economic activity. \\
\hline Agricultural & 2 & $X_{j}$ is part of $X_{1}$ & Crop production is a core part of economic activity in this \\
\hline production & & & context. \\
\hline Labor force & 2 & $X_{j}$ is part of $X_{1}$ & The labor force is a central part of economic activity. \\
\hline Wealth & 2 & $X_{j}$ is part of $X_{1}$ & Wealth is closely tied to economic activity. \\
\hline Crop prices & 2 & $X_{j}$ is part of $X_{1}$ & Crop prices are an indicator of economic activity. \\
\hline Sectoral employment & 2 & $X_{j}$ is part of $X_{1}$ & Labor markets are a central part of economic activity. \\
\hline Agricultural wages & 2 & $X_{j}$ is part of $X_{1}$ & $\begin{array}{l}\text { Agricultural wages are a strong indicator of economic activity in } \\
\text { this context. }\end{array}$ \\
\hline Price & 2 & $X_{j}$ is part of $X_{1}$ & Prices are closely tied to economic activity. \\
\hline Consumption & 2 & $X_{j}$ is part of $X_{1}$ & Consumption is a component of GDP. \\
\hline Hydroelectric power & 2 & $X_{j}$ is part of $X_{1}$ & Hydroelectric power is a contributor to economic activity. \\
\hline Unemployment & 2 & $X_{j}$ is part of $X_{1}$ & Labor markets are a central part of economic activity. \\
\hline Energy demand & 2 & $X_{j}$ is part of $X_{1}$ & $\begin{array}{l}\text { Energy demand could reasonably be defined as part of economic } \\
\text { activity. Given its importance to the economy it seems like an } \\
\text { important component and it does represent actual activity } \\
\text { rather than just prices. }\end{array}$ \\
\hline Rebel recruitment & 4 & $X_{j}$ is part of $Y$ & Rebel recruitment is a component of civil conflict. \\
\hline Crime & 4 & $X_{j}$ is part of $Y$ & $\begin{array}{l}\text { Collier (2000) argues that rebellions are an extension of } \\
\text { organized crime. }\end{array}$ \\
\hline Forest extraction & 6 & $W$ only causes $X_{j}$ via $X_{1}$ & $\begin{array}{l}\text { Völker \& Waibel (2010) consider forest extraction to be a } \\
\text { response to weather-induced income shocks. }\end{array}$ \\
\hline Access to rented land & 6 & $W$ only causes $X_{j}$ via $X_{1}$ & Tione \& Holden (2020) imply income pathway only. \\
\hline Expenditure & 6 & $W$ only causes $X_{j}$ via $X_{1}$ & Bayani-Arias \& Palanca-Tan (2017) make a differential income \\
\hline inequality & & & effect argument. \\
\hline Child Labor & 6 & $W$ only causes $X_{j}$ via $X_{1}$ & Ajefu \& Abiona (2019) only reference income mechanism. \\
\hline Budget balance & 6 & $W$ only causes $X_{j}$ via $X_{1}$ & Income effects are the primary mechanism proposed by Lis 2010 . \\
\hline
\end{tabular}


Firm cash holding

Inflation

expectations

Inequality

Livestock prices

Farming practices
Child mortality
Crop diversity
Child health
Fertility
Health
Dust Exposure
Mortality
Energy prices

$W$ only causes $X_{j}$ via $X_{1} \quad$ An economic activity effect of climate disasters does seem to be the primary mechanism, although there's a case for interpreting it as a capital/wealth shock rather than an income shock.

$W$ only causes $X_{j}$ via $X_{1} \quad$ Inflation is driven by differences in production (which is part of economic activity).

$W$ only causes $X_{j}$ via $X_{1} \quad$ Inequality does seem to being generated by economic factors here although we could quibble about wealth/capital versus income.

$W$ only causes $X_{j}$ via $X_{1} \quad$ Original paper argues that the livestock prices are affected by the productivity of the cattle grazing process (just in the same way as crop failure would be included).

$X_{j}$ does not cause $Y$

No literature claims or plausible pathways for $X_{j} \rightarrow Y$.

No literature claims or plausible pathways for $X_{j} \rightarrow Y$.

No literature claims or plausible pathways for $X_{j} \rightarrow Y$.

No literature claims or plausible pathways for $X_{j} \rightarrow Y$.

No literature claims or plausible pathways for $X_{j} \rightarrow Y$.

No literature claims or plausible pathways for $X_{j} \rightarrow Y$.

No literature claims or plausible pathways for $X_{j} \rightarrow Y$.

No literature claims or plausible pathways for $X_{j} \rightarrow Y$.

Energy prices affect civil conflict primarily because of the economic hardship it creates. A wrinkle is that the conflict

happens because of the attribution to energy prices specifically rather than just by manipulating economic activity. 


\section{Appendix B: Literature review table}

Table B1: Relationships identified in the literature. IV studies have an $X$ and $Y$ variable listed, while studies looking at the relationship between weather and another variable have weather listed as the $X$ variable.

Source of IV estimate/observed

correlation

$\mathrm{X}$

$\mathrm{Y}$

Context

Zimmermann (2020)

Rainfall

Human

India

capital

Zheng et al. (2019)

Pollution

Mood

China

X. Zhang, Lu, and Xue (2022)

Carbon trading

Energy

China

T. Zhang (2016)

Rainfall

Protest

DC and NY

T. Zhang (2016)

Rainfall

Violent

DC and NY

protest

T. Zhang (2016)

Temperature

Protest

DC and NY

T. Zhang (2016)

Temperature

Violent

DC and NY

protest 
Source of IV estimate/observed

\begin{tabular}{llll} 
correlation & X & Y & Context \\
\hline
\end{tabular}

Zaveri, Russ, and Damania Agricultural productivity $\quad$ Crop area worldwide

Yang and Choi (2007)

Yang and Choi (2007)

Yang and Choi (2007)

Xinye and Wei (2019)

Xinye and Wei (2019)

Xia et al. (2013)

Xi et al. (2022)

\begin{abstract}
Xia et al. (2013)
\end{abstract}

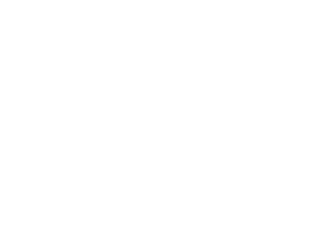

\begin{abstract}
Income
\end{abstract}
Income

Income

Pollution

Pollution

Rainfall 
Source of IV estimate/observed

\begin{tabular}{|c|c|c|c|}
\hline correlation & $\mathrm{X}$ & Y & Context \\
\hline \multirow[t]{2}{*}{ Xi et al. (2022) } & Rainfall & Cinema & 49 Chinese \\
\hline & & attendance & cities \\
\hline Wolpin (1982) & Income & Consumption & India \\
\hline \multirow[t]{2}{*}{ Wiwanitkit (2006) } & Rainfall & Dengue & Thailand \\
\hline & & infection & \\
\hline \multirow[t]{2}{*}{ Wasow (2020) } & Violent protest & Party vote & United \\
\hline & & share & States \\
\hline \multirow[t]{3}{*}{ Wang et al. (2020) } & Haze & Tourist & Beijing \\
\hline & & destination & \\
\hline & & preferences & \\
\hline Waldman, Nicholson, and Adilov & TV watching & Autism & California, \\
\hline$(2006)$ & & & Oregon, \\
\hline
\end{tabular}

Washington 
Source of IV estimate/observed

\begin{tabular}{cccc} 
correlation & X & Y & Context \\
\hline Völker and Waibel (2010) & Rainfall & Forest & Vietnam \\
& & extraction & \\
& & & \\
Vo $(2020)$ & Temperature & Consumption & Australia
\end{tabular}

Viswanathan and Kumar (2015) Agricultural production Emigration India

Viswanathan and Kumar (2015) Agricultural production Immigration India

Ventura-Cots et al. (2019) Alcohol consumption Liver worldwide

Veljanoska (2018)

Rainfall

Agricultural Uganda

production

Vahedi (2015)

Pollution

Human

United

capital States

Trinh, Feeny, and Posso (2021)

Rainfall

Mental

Vietnam

health 
Source of IV estimate/observed

\begin{tabular}{cccc} 
correlation & X & Y & Context \\
\hline Trinh, Feeny, and Posso (2021) & Rainfall & Child health & Vietnam \\
Tiwari, Jacoby, and Skoufias & Income & Hunger & Nepal \\
$(2017)$ & & & \\
Tione and Holden (2020) & Rainfall & Access to & Malawi \\
& & & \\
Theisen (2012) & rented land & \\
& Rainfall & Conflict & Kenya
\end{tabular}

Thai and Myrskylä (2012)

Tevie, Bohara, and Valdez

(2014)

Tevie, Bohara, and Valdez

(2014)
Female employment Breastfeeding Vietnam

Foreclosures

West Nile

California

Virus

and

Colorado

Income

West Nile

California

Colorado 
Source of IV estimate/observed

\begin{tabular}{|c|c|c|c|}
\hline correlation & $\mathrm{X}$ & Y & Context \\
\hline \multirow[t]{2}{*}{ Tamada (2009) } & Party vote share & Government & Japan \\
\hline & & spending & \\
\hline \multirow[t]{4}{*}{ Tack and Holt (2016) } & Temperature & Spatial & Iowa and \\
\hline & & correlation & Illinois \\
\hline & & of crop & \\
\hline & & yields & \\
\hline \multirow[t]{4}{*}{ Tack and Holt (2016) } & Rainfall & Spatial & Iowa and \\
\hline & & correlation & Illinois \\
\hline & & of crop & \\
\hline & & yields & \\
\hline Swamy and Fikkert (2002) & Labor force & Income & worldwide \\
\hline Swamy and Fikkert (2002) & Wealth & Income & worldwide \\
\hline Strobl and Valfort (2015) & Immigration & Unemployment & Uganda \\
\hline
\end{tabular}




\begin{tabular}{|c|c|c|c|}
\hline Source of IV estimate/observec & & & \\
\hline correlation & $\mathrm{X}$ & $\mathrm{Y}$ & Context \\
\hline Stokes (2016) & Wind turbine placement & Incumbent & Ontario \\
\hline & & voting & \\
\hline Spencer and Strobl (2019) & Weather disaster & Crime & Jamaica \\
\hline Skoufias and Vinha (2012) & Rainfall & Child health & Mexico \\
\hline Skoufias and Vinha (2012) & Temperature & Child health & Mexico \\
\hline Siyi, Ruoyu, and Daoguang & Weather disaster & Tax & China \\
\hline$(2017)$ & & avoidance & \\
\hline Shifa (2015) & Income & Manufacturing & worldwide \\
\hline & & growth & \\
\hline Shen, Cai, and Li (2020) & Sunlight & COVID19 & worldwide \\
\hline Shen, Cai, and Li (2020) & Temperature & COVID19 & worldwide \\
\hline Shen, Cai, and Li (2020) & Humidity & COVID19 & worldwide \\
\hline
\end{tabular}


Source of IV estimate/observed

\begin{tabular}{|c|c|c|c|}
\hline correlation & $\mathrm{X}$ & Y & Context \\
\hline \multirow[t]{2}{*}{ Seo (2019) } & Weather disaster & Agricultural & Thailand \\
\hline & & production & \\
\hline T. Schultz (2011) & Food prices & Fertility & England \\
\hline T. Schultz (2011) & Food prices & Marriage & England \\
\hline \multirow[t]{2}{*}{ Schachner (2014) } & Agricultural production & Human & Mongolia \\
\hline & & capital & \\
\hline \multirow[t]{2}{*}{ Sayers et al. (2009) } & Clouds & VitaminD & United \\
\hline & & & Kingdom \\
\hline \multirow[t]{2}{*}{ Sayers et al. (2009) } & Sunlight & VitaminD & United \\
\hline & & & Kingdom \\
\hline Sarsons (2015) & Rainfall & Conflict & India \\
\hline teramo and Searle (2019) & Crop prices & Quantity & worldwide \\
\hline
\end{tabular}


Source of IV estimate/observed

\begin{tabular}{|c|c|c|c|}
\hline correlation & $\mathrm{X}$ & $\mathrm{Y}$ & Context \\
\hline Saldaña-Zorrilla and Sandberg & Weather disaster & Emigration & Mexico \\
\hline \multicolumn{4}{|l|}{$(2009)$} \\
\hline \multirow[t]{2}{*}{ Sager (2019) } & Pollution & Road & United \\
\hline & & accidents & Kingdom \\
\hline \multirow[t]{2}{*}{ Rudolph (2020) } & Turnout & Referendum & United \\
\hline & & voting & Kingdom \\
\hline M. R. Rosenzweig and & Rainfall & Income & India \\
\hline \multicolumn{4}{|l|}{ Binswanger (1993) } \\
\hline M. Rosenzweig and Wolpin & Rainfall & Livestock & India \\
\hline (1993) & & prices & \\
\hline Mark Rosenzweig and Stark & Income & Immigration & India \\
\hline
\end{tabular}




\begin{tabular}{|c|c|c|c|}
\hline \multicolumn{4}{|l|}{ Source of IV estimate/observed } \\
\hline correlation & $\mathrm{x}$ & Y & Context \\
\hline Mark Rosenzweig and Stark & Income & Employing & India \\
\hline (1989) & & servants & \\
\hline Mark Rosenzweig and Stark & Income & Distance & India \\
\hline \multirow[t]{2}{*}{$(1989)$} & & travelled for & \\
\hline & & marriage & \\
\hline Mark Rosenzweig and Stark & Income & Property & India \\
\hline$(1989)$ & & values & \\
\hline \multirow[t]{2}{*}{ Roenneberg and Aschoff (1990) } & Temperature & Month of & worldwide \\
\hline & & birth & \\
\hline \multirow[t]{2}{*}{ Ritter and Conrad (2016) } & Protest & Repression & United \\
\hline & & & States \\
\hline Ritter and Conrad (2016) & Protest & Repression & Africa \\
\hline
\end{tabular}


Source of IV estimate/observed

\begin{tabular}{llll} 
correlation & X & Y & Context \\
\hline
\end{tabular}

Reuveny and Moore (2009)

Weather disaster

Emigration developed

countries

Reichhoff (2017)

Reichhoff (2017)

Rappaport (2007)

Rappaport (2007)

Rappaport (2007)

Ranson (2014)
Temperature

Rainfall

Humidity

Temperature

Immigration

Rainfall

Immigration

Temperature
States

States

Crime

California

States

United

United

States 
Source of IV estimate/observed

\begin{tabular}{|c|c|c|c|}
\hline correlation & $\mathrm{X}$ & $\mathrm{Y}$ & Context \\
\hline \multirow[t]{2}{*}{ Ranson (2014) } & Rainfall & Crime & United \\
\hline & & & States \\
\hline Rana (2013) & Sectoral employment & Terrorism & Pakistan \\
\hline \multirow[t]{3}{*}{ Qiu, Chen, and Shi (2020) } & COVID19 & New & China \\
\hline & & COVID19 & \\
\hline & & infections & \\
\hline Pugatch and Yang (2011) & Emigration & Wages & Mexico/US \\
\hline \multirow[t]{2}{*}{ Pitt and Sigle (1997) } & Rainfall & Child & Senegal \\
\hline & & mortality & \\
\hline Pitt and Sigle (1997) & Rainfall & Fertility & Senegal \\
\hline Pipitpukdee, Attavanich, and & Temperature & Agricultural & Thailand \\
\hline Bejranonda (2020) & & production & \\
\hline
\end{tabular}


Source of IV estimate/observed

\begin{tabular}{cccc} 
correlation & X & Y & Context \\
\hline Pipitpukdee, Attavanich, and & Rainfall & Agricultural & Thailand \\
Bejranonda (2020) & production & \\
Pinckney (2019) & Protest & Party vote & United \\
& & share & States \\
Pinckney (2019) & Protest & Legislator & United \\
& & Pehavior & States \\
Pinckney (2019) & & Protest & United \\
& & & States \\
& & & Sweden
\end{tabular}

Pereira and Menezes (2020)

Income

Crime

Brazil

Peet (2020)

Early life pollution

Human Philippines

capital 
Source of IV estimate/observed

\begin{tabular}{|c|c|c|c|}
\hline correlation & $\mathrm{X}$ & Y & Context \\
\hline Peet $(2020)$ & Early life pollution & Income & Philippines \\
\hline Peet $(2020)$ & Early life pollution & Health & Philippines \\
\hline Paxson (1992) & Income & Savings & Thailand \\
\hline Paul (2005) & Weather disaster & Emigration & Bangladesh \\
\hline Parham and Michael (2010) & Rainfall & Malaria & Tanzania \\
\hline Parham and Michael (2010) & Temperature & Malaria & Tanzania \\
\hline \multirow[t]{2}{*}{ Papaioannou (2017) } & Agricultural production & Property & British \\
\hline & & crime & colonies \\
\hline \multirow[t]{2}{*}{ Papaioannou (2017) } & Agricultural production & Theft & British \\
\hline & & & colonies \\
\hline Papaioannou (2017) & Agricultural production & Cattle & British \\
\hline & & raiding & colonies \\
\hline
\end{tabular}


Source of IV estimate/observed

\begin{tabular}{cccc} 
correlation & X & Y & Context \\
\hline Papaioannou (2017) & Agricultural production & NA & British \\
& & & colonies \\
Papaioannou (2017) & Agricultural production & Violent & British \\
& & & crime \\
& & & colonies
\end{tabular}

Pajaron and Vasquez (2020)

Income

Immigration Philippines

Pajaron (2017)

Income

Consumption Philippines

Pajaron (2017)

Income

Debt

Philippines

Pajaron (2017)

Income

Remittances

Philippines

Pajaron (2017)

Income

Net assets

Philippines

Pajaron (2017)

Income

Domestic Philippines

money

transfers 
Source of IV estimate/observed

\begin{tabular}{cccc} 
correlation & X & Y & Context \\
\hline Oster (2004) & Income & Witch trials & Renaissance \\
Nübler et al. (2020) & Europe & Kenya \\
& & Human & \\
& & capital & \\
Nillesen and Verwimp (2011) & Rainfall & Rebel & Burundi \\
& & recruitment & \\
& & Immigration & Mexico
\end{tabular}

Hunter (2013)

Naudé (2010)

Weather disaster

Net

45

migration Sub-Saharan

African

Countries 
Source of IV estimate/observed

\begin{tabular}{cccc} 
correlation & X & Y & Context \\
\hline Nadolnyak and Hartarska (2012) & Rainfall & Crop & United \\
& disaster & States \\
Nadolnyak and Hartarska $(2012)$ & payments & \\
& Temperature & Crop & United \\
& disaster & States \\
& payments &
\end{tabular}

Munshi (2003)

Migrant social capital

Migrant Mexico/US

employment

Mulder and Scholtens (2013) Energy production $\quad$ Energy Netherlands

prices and

Germany

V. Mueller, Gray, and Kosec

Rainfall

Emigration

Pakistan

$(2014)$ 
Source of IV estimate/observed

\begin{tabular}{cccc} 
correlation & X & Y & Context \\
\hline V. Mueller, Gray, and Kosec & Temperature & Emigration & Pakistan
\end{tabular}

Valerie Mueller and Quisumbing Weather disaster Wages Bangladesh

Valerie Mueller and Osgood

Rainfall

Wages

Brazil

Muehlenbachs and Cohen (2014)

Oil platform inspectors

Oil platform

Gulf of

fines

Mexico

Moretti and Neidell (2011)

Pollution

Health

Los Angeles

Moretti (1998)

\begin{abstract}
Rainfall
\end{abstract}
Retirement

United

community

States

locations 
Source of IV estimate/observed

\begin{tabular}{|c|c|c|c|}
\hline correlation & $\mathrm{X}$ & Y & Context \\
\hline \multirow[t]{3}{*}{ Moretti (1998) } & Temperature & Retirement & United \\
\hline & & community & States \\
\hline & & locations & \\
\hline \multirow[t]{2}{*}{ Moreno-Medina (2021) } & Church attendance & Drug arrests & United \\
\hline & & & States \\
\hline \multirow[t]{2}{*}{ Moreno-Medina (2021) } & Church attendance & Alcohol & United \\
\hline & & arrests & States \\
\hline \multirow[t]{2}{*}{ Moreno-Medina (2021) } & Church attendance & White collar & United \\
\hline & & arrests & States \\
\hline \multirow[t]{2}{*}{ Moreno-Medina (2021) } & Church attendance & Violent & United \\
\hline & & crime & States \\
\hline \multirow[t]{2}{*}{ Moreno-Medina (2021) } & Church attendance & Property & United \\
\hline & & crime & States \\
\hline
\end{tabular}


Source of IV estimate/observed

\begin{tabular}{cccc} 
correlation & X & Y & Context \\
\hline Miguel and Satyanath (2011) & Income & Conflict & worldwide \\
Miguel, Satyanath, and Sergenti & Income & Conflict & Africa
\end{tabular}

Meier, Schmid, and Stutzer

Mehlum, Miguel, and Torvik

Mehlum, Miguel, and Torvik (2006)

Maystadt and Ecker (2014)

Maunder (1973)
Mood

Income

Income

Livestock prices

Temperature
Referendum Switzerland

voting

Violent

Germany

crime

Property Germany

crime

Conflict Somalia

Sales United

States 
Source of IV estimate/observed

\begin{tabular}{|c|c|c|c|}
\hline correlation & $\mathrm{X}$ & Y & Context \\
\hline \multirow[t]{2}{*}{ Maunder (1973) } & Rainfall & Sales & United \\
\hline & & & States \\
\hline \multirow[t]{2}{*}{ Martin et al. (2021) } & Farming practices & Carbon & emerging \\
\hline & & emissions & markets \\
\hline \multirow[t]{2}{*}{ Martin et al. (2021) } & Farming practices & Pollution & emerging \\
\hline & & & markets \\
\hline Marchiori, Maystadt, and & Rainfall & Urbanization & Africa \\
\hline
\end{tabular}

Schumacher (2017)

Marchiori, Maystadt, and

Rainfall Income

Africa

Schumacher (2017)

Marchiori, Maystadt, and

Temperature

Urbanization

Africa

Schumacher (2017) 
Source of IV estimate/observed

\begin{tabular}{cccc} 
correlation & X & Y & Context \\
\hline Marchiori, Maystadt, and & Temperature & Income & Africa
\end{tabular}

Schumacher (2017)

Marchiori, Maystadt, and

Rainfall

Immigration

Africa

Schumacher (2012)

Marchiori, Maystadt, and

Temperature

Immigration

Africa

Schumacher (2012)

Magnusson (2000)

Sunlight

Mood

worldwide

Madestam et al. (2013)

Protest

Legislator

United

behavior

States

Madestam et al. (2013)

Protest

Party vote

United

share

States

Maccini and Yang (2009)

Rainfall

Health

Indonesia 
Source of IV estimate/observed

\begin{tabular}{|c|c|c|c|}
\hline correlation & $\mathrm{X}$ & Y & Context \\
\hline \multirow[t]{2}{*}{ Maccini and Yang (2009) } & Rainfall & Human & Indonesia \\
\hline & & capital & \\
\hline Maccini and Yang (2009) & Rainfall & Wealth & Indonesia \\
\hline \multirow[t]{2}{*}{ Luechinger (2014) } & Pollution & Child & Germany \\
\hline & & mortality & \\
\hline Lo Prete and Revelli (2020) & Turnout & Life quality & Italy \\
\hline \multirow[t]{3}{*}{ Lo Prete and Revelli (2020) } & Turnout & Speed of & Italy \\
\hline & & revenue & \\
\hline & & collection & \\
\hline Lo Prete and Revelli (2020) & Turnout & Environmental & Italy \\
\hline
\end{tabular}


Source of IV estimate/observed

\begin{tabular}{|c|c|c|c|}
\hline correlation & $\mathrm{X}$ & Y & Context \\
\hline \multirow[t]{3}{*}{ Lo Prete and Revelli (2020) } & Turnout & Speed of & Italy \\
\hline & & public good & \\
\hline & & provision & \\
\hline \multirow[t]{2}{*}{ Lo Prete and Revelli (2020) } & Turnout & Mayoral & Italy \\
\hline & & quality & \\
\hline \multirow[t]{3}{*}{ Lo Prete and Revelli (2020) } & Turnout & Number of & Italy \\
\hline & & mayoral & \\
\hline & & candidates & \\
\hline \multirow[t]{2}{*}{ Lo Prete and Revelli (2020) } & Turnout & Waste & Italy \\
\hline & & recycling & \\
\hline López-córdova (2006) & Remittances & Human & Mexico \\
\hline
\end{tabular}


Source of IV estimate/observed

\begin{tabular}{|c|c|c|c|}
\hline correlation & $\mathrm{X}$ & Y & Context \\
\hline \multirow[t]{2}{*}{ López-córdova (2006) } & Remittances & Child & Mexico \\
\hline & & mortality & \\
\hline López-córdova (2006) & Remittances & Marginalization & Mexico \\
\hline López-córdova (2006) & Remittances & Poverty & Mexico \\
\hline \multirow[t]{2}{*}{ Liu, Thomadsen, and Yao } & Social distancing & COVID19 & United \\
\hline & & & States \\
\hline \multirow[t]{2}{*}{ Lis and Nickel (2010) } & Weather disaster & Budget & worldwide \\
\hline & & balance & \\
\hline \multirow[t]{2}{*}{ Lind (2019) } & Party vote share & Government & Norway \\
\hline & & spending & \\
\hline \multirow[t]{2}{*}{ Li, Johnson, and Zaval (2011) } & Perceived Temperature & Global & US and \\
\hline & variation & warming & Australia \\
\hline
\end{tabular}


Source of IV estimate/observed

\begin{tabular}{|c|c|c|c|}
\hline correlation & $\mathrm{X}$ & Y & Context \\
\hline \multirow[t]{2}{*}{ Lewin, Fisher, and Weber (2012) } & Rainfall & Agricultural & Malawi \\
\hline & & production & \\
\hline Lewin, Fisher, and Weber (2012) & Rainfall & Emigration & Malawi \\
\hline \multirow[t]{2}{*}{ Levin et al. (2020) } & Rainfall & Lead & various \\
\hline & & exposure & \\
\hline \multirow[t]{2}{*}{ Levin et al. (2020) } & Humidity & Lead & various \\
\hline & & exposure & \\
\hline \multirow[t]{2}{*}{ Levin et al. (2020) } & Temperature & Lead & various \\
\hline & & exposure & \\
\hline \multirow[t]{2}{*}{ Levin et al. (2020) } & Sunlight & Lead & various \\
\hline & & exposure & \\
\hline Leimdörfer and Hauge (2020) & Child mortality & Fertility & Niger \\
\hline
\end{tabular}


Source of IV estimate/observed

\begin{tabular}{cccc} 
correlation & X & Y & Context \\
\hline W.-S. Lee and Li (2020) & Economic conditions in & Health & China \\
& childhood & & \\
& & & \\
C. Lee and Chiu (2011) & Energy prices & Consumption & OECD
\end{tabular}

Ledlie et al. (2018)

Rainfall

Child health

Ethiopia

Larreboure and Gonz (2021)

Protest

Female

United

candidate

States

votes

Larreboure and Gonz (2021)

Protest

Minority

United

candidate

States

votes

Landis et al. (2017)

Rainfall

Conflict

Niger River

Basin 
Source of IV estimate/observed

\begin{tabular}{cccc} 
correlation & X & Context \\
\hline Laidley and Conley (2018) & Exercise & Human & United \\
Lahiri (2018) & capital & States \\
& Unemployment & Racial & United \\
Lagerlöf and Basher (2006) & earnings & States \\
& Urbanization & Income & North \\
& & & America \\
& & & Income \\
Lagerlöf and Basher $(2006)$ & Suman capital & North
\end{tabular}

America

Kumar and Viswanathan (2012) Agricultural production Emigration India

Kubik and May (2018) Food prices $\quad$ Hunger South Africa 
Source of IV estimate/observed

\begin{tabular}{|c|c|c|c|}
\hline correlation & $\mathrm{X}$ & Y & Context \\
\hline \multirow[t]{2}{*}{ Kovács (2017) } & Clouds & Patents & United \\
\hline & & & States \\
\hline \multirow[t]{2}{*}{ Kovács (2017) } & Temperature & Patents & United \\
\hline & & & States \\
\hline \multirow[t]{2}{*}{ Koks et al. (2019) } & Rainfall & Transport in- & worldwide \\
\hline & & frastructure & \\
\hline Kochar (1999) & Income & Consumption & India \\
\hline \multirow[t]{2}{*}{ Knack (1994) } & Turnout & Party vote & United \\
\hline & & share & States \\
\hline Kleemans and Magruder (2018) & Emigration & Unemployment & Indonesia \\
\hline Kleemans and Magruder (2018) & Emigration & Wages & Indonesia \\
\hline Y. Kim, Sesmero, and Waldorf & Rainfall & Immigration & India \\
\hline
\end{tabular}


Source of IV estimate/observed

\begin{tabular}{cccc} 
correlation & X & Y & Context \\
\hline N. Kim (2016) & Income & Coup & worldwide \\
Khanthavit (2019c) & Mood & Stock & Thailand \\
& & & \\
& & returns
\end{tabular}

Khanthavit (2019a)

Air pressure

Government Thailand

bond returns

Khanthavit (2019a)

Clouds

Government Thailand

bond returns

Khanthavit (2019a)

Rainfall

Government Thailand

bond returns

Khanthavit (2019a)

Humidity

Government

Thailand

bond returns

Khanthavit (2019a)

Haze

Government Thailand

bond returns 
Source of IV estimate/observed

\begin{tabular}{|c|c|c|c|}
\hline correlation & $\mathrm{X}$ & Y & Context \\
\hline \multirow[t]{2}{*}{ Khanthavit (2019a) } & Temperature & Government & Thailand \\
\hline & & bond returns & \\
\hline \multirow[t]{2}{*}{ Khanthavit (2019b) } & Mood & Stock & Thailand \\
\hline & & returns & \\
\hline \multirow[t]{2}{*}{ Khanthavit (2017a) } & Air pressure & Stock & Bangkok, \\
\hline & & returns & Thailand \\
\hline \multirow[t]{2}{*}{ Khanthavit (2017a) } & Rainfall & Stock & Bangkok, \\
\hline & & returns & Thailand \\
\hline \multirow[t]{2}{*}{ Khanthavit (2017b) } & Mood & Stock & Thailand \\
\hline & & returns & \\
\hline \multirow[t]{2}{*}{ Keele and Morgan (2016) } & Turnout & Party vote & United \\
\hline & & share & States \\
\hline
\end{tabular}


Source of IV estimate/observed

\begin{tabular}{cccc} 
correlation & X & Y & Context \\
\hline Kazianga and Udry (2006) & Income & Consumption & Burkina
\end{tabular}

Katz et al. (2020)

Skin Tone

Unemployment

United

States

Kapoor et al. (2020)

Social distancing

COVID19

United

States

W. Kang (2019)

Turnout

Party vote

South Korea

share

H. Kang, Suh, and Yu (2019)

Pollution

Sales

South Korea

P. Jensen and Gleditsch (2009)

Income

Conflict

african

countries

R. Jensen (2000)

Income

Human

Cote

capital D'Ivoire 
Source of IV estimate/observed

\begin{tabular}{cccc} 
correlation & X & Y & Context \\
\hline R. Jensen $(2000)$ & Income & Hunger & Cote
\end{tabular}

D'Ivoire

Jayachandran (2006) Agricultural production Agricultural India

$\begin{array}{llll}\text { Jacoby and Skoufias (1997) } & \text { Income } & \text { Human }\end{array}$

$\begin{array}{llll}\text { Jacobsen and Marquering (2008) } & \text { Mood } & \text { Stock } & \text { worldwide }\end{array}$

$\begin{array}{llll}\text { Jacob, Lefgren, and Moretti } & \text { Traffic } & \text { Future } & \text { United }\end{array}$

Jacob, Lefgren, and Moretti

Property crime

Future

United

(2007)

property States

crime 


\begin{tabular}{|c|c|c|c|}
\hline \multicolumn{4}{|l|}{ Source of IV estimate/observed } \\
\hline correlation & $\mathrm{X}$ & $\mathrm{Y}$ & Context \\
\hline Jacob, Lefgren, and Moretti & Violent crime & Future & United \\
\hline$(2007)$ & & violent crime & States \\
\hline \multirow[t]{2}{*}{ Ito and Reguant (2016) } & Energy production & Energy & Spain/Portugal \\
\hline & & prices & \\
\hline \multirow[t]{2}{*}{ Huet-Vaughn (2013) } & Violent protest & Policy & France \\
\hline & & concessions & \\
\hline H. Huang, Kerstein, and Wang & Weather disaster & Firm cash & worldwide \\
\hline$(2018)$ & & holding & \\
\hline F. Huang et al. (2011) & Rainfall & Malaria & Tibet \\
\hline \multirow[t]{2}{*}{ Hu and Lee (2020) } & Consumer sentiment & Property & Sydney \\
\hline & & values & \\
\hline Hsiang, Burke, and Miguel & Temperature & Conflict & worldwide \\
\hline
\end{tabular}


Source of IV estimate/observed

\begin{tabular}{|c|c|c|c|}
\hline correlation & $\mathrm{X}$ & Y & Context \\
\hline Hsiang, Burke, and Miguel & Rainfall & Conflict & worldwide \\
\hline \multicolumn{4}{|l|}{$(2013)$} \\
\hline Hsiang, Meng, and Cane (2011) & Temperature & Conflict & worldwide \\
\hline Horrocks and Menclova (2011) & Temperature & Crime & New Zealand \\
\hline Horrocks and Menclova (2011) & Rainfall & Crime & New Zealand \\
\hline \multirow[t]{2}{*}{ Hornbeck et al. (2012) } & Erosion & Property & United \\
\hline & & values & States \\
\hline \multirow[t]{2}{*}{ Horiuchi and Kang (2018) } & Turnout & Party vote & United \\
\hline & & share & States \\
\hline \multirow[t]{2}{*}{ Horiuchi and Kang (2015) } & Rainfall & Party vote & United \\
\hline & & share & States \\
\hline Hoogeveen, Van Der Klaauw, & Wealth & Marriage & Zimbabwe \\
\hline
\end{tabular}

and Van Lomwel (2011) 


\begin{tabular}{|c|c|c|c|}
\hline Source of IV estimate/observed & & & \\
\hline correlation & $\mathrm{X}$ & $\mathrm{Y}$ & Context \\
\hline Hodler and Raschky (2014) & Income & Conflict & Africa \\
\hline Herrnstadt and Muehlegger & Issue salience & Legislator & United \\
\hline$(2014)$ & & behavior & States \\
\hline Henry, Spencer, and Strobl & Weather disaster & Consumption & Jamaica \\
\hline$(2020)$ & & & \\
\hline Hendricks, Janzen, and Smith & Agricultural production & Crop prices & worldwide \\
\hline$(2015)$ & & & \\
\hline S. Henderson and Ryabova & Sustainability & Income & California \\
\hline$(2020)$ & investments & & \\
\hline J. Henderson and Brooks (2016) & Party vote share & Representative & United \\
\hline & & voting & States \\
\hline
\end{tabular}


Source of IV estimate/observed

\begin{tabular}{|c|c|c|c|}
\hline correlation & $\mathrm{X}$ & Y & Context \\
\hline Heinen, Khadan, and Strobl & Rainfall;Wind speed & Price & 15 \\
\hline \multirow[t]{2}{*}{$(2019)$} & & & Caribbean \\
\hline & & & Islands \\
\hline \multirow[t]{2}{*}{ Healy and Malhotra (2010) } & Weather disaster & Incumbent & United \\
\hline & & voting & States \\
\hline \multirow[t]{2}{*}{ Hansford and Gomez (2010) } & Turnout & Incumbent & non- \\
\hline & & voting & Southern US \\
\hline \multirow[t]{2}{*}{ Hansford and Gomez (2010) } & Turnout & Party vote & non- \\
\hline & & share & Southern US \\
\hline Hanandita and Tampubolon & Income & Mental & Indonesia \\
\hline$(2014)$ & & health & \\
\hline
\end{tabular}

Hales et al. (2000)

Temperature

Mortality

Christchurch,

New Zealand 
Source of IV estimate/observed

\begin{tabular}{|c|c|c|c|}
\hline correlation & $\mathrm{X}$ & $\mathrm{Y}$ & Context \\
\hline \multirow[t]{2}{*}{ Hales et al. (2000) } & Pollution & Mortality & Christchurch, \\
\hline & & & New Zealand \\
\hline Guven and Hoxha (2015) & Mood & Unemployment & Netherlands \\
\hline \multirow[t]{2}{*}{ Guven and Hoxha (2015) } & Mood & Risk & Netherlands \\
\hline & & tolerance & \\
\hline \multirow[t]{2}{*}{ Guven and Hoxha (2015) } & Mood & Inflation & Netherlands \\
\hline & & expectations & \\
\hline \multirow[t]{3}{*}{ Guven and Hoxha (2015) } & Mood & Decision & Netherlands \\
\hline & & making & \\
\hline & & speed & \\
\hline
\end{tabular}


Source of IV estimate/observed

\begin{tabular}{|c|c|c|c|}
\hline correlation & $\mathrm{X}$ & Y & Context \\
\hline \multirow[t]{3}{*}{ Guven and Hoxha (2015) } & Mood & Subjective & Netherlands \\
\hline & & perceptions & \\
\hline & & expectancy & \\
\hline \multirow[t]{2}{*}{ Guven and Hoxha (2015) } & Mood & Holding & Germany \\
\hline & & investments & \\
\hline Guven and Hoxha (2015) & Mood & Savings & Germany \\
\hline Guven and Hoxha (2015) & Mood & Insurance & Germany \\
\hline \multirow[t]{3}{*}{ Guven and Hoxha (2015) } & Mood & Operating & Germany \\
\hline & & asset & \\
\hline & & ownership & \\
\hline
\end{tabular}


Source of IV estimate/observed

\begin{tabular}{cccc} 
correlation & Y & Context \\
\hline Gurgand (2003) & Rainfall & Farmers & Taiwan \\
& returns to & \\
Gu et al. (2020) & education & \\
& Pollution & Mental & China \\
Groppo and Kraehnert (2017) & Agricultural production & Human & Mongolia \\
& & capital &
\end{tabular}

$\begin{array}{llll}\text { Graddy and Kennedy (2010) } & \text { Food prices } & \text { Quantity } & \text { Fulton Fish }\end{array}$

Market (New

York)

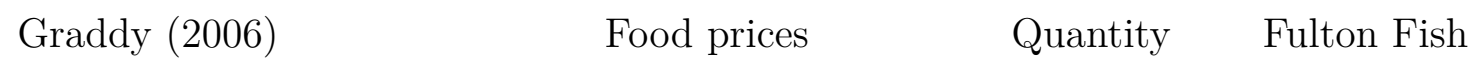

Market (New

York) 


\begin{tabular}{|c|c|c|c|}
\hline \multicolumn{4}{|l|}{ Source of IV estimate/observed } \\
\hline correlation & $\mathrm{X}$ & Y & Context \\
\hline \multirow[t]{2}{*}{ Gong and Rogers (2014) } & Turnout & Support for & United \\
\hline & & school bonds & States \\
\hline Gomez, Hansford, and Krause & Turnout & Party vote & United \\
\hline$(2007)$ & & share & States \\
\hline Goetzke and Rave (2011) & Cycling & Cycling & Germany \\
\hline Giulietti, Wahba, and Zenou & Migrant social capital & Migration & China \\
\hline \multicolumn{4}{|l|}{$(2018)$} \\
\hline Gillett et al. (2004) & Temperature & Forest fires & Canada \\
\hline Gajate-Garrido (2013) & Health access & Child health & Philippines \\
\hline \multirow[t]{2}{*}{ Fujiwara, Meng, and Vogl (2016) } & Turnout & Future & United \\
\hline & & turnout & States \\
\hline Frijters, Lalji, and Pakrashi & Temperature & Health & United \\
\hline$(2020)$ & & & States \\
\hline
\end{tabular}


Source of IV estimate/observed

\begin{tabular}{cccc} 
correlation & X & Y & Context \\
\hline Frijters, Lalji, and Pakrashi & Temperature & Mood & United
\end{tabular}

States

Frijters, Lalji, and Pakrashi

Rainfall

Health

United

Frijters, Lalji, and Pakrashi

Rainfall

Mood

United

Fraga and Hersh (2011)

Rainfall

Turnout

United

States

Fontenla, Goodwin, and

Pollution

Property Mexico City

Gonzalez (2019)

Fontenla, Goodwin, and

Pollution

Wages

Mexico City

Gonzalez (2019) 
Source of IV estimate/observed

correlation

X

Y

Context

Flyr et al. (2019)

Temperature

Water

Fort Collins

consumption

municipal

utility

Fisher-Vanden, Mansur, and

Energy consumption

Production

China

Wang (2015)

Fisher-Vanden, Mansur, and

Energy consumption

Factor

China

Wang (2015)

substitution

Fichera and Savage (2015)

Income

Vaccination

Tanzania

Fichera and Savage (2015)

Income

NA

Tanzania

Fichera and Savage (2015)

Income

BMI

Tanzania

Fichera and Savage (2015)

Income

Health

Tanzania

Feng, Oppenheimer, and

Agricultural production

Immigration

US Corn

Schlenker (2012)

Belt 
Source of IV estimate/observed

\begin{tabular}{cccc} 
correlation & X & Y & Context \\
\hline Feng, Krueger, and & Agricultural production & Immigration & Mexico
\end{tabular}

Oppenheimer (2010)

Farah and Torell (2018)

Snow

Water prices

United

States

Farah and Torell (2018)

Snow

willingness

United

to pay for

States

water

hardness

reduction

Faradiba (2021)

Rainfall

Malaria

Indonesia

Fan and Wang (2020)

Pollution

Mortality

United

States 
Source of IV estimate/observed

\begin{tabular}{|c|c|c|c|}
\hline correlation & $\mathrm{X}$ & Y & Context \\
\hline \multirow[t]{2}{*}{ Fan and Wang (2020) } & Wind direction & Pollution & United \\
\hline & & & States \\
\hline \multirow[t]{3}{*}{ Di Falco and Doku (2019) } & Income & Mood & Nile Basin \\
\hline & & & Region of \\
\hline & & & Ethiopia \\
\hline Di Falco et al. (2014) & Insurance & Income & Italy \\
\hline Di Falco et al. (2014) & Crop diversity & Income & Italy \\
\hline Elum, Nhamo, and Antwi (2018) & Insurance & Income & South Africa \\
\hline Elsner and Wozny (2019) & Radiation exposure & Human & Germany \\
\hline
\end{tabular}

Elliott et al. (2019)

Weather disaster

Manufacturing

China

revenue

Elliott, Strobl, and Sun (2015)

Weather disaster

Income

China 
Source of IV estimate/observed

\begin{tabular}{|c|c|c|c|}
\hline correlation & $\mathrm{X}$ & Y & Context \\
\hline \multirow[t]{2}{*}{ Dustmann, Fasani, and Speciale } & Migration legal status & Consumption & Italy \\
\hline & & & \\
\hline \multirow[t]{2}{*}{ Duhaime and Moulton (2018) } & Mood & Party vote & United \\
\hline & & share & States \\
\hline Douglas, Lena, and Mårten & Radiation exposure & Human & Sweden \\
\hline$(2009)$ & & capital & \\
\hline \multirow[t]{2}{*}{ Di Falco et al. (2019) } & Income & Discount & Ethiopia \\
\hline & & rates & \\
\hline \multirow[t]{2}{*}{ Di Falco and Chavas (2008) } & Rainfall & Agricultural & Italy \\
\hline & & production & \\
\hline Di Falco and Chavas (2008) & Crop diversity & Agricultural & Italy \\
\hline
\end{tabular}


Source of IV estimate/observed

\begin{tabular}{|c|c|c|c|}
\hline correlation & $\mathrm{X}$ & Y & Context \\
\hline Deschênes and Greenstone & Temperature & Agricultural & United \\
\hline$(2012)$ & & production & States \\
\hline Dercon (2004) & Rainfall & Consumption & Ethiopia \\
\hline \multirow{2}{*}{ Del Valle et al. (2018) } & Weather disaster & Income & Guandong, \\
\hline & & & China \\
\hline Dell, Jones, and Olken (2009) & Temperature & Income & worldwide \\
\hline Davis (2016) & Individual responsibility & Income & worldwide \\
\hline Davies (2010) & Rainfall & Consumption & Malawi \\
\hline Dacuycuy (2016) & Income & Consumption & Philippines \\
\hline \multirow[t]{2}{*}{ X. Cui (2020) } & Temperature & Crop aban- & United \\
\hline & & donment & States \\
\hline C. Cui et al. (2019) & Pollution & Emigration & China \\
\hline
\end{tabular}


Source of IV estimate/observed

\begin{tabular}{|c|c|c|c|}
\hline correlation & $\mathrm{X}$ & $\mathrm{Y}$ & Context \\
\hline \multirow[t]{2}{*}{ Coviello et al. (2014) } & Mood & Friends & United \\
\hline & & $\operatorname{mood}$ & States \\
\hline Courtemanche, Pinkston, and & Exercise & BMI & United \\
\hline Stewart (2020) & & & States \\
\hline Courtemanche, Pinkston, and & Cycling & BMI & United \\
\hline Stewart (2020) & & & States \\
\hline Corbi and Ferraz (2018) & Emigration & Unemployment & Brazil \\
\hline \multirow[t]{2}{*}{ Cooperman (2017) } & Rainfall & Turnout & United \\
\hline & & & States \\
\hline Cools, Flat $\varnothing$, and Kotsadam & Rainfall & Domestic & Africa \\
\hline$(2020)$ & & abuse & \\
\hline Cook and Garrett (2013) & Wind speed & Pirate & Somalia \\
\hline
\end{tabular}


Source of IV estimate/observed

\begin{tabular}{|c|c|c|c|}
\hline correlation & $\mathrm{X}$ & Y & Context \\
\hline \multirow[t]{2}{*}{ Considine (2000) } & Temperature & Carbon & United \\
\hline & & emissions & States \\
\hline \multirow[t]{2}{*}{ Considine (2000) } & Temperature & Consumption & United \\
\hline & & & States \\
\hline \multirow[t]{2}{*}{ Collins and Margo (2007) } & Violent protest & Property & US cities \\
\hline & & values & \\
\hline \multirow[t]{2}{*}{ Cohen (2011) } & Clouds & Presidential & United \\
\hline & & approval & States \\
\hline \multirow[t]{2}{*}{ Chin (2012) } & Female employment & Domestic & India \\
\hline & & abuse & \\
\hline Chia et al. (2016) & Violent crime & Inequality & United \\
\hline
\end{tabular}

States 
Source of IV estimate/observed

\begin{tabular}{|c|c|c|c|}
\hline correlation & $\mathrm{X}$ & $\mathrm{Y}$ & Context \\
\hline Chia et al. (2016) & Property crime & Inequality & United \\
\hline \multirow{3}{*}{ Chhaochharia et al. (2019) } & & & States \\
\hline & Perceived economic & Capital & United \\
\hline & outlook & expenditure & States \\
\hline \multirow[t]{2}{*}{ Chhaochharia et al. (2019) } & Perceived economic & Labor & United \\
\hline & outlook & markets & States \\
\hline \multirow[t]{2}{*}{ Chen and Mahmassani (2015) } & Rainfall & Travel time & San \\
\hline & & & Francisco \\
\hline Chen and Mahmassani (2015) & Rainfall & Mood & San \\
\hline
\end{tabular}

Francisco

Chavas et al. (2019)

Rainfall Agricultural Italy
production


Source of IV estimate/observed

\begin{tabular}{cccc} 
correlation & X & Context \\
\hline Chavas et al. (2019) & Temperature & Agricultural & Italy \\
& & production & \\
Chavas et al. (2019) & Weather disaster & Disaster & Taiwan \\
& & & \\
Chalfin (2014) & payments & \\
& Emigration & Crime & Mexico/US \\
Cashin, Mohaddes, and Raissi & Air pressure & Energy & 21 Countries \\
& & prices &
\end{tabular}

Cashin, Mohaddes, and Raissi

Air pressure

Income

21 Countries

Cashin, Mohaddes, and Raissi

Cashin, Mohaddes, and Raissi
Air pressure

Air pressure
Inflation

21 Countries

expectations

Price

21 Countries 
Source of IV estimate/observed

\begin{tabular}{cccc} 
correlation & X & Y & Context \\
\hline Caruso, Petrarca, and Ricciuti & Agricultural production & Conflict & Indonesia \\
$(2016)$ & Inventory & Sales & United \\
Cachon, Gallino, and Olivares & & & States \\
(2019) & & & India \\
Burgess et al. (2014) & Temperature & Mortality & India \\
Burgess and Donaldson (2010) & Rainfall & Hunger & Vietnam
\end{tabular}

mentation

A. Bui et al. (2014) Weather disaster Income Vietnam

A. Bui et al. (2014) Weather disaster Consumption Vietnam

Bruederle, Peters, and Roberts $\quad$ Temperature Crime $\quad$ South Africa

Bruckner and Ciccone (2011)

Income

Democracy

Africa 
Source of IV estimate/observed

\begin{tabular}{cccc} 
correlation & X & Y & Context \\
\hline Branco and Feres (2020) & Rainfall & Unemployment & Brazil \\
Branco and Feres (2020) & Rainfall & Sectoral & Brazil
\end{tabular}

employment

Boustan, Fishback, and Kantor

Boustan, Fishback, and Kantor

Boustan, Fishback, and Kantor

Bondy, Roth, and Sager (2020)

Blumberg (2015)
Net migration

Net migration

Net migration

Pollution

Rainfall
United

States

Wages

United

States

Unemployment United

States

Crime

London

employment Asia and

Africa 
Source of IV estimate/observed

\begin{tabular}{|c|c|c|c|}
\hline correlation & $\mathrm{X}$ & Y & Context \\
\hline \multirow[t]{2}{*}{ Blanc and Strobl (2016) } & Weather disaster & Agricultural & Philippines \\
\hline & & production & \\
\hline \multirow[t]{4}{*}{ Blanc (2012) } & Temperature & Agricultural & $37 \mathrm{sub}$ \\
\hline & & production & saharan \\
\hline & & & african \\
\hline & & & countries \\
\hline \multirow[t]{4}{*}{ Blanc (2012) } & Rainfall & Agricultural & 37 sub \\
\hline & & production & saharan \\
\hline & & & african \\
\hline & & & countries \\
\hline Blakeslee and Fishman (2018) & Rainfall & Crime & India \\
\hline Blakeslee and Fishman (2018) & Temperature & Crime & India \\
\hline Bhavnani and Lacina (2015) & Immigration & Conflict & India \\
\hline
\end{tabular}




\begin{tabular}{|c|c|c|c|}
\hline \multicolumn{4}{|l|}{ Source of IV estimate/observed } \\
\hline correlation & $\mathrm{X}$ & Y & Context \\
\hline Bertelli (2015) & Child mortality & Fertility & Nigeria \\
\hline Berry and Schlenker (2011) & Crop prices & Crop area & worldwide \\
\hline \multirow[t]{2}{*}{ Berry and Schlenker (2011) } & Crop prices & Crop area & United \\
\hline & & & States \\
\hline \multirow[t]{2}{*}{ Berry and Schlenker (2011) } & Crop prices & Agricultural & United \\
\hline & & production & States \\
\hline Bensassi, Mohan, and Strobl & Weather disaster & Crop prices & Britain \\
\hline \multicolumn{4}{|l|}{$(2017)$} \\
\hline Ben Lakhdar and Dubois (2006) & \multicolumn{2}{|c|}{ Rainfall;Sunlight;TemperatureTurnout } & France \\
\hline Beltrán, Maddison, and Elliott & Weather disaster & Property & England \\
\hline$(2019)$ & & values & \\
\hline Beltrán, Maddison, and Elliott & Weather disaster & Property & various \\
\hline (2018) & & values & \\
\hline
\end{tabular}


Source of IV estimate/observed

\begin{tabular}{cccc} 
correlation & X & Y & Context \\
\hline Bellet, De Neve, and Ward & Mood & Sales & United
\end{tabular}

Kingdom

Beine and Parsons (2015)

Beaudin and Huang (2014)

Baylis et al. (2018)

Baylis et al. (2018)

Baylis et al. (2018)

Baylis et al. (2018)

Bayani-Arias and Palanca-Tan

Bayani-Arias and Palanca-Tan
Rainfall;Temperature

Snow

Humidity

Clouds

Rainfall

Temperature

Rainfall

Weather disaster
Immigration

worldwide

ski areas

England

Mood

worldwide

Mood

worldwide

Mood

worldwide

Mood

worldwide

inequality

Inequality Philippines 
Source of IV estimate/observed

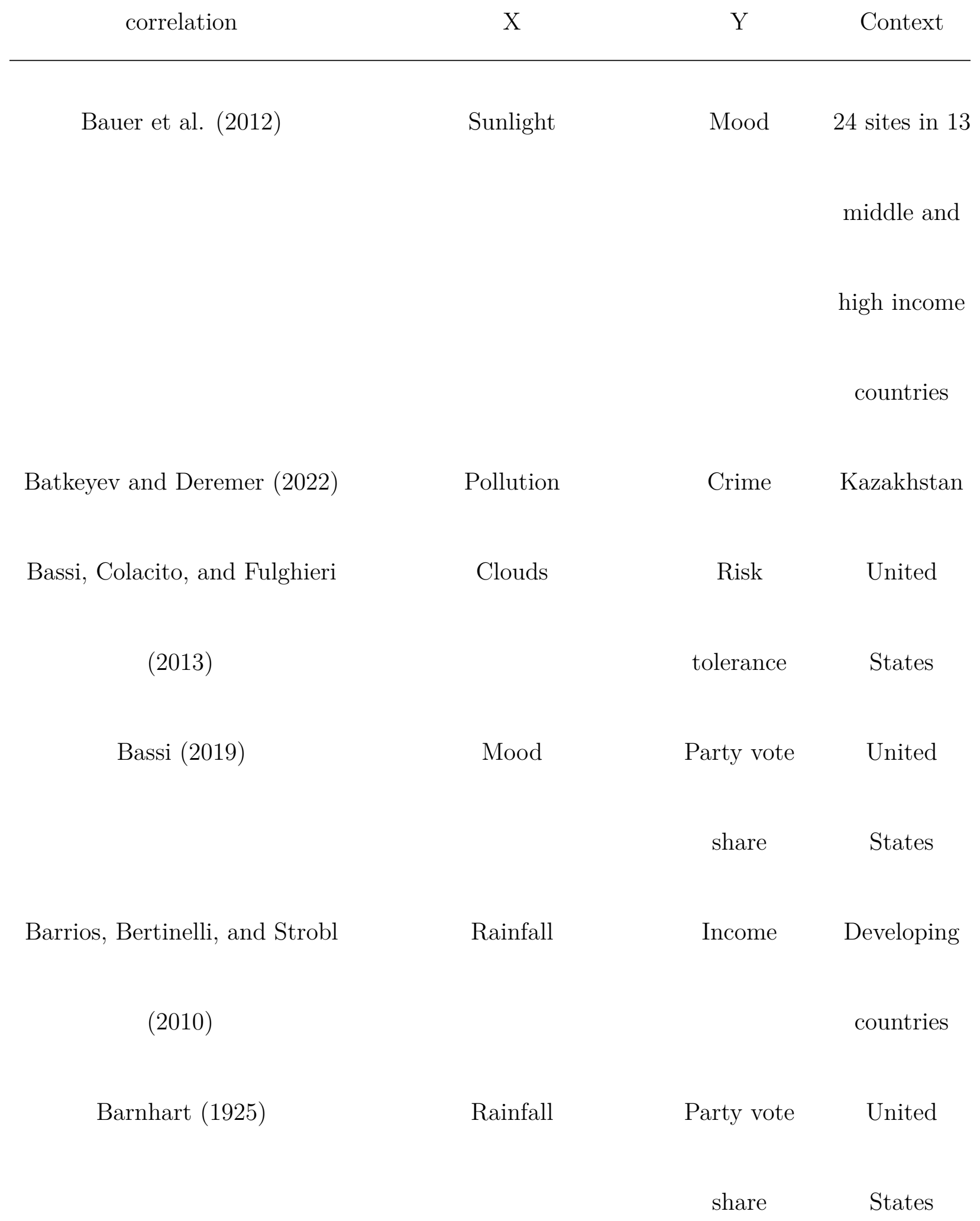


Source of IV estimate/observed

\begin{tabular}{|c|c|c|c|}
\hline correlation & $\mathrm{X}$ & Y & Context \\
\hline \multirow[t]{2}{*}{ Bai and Kung (2014) } & Hunger & Farming & China \\
\hline & & practices & \\
\hline Bae, Lim, and Hong (2020) & Pollution & Mortality & Seoul \\
\hline Badaoui, Strobl, and Walsh & Emigration & Wages & Thailand \\
\hline \multicolumn{4}{|l|}{$(2017)$} \\
\hline Badaoui, Strobl, and Walsh & Immigration & Wages & Thailand \\
\hline \multicolumn{4}{|l|}{$(2017)$} \\
\hline Atalla, Bigerna, and Bollino & Temperature & Energy & worldwide \\
\hline$(2018)$ & & demand & \\
\hline Asfaw, Pallante, and Palma & Crop diversity & Inequality & Niger \\
\hline$(2018)$ & & & \\
\hline Asfaw, Pallante, and Palma & Crop diversity & Hunger & Niger \\
\hline
\end{tabular}


Source of IV estimate/observed

$\begin{array}{cccc}\text { correlation } & \text { X } & \text { Y } & \text { Context } \\ \text { Asfaw, Pallante, and Palma } & \text { Crop diversity } & \text { Income } & \text { Niger } \\ (2018) & & & \\ \text { Artés (2014) } & \text { Turnout } & \text { Party vote } & \text { Spain } \\ & & \text { share } & \\ \text { Arnold and Freier (2016) } & \text { Turnout } & \text { Party vote } & \text { Germany } \\ & & \text { share } & \\ \text { Arezki and Brückner (2012) } & \text { Income } & \text { Remittances } & \text { 41 }\end{array}$

Sub-saharan

African

countries

Aral and Nicolaides (2017)

Exercise

Friends worldwide

exercise 


\begin{tabular}{|c|c|c|c|}
\hline \multicolumn{4}{|l|}{ Source of IV estimate/observed } \\
\hline correlation & $\mathrm{X}$ & Y & Context \\
\hline Apergis, Artikis, and & Rainfall;Temperature;Sı & N;CBrands loan & United \\
\hline Mamatzakis (2012) & & efficiency & States \\
\hline Angrist, Graddy, and Imbens & Food prices & Quantity & Fulton Fish \\
\hline \multirow[t]{2}{*}{$(2000)$} & & & Market (New \\
\hline & & & York) \\
\hline Allcott, Collard-Wexler, and & Rainfall & Hydroelectric & India \\
\hline O'Connell (2016) & & power & \\
\hline Allcott, Collard-Wexler, and & Hydroelectric power & Production & India \\
\hline \multicolumn{4}{|l|}{ O'Connell (2016) } \\
\hline Akobeng (2017) & Agricultural wages & Consumption & Ghana \\
\hline Aklilu (2007) & Income & Savings & Peru \\
\hline Ajefu and Abiona (2019) & Rainfall & Unemployment & India \\
\hline Ajefu and Abiona (2019) & Rainfall & Child labor & India \\
\hline
\end{tabular}


Source of IV estimate/observed

\begin{tabular}{|c|c|c|c|}
\hline correlation & $\mathrm{X}$ & $\mathrm{Y}$ & Context \\
\hline \multirow[t]{2}{*}{ Ahmed et al. (2011) } & Rainfall & Agricultural & Tanzania \\
\hline & & production & \\
\hline Aguiar-Moya, Prozzi, and de & Rainfall & Pavement & United \\
\hline Fortier Smit (2011) & & roughness & States \\
\hline Adhvaryu et al. (2019) & Dust Exposure & Health & West Africa \\
\hline \multirow[t]{2}{*}{ Adhvaryu et al. (2015) } & Temperature & Mood & 19 African \\
\hline & & & countries \\
\hline \multirow[t]{2}{*}{ Achen and Bartels (2016) } & Rainfall & Incumbent & United \\
\hline & & voting & States \\
\hline \multirow[t]{2}{*}{ Acharya, Blackwell, and Sen } & Slavery & Racism & United \\
\hline & & & States \\
\hline Acharya, Blackwell, and Sen & Slavery & Racial policy & United \\
\hline$(2016)$ & & preferences & States \\
\hline
\end{tabular}




\begin{tabular}{|c|c|c|c|}
\hline Source of IV estimate/observed & & & \\
\hline correlation & $\mathrm{X}$ & $\mathrm{Y}$ & Context \\
\hline Acharya, Blackwell, and Sen & Slavery & Party vote & United \\
\hline$(2016)$ & & share & States \\
\hline Abiona (2017) & Agricultural wages & Contraceptive & Uganda \\
\hline & & use & \\
\hline Theisen and Holtermann (2010) & Rainfall & Conflict & Africa \\
\hline Burke et al. (2009) & Temperature;Rainfall & Conflict & Africa \\
\hline Burke et al. (2009) & Temperature & Conflict & Africa \\
\hline Saeed and Spagat (2021) & Drone strikes & Terrorism & Pakistan \\
\hline Belasen and Polachek (2009) & Weather disaster & Wages & Florida \\
\hline Currie and Rossin-Slater (2013) & Weather disaster & Child health & United \\
\hline & & & States \\
\hline Persico and Marcotte (2022) & Pollution & Suicide & United \\
\hline
\end{tabular}




\begin{tabular}{cccc}
\hline Source of IV estimate/observed & & & \\
correlation & X & Y & Context \\
Cutler et al. (2010) & Malaria & Consumption & India \\
Chang et al. (2014) & Malaria & Health & Taiwan \\
McCord, Conley, and Sachs & Fertility & worldwide \\
(2017) & & & \\
K. Schultz and Mankin (2019) & Temperature & Conflict & Africa \\
& & & Party vote \\
Kitamura (2022) & United & States \\
\hline
\end{tabular}




\section{Appendix C: Number of social science articles published annually}

Between 2010 and 2020, Scopus lists an average of 58,544 journal articles published in "So-

ciology and Political Science" and "Economics and Econometrics" each year (Thelwall and

Sud 2022). 
Table D1: Number of existing IV studies in this paper's review that uses each weather type as an instrument for an x-variable.

\begin{tabular}{lr}
\hline Weather & Number of studies \\
\hline Rainfall & 219 \\
Temperature & 50 \\
Wind speed & 14 \\
Sunlight & 11 \\
Clouds & 8 \\
Wind direction & 8 \\
Snow & 6 \\
Atmospheric inversion & 5 \\
Humidity & 4 \\
Weather disaster & 4 \\
Air pressure & 3 \\
Wave height & 3 \\
Haze & 1 \\
Storms & 1 \\
Terrain & 1 \\
Weather-related absences & 1 \\
\hline a Counts are of uses of an instrument, so studies \\
using multiple weather variables as an instrument \\
appear multiple times.
\end{tabular}

\section{Appendix D: Weather types used}

Table D1 shows the number of studies using each weather variable (some studies use multiple

types of weather). 
Table E1: Count of weather-IV reduced forms and $R_{X_{j} \sim W \mid K}^{2}$ modeling different variance types. IV studies refers to the count of estimates modeling that variance type. Reduced-form count refers to the count of IV estimates with available information to use the reduced-form in sensitivity analysis. $R_{X_{j} \sim W \mid K}^{2}$ refers to the count of estimates of the strength of the $W \rightarrow X_{j}$ relationships available in the literature.

\begin{tabular}{lrr}
\hline Variance modelled & Reduced-form count & $R_{X_{j} \sim W \mid K}^{2}$ count \\
\hline within-subnational & 27 & 47 \\
within-person & 12 & 19 \\
between-subnational & 8 & 20 \\
between-person & 8 & 18 \\
within-country & 3 & 6 \\
time-series & 0 & 5 \\
between-organization & 2 & 1 \\
within-organization & 0 & 3 \\
between-country & 1 & 1 \\
between-event & 2 & 0 \\
\hline
\end{tabular}

\section{Appendix E: Variance type modelled}

Table E1 shows the level of variance the weather-IV reduced-forms and $R_{X_{j} \sim W \mid K}^{2}$ estimates

are based on. 


\section{Literature Review References}

Abiona, Olukorede. 2017. "The Impact of Unanticipated Economic Shocks on the Demand for Contraceptives: Evidence from Uganda." Health Economics 26 (12): 1696-1709.

Acharya, Avidit, Matthew Blackwell, and Maya Sen. 2016. "The political legacy of American Slavery." Journal of Politics 78 (3): 621-41.

Achen, Christopher, and Larry Bartels. 2016. Democracy for realists: Why Elections Do Not Produce Responsive Government. Princeton University Press.

Adhvaryu, Achyuta, Prashant Bharadwaj, James Fenske, Anant Nyshadham, and Richard Stanley. 2019. "Dust and Death: Evidence from the West African Harmattan." NBER Preprint.

Adhvaryu, Achyuta, James Fenske, Namrata Kala, and Anant Nyshadham. 2015. "Fetal Origins of Mental Health: Evidence from Africa." CSAE 44: 1-47.

Aguiar-Moya, José, Jorge Prozzi, and Andre de Fortier Smit. 2011. "Mechanistic-empirical IRI model accounting for potential bias." Journal of Transportation Engineering 137 (5): 297-304. 
Ahmed, Syud, Noah Diffenbaugh, Thomas Hertel, David Lobell, Navin Ramankutty, Ana Rios, and Pedram Rowhani. 2011. "Climate volatility and poverty vulnerability in Tanzania." Global Environmental Change 21 (1): 46-55.

Ajefu, Joseph, and Olukorede Abiona. 2019. "Impact of Shocks on Labour and Schooling Outcomes and the Role of Public Work Programmes in Rural India." Journal of Development Studies 55 (6): 1140-57.

Aklilu, Solomon. 2007. "Weather variability, income shocks and savings of rural households in Peru." The Latin Americanist 51 (1): 23-46.

Akobeng, Eric. 2017. "The invisible hand of rain in spending: Effect of rainfall-driven agricultural income on per capita expenditure in Ghana." South African Journal of Economics 85 (1): 98-122.

Allcott, Hunt, Allan Collard-Wexler, and Stephen O'Connell. 2016. "How do electricity shortages affect industry? Evidence from India." American Economic Review 106 (3): $587-624$.

Angrist, Joshua, Kathryn Graddy, and Guido Imbens. 2000. "The interpretation of instru- 
mental variables estimators in simultaneous equations models with an application to the demand for fish." Review of Economic Studies 67 (3): 499-527.

Apergis, Nicholas, Panagiotis Artikis, and Emmanuel Mamatzakis. 2012. "Is weather important for US banking? A study of bank loan inefficiency." Journal of Applied Finance and Banking 2 (3): 1-38.

Aral, Sinan, and Christos Nicolaides. 2017. "Exercise contagion in a global social network." Nature Communications 8 (1): 1-8.

Arezki, Rabah, and Markus Brückner. 2012. "Rainfall, financial development, and remittances: Evidence from Sub-Saharan Africa." Journal of International Economics 87 (2): $377-85$.

Arnold, Felix, and Ronny Freier. 2016. "Only conservatives are voting in the rain: Evidence from German local and state elections." Electoral Studies 41: 216-21.

Artés, Joaquín. 2014. "The rain in Spain: Turnout and partisan voting in Spanish elections." European Journal of Political Economy 34: 126-41.

Asfaw, Solomon, Giacomo Pallante, and Alessandro Palma. 2018. "Diversification Strategies 
and Adaptation Deficit: Evidence from Rural Communities in Niger." World Development

101: 219-34.

Atalla, Tarek, Simona Bigerna, and Carlo Bollino. 2018. "Energy demand elasticities and weather worldwide." Economia Politica 35 (1): 207-37.

Badaoui, Eliane, Eric Strobl, and Frank Walsh. 2017. "The Impact of Internal Migration on Local Labour Markets in Thailand." Economic Development and Cultural Change.

Bae, Sanghyuk, Youn Lim, and Yun Hong. 2020. "Causal association between ambient ozone concentration and mortality in Seoul, Korea." Environmental Research 182 (October 2019): 109098.

Bai, Ying, and James sing Kung. 2014. "The shaping of an institutional choice: Weather shocks, the Great Leap Famine, and agricultural decollectivization in China." Explorations in Economic History 54 (642010): 1-26.

Barnhart, John. 1925. "Rainfall and the Populist Party in Nebraska." The American Political Science Review 19 (3): 527-40.

Barrios, Salvador, Luisito Bertinelli, and Eric Strobl. 2010. "Trends in rainfall and economic 
growth in Africa: A neglected cause of the african growth tragedy." Review of Economics and Statistics 92 (2): 350-66.

Bassi, Anna. 2019. "Weather, Risk, and Voting: An Experimental Analysis of the Effect of Weather on Vote Choice." Journal of Experimental Political Science 6 (1): 17-32.

Bassi, Anna, Riccardo Colacito, and Paolo Fulghieri. 2013. "'O sole mio: An experimental analysis of weather and risk attitudes in financial decisions." Review of Financial Studies $26(7): 1824-52$.

Batkeyev, Birzhan, and David Deremer. 2022. "Mountains of Evidence: The Effects of Abnormal Air Pollution on Crime." NUGSB Preprint 2022 (4).

Bauer, Michael, Tasha Glenn, Martin Alda, Ole Andreassen, Raffaella Ardau, Frank Bellivier, Michael Berk, et al. 2012. "Impact of sunlight on the age of onset of bipolar disorder." Bipolar Disorders 14 (6): 654-63.

Bayani-Arias, Jaimie, and Rosalina Palanca-Tan. 2017. "Analyzing the Relationship Between Exposure to Extreme Weather and Economic Inequality in the Philippines." Journal of Economics, Management \& Agricultural Development 3: 27-39. 
Baylis, Patrick, Nick Obradovich, Yury Kryvasheyeu, Haohui Chen, Lorenzo Coviello, Esteban Moro, Manuel Cebrian, and James Fowler. 2018. "Weather impacts expressed sentiment." PLoS ONE 13 (4): 1-11. https://arxiv.org/abs/1709.00071.

Beaudin, Laura, and Ju Huang. 2014. "Weather conditions and outdoor recreation: A study of New England ski areas." Ecological Economics 106: 56-68.

Beine, Michel, and Christopher Parsons. 2015. "Climatic factors as determinants of international migration.” Scandinavian Journal of Economics 117 (2): 723-67.

Belasen, Ariel, and Solomon Polachek. 2009. "How disasters affect local labor markets: The effects of hurricanes in Florida." Journal of Human Resources 44 (1): 251-76.

Bellet, Clement, Jan-Emmanuel De Neve, and George Ward. 2019. "Does Employee Happiness Have an Impact on Productivity?" CEP Discussion Paper 2020 (1655).

Beltrán, Allan, David Maddison, and Robert Elliott. 2018. "Is Flood Risk Capitalised Into Property Values?" Ecological Economics 146: 668-85.

of Environmental Economics and Management 95: 62-86. 
Ben Lakhdar, Christian, and Eric Dubois. 2006. "Climate and Electoral Turnout in France." French Politics 4 (2): 137-57.

Bensassi, Sami, Preeya Mohan, and Eric Strobl. 2017. "A storm in a teacup? Hurricanes and sugar prices in the first half of the nineteenth century." Weather, Climate, and Society 9 (4): $753-68$.

Berry, Steven, and Wolfram Schlenker. 2011. "Technical Report for the ICCT : Empirical Evidence on Crop Yield Elasticities." The International Council on Clean Transportation, $1-18$.

Bertelli, Olivia. 2015. "The more the merrier? Adjusting fertility to weather shocks." Paris School of Economics Preprint 38 (0).

Bhavnani, Rikhil, and Bethany Lacina. 2015. "The Effects of Weather-Induced Migration on Sons of the Soil Riots in India." World Politics 67 (4): 760-94.

Blakeslee, David, and Ram Fishman. 2018. "Weather shocks, agriculture, and crime: Evidence from India." Journal of Human Resources 53 (3): 750-82.

Blanc, Elodie. 2012. "The Impact of Climate Change on Crop Yields in Sub-Saharan Africa." 
American Journal of Climate Change 01 (01): 1-13.

Blanc, Elodie, and Eric Strobl. 2016. "Assessing the impact of typhoons on rice production in the Philippines." Journal of Applied Meteorology and Climatology 55 (4): 993-1007.

Blumberg, Rae. 2015. “'Dry' Versus 'Wet' Development and Women in Three World Regions." Sociology of Development 1 (1): 91-122.

Bondy, Malvina, Sefi Roth, and Lutz Sager. 2020. "Crime Is in the Air: The Contemporaneous Relationship between Air Pollution and Crime." Journal of the Association of Environmental and Resource Economists 7 (3): 555-85.

Boustan, Leah, Price Fishback, and Shawn Kantor. 2010. "The effect of internal migration on local labor markets: American cities during the great depression." Journal of Labor Economics 28 (4): 719-46.

Branco, Danyelle, and Jose Feres. 2020. "Weather Shocks and Labor Allocation Evidence from Rural Brazil." American Journal of Agricultural Economics 0 (0): 1-19.

Bruckner, Markus, and Antonio Ciccone. 2011. "Rain and the Democratic Window of Opportunity." Econometrica 79 (3): 923-47. 
Bruederle, Anna, Jörg Peters, and Gareth Roberts. 2017. "Weather and Crime in South Africa." Ruhr Economics Papers, no. 739.

Bui, Anh, Mardi Dungey, Cuong Nguyen, and Thu Pham. 2014. "The impact of natural disasters on household income, expenditure, poverty and inequality: Evidence from Vietnam." Applied Economics 46 (15): 1751-66.

Bui, Quang, Trung Hoang, Minh Nguyen, and Trung Nguyen. 2020. "Land fragmentation, women empowerment and school dropout of children in Vietnam." Land Use Policy 97 (September 2019): 104749.

Burgess, Robin, Olivier Deschenes, Dave Donaldson, and Michael Greenstone. 2014. "The Unequal Effects of Weather and Climate Change: Evidence from Mortality in India." Journal of Economic Growth 15 (4): 291-321.

Burgess, Robin, and Drive Donaldson. 2010. "Can openness mitigate the effects of weather shocks? evidence from India's famine era." American Economic Review: Papers \& Proceedings $100(2)$ : 449-53.

Burke, Marshall, Edward Miguel, Shanker Satyanath, John Dykema, and David Lobell. 2009. 
"Warming increases the risk of civil war in Africa." PNAS 106 (49): 20670-74.

Cachon, Gérard, Santiago Gallino, and Marcelo Olivares. 2019. "Does adding inventory increase sales? Evidence of a scarcity effect in U.S. Automobile dealerships." Management Science 65 (4): 1469-85.

Caruso, Raul, Ilaria Petrarca, and Roberto Ricciuti. 2016. "Climate change, rice crops, and violence: Evidence from Indonesia." Journal of Peace Research 53 (1): 66-83.

Cashin, Paul, Kamiar Mohaddes, and Mehdi Raissi. 2017. "Fair weather or foul? The macroeconomic effects of El Niño." Journal of International Economics 106: 37-54.

Chalfin, Aaron. 2014. "What is the contribution of Mexican immigration to U.S. crime rates? Evidence from rainfall shocks in Mexico." American Law and Economics Review $16(1): 220-68$.

Chang, Simon, Belton Fleisher, Seonghoon Kim, and Shi Liu. 2014. "Long-term health effects of malaria exposure around birth: Evidence from colonial Taiwan." Economic Development and Cultural Change 62 (3): 519-36.

Chavas, Jean, Salvatore Di Falco, Felice Adinolfi, and Fabian Capitanio. 2019. "Weather 
effects and their long-term impact on the distribution of agricultural yields: Evidence from Italy." European Review of Agricultural Economics 46 (1): 1-23.

Chen, Roger, and Hani Mahmassani. 2015. "Let it rain: Weather effects on activity stress and scheduling behavior." Travel Behaviour and Society 2 (1): 55-64.

Chhaochharia, Vidhi, Dasol Kim, George Korniotis, and Alok Kumar. 2019. "Mood, firm behavior, and aggregate economic outcomes." Journal of Financial Economics 132 (2): $427-50$.

Chia, Wei, Calvin Tay, Jan Ertl, Jasmine Zhang, and Bill Cai. 2016. "Intergenerational Mobility and Crime Rates: Using Climate as an Instrumental Variable." Preprint.

Chin, Yoo. 2012. "Male backlash, bargaining, or exposure reduction? Women's working status and physical spousal violence in India." Journal of Population Economics 25 (1): $175-200$.

Cohen, Alexander. 2011. "The photosynthetic President: Converting sunshine into popularity." Social Science Journal 48 (2): 295-304.

Collins, William, and Robert Margo. 2007. "The economic aftermath of the 1960s Riots in 
American Cities: Evidence from property values." Journal of Economic History 67 (4): 849-83.

Considine, Timothy. 2000. "The impacts of weather variations on energy demand and carbon emissions." Resource and Energy Economics 22 (4): 295-314.

Cook, Duncan, and Sally Garrett. 2013. "Somali piracy and the monsoon." Weather, Climate, and Society 5 (4): 309-16.

Cools, Sara, Martin Flatø, and Andreas Kotsadam. 2020. "Rainfall shocks and intimate partner violence in sub-Saharan Africa." Journal of Peace Research 57 (3): 377-90.

Cooperman, Alicia. 2017. "Randomization inference with rainfall data: Using historical weather patterns for variance estimation." Political Analysis 25 (3): 277-88.

Corbi, Raphael, and Tiago Ferraz. 2018. "Rainfall, Internal Migration and Local Labor Markets in Brazil." Preprint.

Courtemanche, Charles, Joshua Pinkston, and Jay Stewart. 2020. “Time spent exercising and obesity: An application of Lewbel's instrumental variables method." Economics and Human Biology 41. 
Coviello, Lorenzo, Yunkyu Sohn, Adam Kramer, Cameron Marlow, Massimo Franceschetti, Nicholas Christakis, and James Fowler. 2014. "Detecting emotional contagion in massive social networks." PLoS ONE 9 (3): 1-6.

Cui, Can, Zhen Wang, Pan He, Shanfeng Yuan, Beibei Niu, Ping Kang, and Chaogui Kang. 2019. "Escaping from pollution: The effect of air quality on inter-city population mobility in China." Environmental Research Letters 14 (12).

Cui, Xiaomeng. 2020. "Beyond Yield Response: Weather Shocks and Crop Abandonment." Journal of the Association of Environmental and Resource Economists 7 (5): 901-32.

Currie, Janet, and Maya Rossin-Slater. 2013. "Weathering the storm: Hurricanes and birth outcomes." Journal of Health Economics 32 (3): 487-503.

Cutler, David, Winnie Fung, Michael Kremer, Monica Singhal, and Tom Vogl. 2010. "Earlylife malaria exposure and adult outcomes: Evidence from malaria eradication in india." American Economic Journal: Applied Economics 2 (2): 72-94.

Dacuycuy, Connie. 2016. "Weather events and welfare in the Philippine households." PIDS Discussion Paper Series. 
Davies, Simon. 2010. "Do shocks have a persistent impact on consumption?: The case of rural Malawi." Progress in Development Studies 10 (1): 75-79.

Davis, Lewis. 2016. "Individual Responsibility and Economic Development: Evidence from Rainfall Data." Kyklos 69 (3): 426-70.

Del Valle, Alejandro, Robert Elliott, Eric Strobl, and Meng Tong. 2018. "The Short-Term Economic Impact of Tropical Cyclones: Satellite Evidence from Guangdong Province." Economics of Disasters and Climate Change 2 (3): 225-35.

Dell, Melissa, Benjamin Jones, and Benjamin Olken. 2009. "Temperature and income: Reconciling new cross-sectional and panel estimates." American Economic Review 99 (2): 198-204.

Dercon, Stefan. 2004. "Growth and shocks: Evidence from rural Ethiopia." Journal of Development Economics 74 (2): 309-29.

Deschênes, Olivier, and Michael Greenstone. 2012. "The economic impacts of climate change: Evidence from agricultural output and random fluctuations in weather: Reply." American Economic Review 102 (7): 3761-73. 
Di Falco, Salvatore, Felice Adinolfi, Martina Bozzola, and Fabian Capitanio. 2014. "Crop Insurance as a Strategy for Adapting to Climate Change." Journal of Agricultural Economics 65 (2): 485-504.

Di Falco, Salvatore, Peter Berck, Mintewab Bezabih, and Gunnar Köhlin. 2019. "Rain and impatience: Evidence from rural Ethiopia." Journal of Economic Behavior and Organization 160: 40-51.

Di Falco, Salvatore, and Jean Chavas. 2008. "Rainfall shocks, resilience, and the effects of crop biodiversity on agroecosystem productivity." Land Economics 84 (1): 83-96.

Di Falco, Salvatore, and Angela Doku. 2019. "Weather Shocks and Self Esteem." Preprint.

Douglas, Almond, Edlund Lena, and Palme Mårten. 2009. "Chernobyl's subclinical legacy: Prenatal exposure to radioactive fallout and school outcomes in Sweden." Quarterly Journal of Economics 124 (4): 1729-72.

Duhaime, Erik, and Taylor Moulton. 2018. "Swingin' in the Rain: The Impact of Inclement Weather on Voting Behavior in U.S. Presidential Elections." SSRN.

Dustmann, Christian, Francesco Fasani, and Biagio Speciale. 2017. "Illegal migration and 
consumption behavior of immigrant households." Journal of the European Economic Association 15 (3): 654-91.

Elliott, Robert, Yi Liu, Eric Strobl, and Meng Tong. 2019. "Estimating the direct and indirect impact of typhoons on plant performance: Evidence from Chinese manufacturers." Journal of Environmental Economics and Management 98: 102252.

Elliott, Robert, Eric Strobl, and Puyang Sun. 2015. "The local impact of typhoons on economic activity in China: A view from outer space." Journal of Urban Economics 88: $50-66$.

Elsner, Benjamin, and Florian Wozny. 2019. "The Cognitive Meltdown: Radiation and Human Capital after Birth." Preprint.

Elum, Zelda, Godwell Nhamo, and Michael Antwi. 2018. "Effects of climate variability and insurance adoption on crop production in select provinces of South Africa." Journal of Water and Climate Change 9 (3): 500-511.

Fan, Maoyong, and Yi Wang. 2020. "The impact of PM2.5 on mortality in older adults: Evidence from retirement of coal-fired power plants in the United States." Environmental 
Health: A Global Access Science Source 19 (1): 1-13.

Faradiba, Faradiba. 2021. "The effect of rainfall on the spread of malaria in Indonesia." International Journal Of Community Medicine And Public Health 8 (3): 1146.

Farah, Naima, and Gregory Torell. 2018. "Defensive Investment in Water Hardness Reduction." Water Resources Research.

Feng, Shuaizhang, Alan Krueger, and Michael Oppenheimer. 2010. "Linkages among climate change, crop yields and Mexico-US cross-border migration.” PNAS 107 (32): 14257-62.

Feng, Shuaizhang, Michael Oppenheimer, and Wolfram Schlenker. 2012. "Climate Change, Crop Yields, and Internal Migration in the United States." NBER Preprint 17734: 1-43.

Fichera, Eleonora, and David Savage. 2015. "Income and Health in Tanzania. An Instrumental Variable Approach." World Development 66: 500-515.

Fisher-Vanden, Karen, Erin Mansur, and Qiong Wang. 2015. "Electricity shortages and firm productivity: Evidence from China's industrial firms." Journal of Development Economics 114: $172-88$.

Flyr, Matthew, Jesse Burkhardt, Christopher Goemans, Liesel Hans, Abbye Neel, and 
Alexander Maas. 2019. "Modeling commercial demand for water: Exploring alternative prices, instrumental variables, and heterogeneity." Land Economics 95 (2): 211-24.

Fontenla, Matías, M. Goodwin, and Fidel Gonzalez. 2019. "Pollution and the choice of where to work and live within Mexico City." Latin American Economic Review 28 (1).

Fraga, Bernard, and Eitan Hersh. 2011. "Voting costs and voter turnout in competitive elections." Quarterly Journal of Political Science 5 (4): 339-56.

Frijters, Paul, Chitwan Lalji, and Debayan Pakrashi. 2020. "Daily weather only has small effects on wellbeing in the US." Journal of Economic Behavior and Organization 176: $747-62$.

Fujiwara, Thomas, Kyle Meng, and Tom Vogl. 2016. "Habit formation in voting: Evidence from rainy elections." American Economic Journal: Applied Economics 8 (4): 160-88.

Gajate-Garrido, Gissele. 2013. "The impact of adequate prenatal care on urban birth outcomes: An analysis in a developing country context." Economic Development and Cultural Change 62 (1): 95-130.

Gillett, N., A. Weaver, F. Zwiers, and M. Flannigan. 2004. "Detecting the effect of climate 
change on Canadian forest fires." Geophysical Research Letters 31 (18).

Giulietti, Corrado, Jackline Wahba, and Yves Zenou. 2018. "Strong versus weak ties in migration." European Economic Review 104: 111-37.

Goetzke, Frank, and Tilmann Rave. 2011. "Bicycle use in Germany: Explaining differences between municipalities with social network effects." Urban Studies 48 (2): 427-37.

Gomez, Brad, Thomas Hansford, and George Krause. 2007. "The Republicans should pray for rain: Weather, turnout, and voting in U.S. presidential elections." Journal of Politics $69(3): 649-63$.

Gong, Huan, and Cynthia Rogers. 2014. "Does Voter Turnout Influence School Bond Elections?" Southern Economic Journal 81 (1): 247-62.

Graddy, Kathryn. 2006. "The fulton fish market." Journal of Economic Perspectives 20 (2): 207-20.

Graddy, Kathryn, and Peter Kennedy. 2010. "When Are Supply And Demand Determined Recursively Rather Than Simultaneously?" Eastern Economic Journal 36: 188-97.

Groppo, Valeria, and Kati Kraehnert. 2017. The impact of extreme weather events on 
education. Vol. 30. 2. Journal of Population Economics.

Gu, Hejun, Weiran Yan, Ehsan Elahi, and Yuxia Cao. 2020. "Air pollution risks human mental health: an implication of two-stages least squares estimation of interaction effects." Environmental Science and Pollution Research 27 (2): 2036-43.

Gurgand, Marc. 2003. "Farmer education and the weather: Evidence from Taiwan (19761992)." Journal of Development Economics 71 (1): 51-70.

Guven, Cahit, and Indrit Hoxha. 2015. "Rain or shine: Happiness and risk-taking." Quarterly Review of Economics and Finance 57: 1-10.

Hales, Simon, Clare Salmond, G. Town, Tord Kjellstrom, and Alistair Woodward. 2000. "Daily mortality in relation to weather and air pollution in Christchurch, New Zealand." Australian and New Zealand Journal of Public Health 24 (1): 89-91.

Hanandita, Wulung, and Gindo Tampubolon. 2014. "Does poverty reduce mental health? An instrumental variable analysis." Social Science and Medicine 113: 59-67.

Hansford, Thomas, and Brad Gomez. 2010. "Estimating the electoral effects of voter turnout." American Political Science Review 104 (2): 268-88. 
Healy, Andrew, and Neil Malhotra. 2010. "Random events, economic losses, and retrospective voting: Implications for democratic competence." Quarterly Journal of Political Science 5 (2): 193-208.

Heinen, Andréas, Jeetendra Khadan, and Eric Strobl. 2019. "The price impact of extreme weather in developing countries." Economic Journal 129 (619): 1327-42.

Henderson, John, and John Brooks. 2016. "Mediating the electoral connection: The information effects of voter signals on legislative behavior." Journal of Politics 78 (3): 653-69.

Henderson, Susan, and Tatyana Ryabova. 2020. "How do sustainability investments affect financial performance? An Instrumental Variable Approach.” Journal of Accounting and Finance 20 (3): 104-26.

Hendricks, Nathan, Joseph Janzen, and Aaron Smith. 2015. "Futures prices in supply analysis: Are instrumental variables necessary?" American Journal of Agricultural Economics 97 (1): 22-39.

Henry, Michael, Nekeisha Spencer, and Eric Strobl. 2020. "The Impact of Tropical Storms on Households: Evidence from Panel Data on Consumption." Oxford Bulletin of Economics 
and Statistics 82 (1): 1-22.

Herrnstadt, Evan, and Erich Muehlegger. 2014. "Weather, salience of climate change and congressional voting." Journal of Environmental Economics and Management 68 (3): $435-48$.

Hodler, Roland, and Paul Raschky. 2014. "Economic shocks and civil conflict at the regional level." Economics Letters 124 (3): 530-33.

Hoogeveen, Johannes, Bas Van Der Klaauw, and Gijsbert Van Lomwel. 2011. "On the timing of marriage, cattle, and shocks." Economic Development and Cultural Change 60 (1): $121-54$.

Horiuchi, Yusaku, and Woo Kang. 2015. "Electoral Consequences of Rainfall on the Election Day: Compositional Data Analysis." SSRN 1 (603): 1-24.

Rainfall Revisited." American Politics Research 46 (5): 869-89.

Hornbeck, Richard, Abhijit Banerjee, Nick Bloom, Geoff Cunfer, Joe Doyle, Price Fishback, Tim Guinnane, et al. 2012. "The Enduring Impact of the American Dust Bowl: Short- 
and Long-run adjustments to environmental catastrophe." American Economic Review 102 (4): 1477-507.

Horrocks, James, and Andrea Menclova. 2011. "The effects of weather on crime." New Zealand Economic Papers 45 (3): 231-54.

Hsiang, Solomon, Marshall Burke, and Edward Miguel. 2013. "Quantifying the influence of climate on human conflict." Science 341 (6151).

Hsiang, Solomon, Kyle Meng, and Mark Cane. 2011. "Civil conflicts are associated with the global climate." Nature 476 (7361): 438-41.

Hu, Maggie, and Adrian Lee. 2020. "Outshine to outbid: Weather-induced sentiment and the housing market." Management Science 66 (3): 1440-72.

Huang, Fang, Shuisen Zhou, Shaosen Zhang, Hongju Wang, and Linhua Tang. 2011. "Temporal correlation analysis between malaria and meteorological factors in Motuo County, Tibet." Malaria Journal 10: 1-8.

Huang, Henry, Joseph Kerstein, and Chong Wang. 2018. "The impact of climate risk on firm performance and financing choices: An international comparison." Journal of 
International Business Studies 49 (5): 633-56.

Huet-Vaughn, Emiliano. 2013. "Quiet Riot: The Causal Effect of Protest Violence." SSRN, no. September: 1-37.

Ito, By, and Mar Reguant. 2016. "Sequential Markets, Market Power, and Arbitrage." The American Economic Review 106 (7): 1921-57.

Jacob, Brian, Lars Lefgren, and Enrico Moretti. 2007. "The dynamics of criminal behavior: Evidence from weather shocks." Journal of Human Resources 42 (3): 489-527.

Jacobsen, Ben, and Wessel Marquering. 2008. "Is it the weather?" Journal of Banking and Finance 32 (4): 526-40.

Jacoby, Hanan, and Emmanuel Skoufias. 1997. "Risk, Financial Markets, and Human Capital in a Developing Country." Review of Economic Studies 64 (3): 311-35.

Jayachandran, Seema. 2006. "Selling labor low: Wage responses to productivity shocks in developing countries." Journal of Political Economy 114 (3): 538-75.

Jensen, Peter, and Kristian Gleditsch. 2009. "Rain, growth, and civil war: The importance of location." Defence and Peace Economics 20 (5): 359-72. 
Jensen, Robert. 2000. "American Economic Association Agricultural Volatility and Investments in Children." The American Economic Review 90 (2): 399-404.

Kang, Hyunju, Hyunduk Suh, and Jongmin Yu. 2019. "Does Air Pollution Affect Consumption Behavior? Evidence from Korean Retail Sales." Asian Economic Journal 33 (3): $235-51$.

Kang, Woo. 2019. "Liberals should pray for rain: weather, opportunity costs of voting and electoral outcomes in South Korea." Political Science 71 (1): 61-78.

Kapoor, Rolly, Haedong Rho, Kinpritma Sangha, Bhavyaa Sharma, Ajay Shenoy, and Guanghong Xu. 2020. "God is in the Rain: The Impact of Rainfall-Induced Early Social Distancing on COVID-19 Outbreaks." SSRN.

Katz, Tamar, Tali Regev, Shay Lavie, Haggai Porat, and Ronen Avraham. 2020. "Those who tan and those who don't: A natural experiment on colorism." PLoS ONE 15 (7): $1-14$.

Kazianga, Harounan, and Christopher Udry. 2006. "Consumption smoothing? Livestock, insurance and drought in rural Burkina Faso." Journal of Development Economics 79 (2): 
$413-46$.

Keele, Luke, and Jason Morgan. 2016. "How strong is strong enough? Strengthening instruments through matching and weak instrument tests." The Annals of Applied Statistics $10(2)$.

Khanthavit, Anya. 2017a. "Instrumental-variable estimation of Bangkok-weather effects in the stock exchange of Thailand." Asian Academy of Management Journal of Accounting and Finance 13 (1): 83-111.

. 2017b. "Weather-Induced Mood Effects on Stock Returns." Thammasat Review 20 (1): $1-18$.

—. 2019a. "Time-varying weather effects on thai government bond returns." DLSU

Business and Economics Review 28 (2): 122-32.

Thailand." ABAC Journal 39 (1): 1-14.

_. 2019c. "Weather-Driven Stock-Return Correlations." ABAC Journal 39 (3): 42-55.

Kim, Nam. 2016. "Revisiting Economic Shocks and Coups." Journal of Conflict Resolution 
$60(1): 3-31$.

Kim, Yong, Juan Sesmero, and Brigitte Waldorf. 2018. "Temporary Migration as a Strategy against Weather Shocks: Evidence from Rural India." Agricultural \& Applied Economics Association Annual Meeting.

Kitamura, Shuhei. 2022. "UFOs: The Political Economy of Unidentified Threats." Preprint. Kleemans, Marieke, and Jeremy Magruder. 2018. "Labour Market Responses To Immigration: Evidence From Internal Migration Driven By Weather Shocks." Economic Journal 128 (613): 2032-65.

Knack, Steve. 1994. "Does rain help the Republicans? Theory and evidence on turnout and the vote." Public Choice 79: 187-209.

Kochar, Anjini. 1999. "Smoothing consumption by smoothing income: Hours-of-work responses to idiosyncratic agricultural shocks in Rural India." Review of Economics and Statistics 81 (1): 50-61.

Koks, E., J. Rozenberg, C. Zorn, M. Tariverdi, M. Vousdoukas, S. Fraser, J. Hall, and S. Hallegatte. 2019. "A global multi-hazard risk analysis of road and railway infrastructure 
assets." Nature Communications 10 (1): 1-11.

Kovács, Balázs. 2017. "Too hot to reject: The effect of weather variations on the patent examination process at the United States Patent and Trademark Office." Research Policy 46 (10): 1824-35.

Kubik, Zaneta, and Julian May. 2018. "Weather shocks, food prices and food security: Evidence from South Africa." The 56th Annual Conference of the Agricultural Economics Association of South Africa, 42.

Kumar, K., and Brinda Viswanathan. 2012. "Weather Variability and Agriculture: Implications for Long and Short-Term Migration in India." CDE Preprint, no. 220.

Lagerlöf, Nils-Petter, and Syed Basher. 2006. "Geography, population density, and percapita income gaps across US states and Canadian provinces." Munich Personal RePEc Archive, no. 369.

Lahiri, Bidisha. 2018. "Racial Earnings Disparities with Endogenous Labor Market Participation." Journal of Economics, Race, and Policy 1 (1): 16-25.

Laidley, Thomas, and Dalton Conley. 2018. "The effects of active and passive leisure on 
cognition in children: Evidence from exogenous variation in weather." Social Forces 97 (1): $129-56$.

Landis, Steven, Babak Rezaeedaryakenari, Yifan Zhang, Cameron Thies, and Ross Maciejewski. 2017. "Fording differences? Conditions mitigating water insecurity in the Niger River Basin.” Political Geography 56: 77-90.

Larreboure, Magdalena, and Felipe Gonz. 2021. "The Impact of the Women's March on the U.S. House Election.” Preprint, ASPA 2021,.

Ledlie, N., H. Alderman, J. Leroy, and L. You. 2018. "Rainfall shocks are not necessarily a sensitive early indicator of changes in wasting prevalence." European Journal of Clinical Nutrition 72 (1): 177-78.

Lee, Chien, and Yi Chiu. 2011. "Electricity demand elasticities and temperature: Evidence from panel smooth transition regression with instrumental variable approach." Energy Economics 33 (5): 896-902.

Lee, Wang-Sheng, and Ben Li. 2020. "Extreme Weather and Long-term Health: Evidence from Two Millennia of Chinese Elites." Journal of Health Economics. 
Leimdörfer, August, and Vincent Hauge. 2020. "Can death predict life ?" Bachelor Thesis.

Levin, Ronnie, Carolina Zilli Vieira, Daniel Mordarski, and Marieke Rosenbaum. 2020. "Lead seasonality in humans, animals, and the natural environment." Environmental Research 180: 108797.

Lewin, Paul, Monica Fisher, and Bruce Weber. 2012. "Do rainfall conditions push or pull rural migrants: Evidence from Malawi." Agricultural Economics 43 (2): 191-204.

Li, Ye, Eric Johnson, and Lisa Zaval. 2011. "Local warming: Daily temperature change influences belief in global warming." Psychological Science 22 (4): 454-59.

Lind, Jo. 2019. "Rainy day politics. An instrumental variables approach to the effect of parties on political outcomes." European Journal of Political Economy 61 (179552): 101821.

Lis, Eliza, and Christiane Nickel. 2010. "The impact of extreme weather events on budget balances." International Tax and Public Finance 17 (4): 378-99.

Liu, Meng, Raphael Thomadsen, and Song Yao. 2020. "Forecasting the spread of COVID-19 under different reopening strategies." Scientific Reports 10 (1): 1-8. 
Lo Prete, Anna, and Federico Revelli. 2020. "Voter Turnout and City Performance." The Journal of Law, Economics, and Organization 0 (0).

López-córdova, Ernesto. 2006. "Globalization, Migration and Development: The Role of Mexican Migrant Remittances." Inter-American Development Bank Preprint 20.

Luechinger, Simon. 2014. "Air pollution and infant mortality: A natural experiment from power plant desulfurization.” Journal of Health Economics 37: 219-31.

Maccini, Sharon, and Dean Yang. 2009. "Under the weather: Health, schooling, and economic consequences of early-life rainfall.” American Economic Review 99 (3): 1006-26.

Madestam, Andreas, Daniel Shoag, Stan Veuger, and David Yanagizawa-Drott. 2013. "Do Political Protests Matter? Evidence from the Tea Party Movement." Quarterly Journal of Economics, 1633-85.

Magnusson, Andres. 2000. "An overview of epidemiological studies on seasonal affective disorder." Acta Psychiatrica Scandinavica 101 (3): 176-84.

Marchiori, Luca, Jean-François Maystadt, and Ingmar Schumacher. 2017. "Is environmentally induced income variability a driver of human migration?" Migration and Develop- 
ment $6(1): 33-59$.

Marchiori, Luca, Jean Maystadt, and Ingmar Schumacher. 2012. "The impact of weather anomalies on migration in sub-Saharan Africa." Journal of Environmental Economics and Management 63 (3): 355-74.

Martin, Ralf, Ralph De Haas, Mirabelle Muûls, and Helena Schweiger. 2021. "Managerial and Financial Barriers to the Net-Zero Transition." SSRN.

Maunder, W. 1973. "Weekly Weather and Economic Activities on a National Scale: an Example Using United States Retail Trade Data." Weather 28 (1): 2-19.

Maystadt, Jean, and Olivier Ecker. 2014. "Extreme weather and civil war: Does drought fuel conflict in Somalia through livestock price shocks?" American Journal of Agricultural Economics 96 (4): 1157-82.

McCord, Gordon, Dalton Conley, and Jeffrey Sachs. 2017. "Malaria ecology, child mortality \& fertility." Economics and Human Biology 24: 1-17.

Mehlum, Halvor, Edward Miguel, and Ragnar Torvik. 2006. "Poverty and crime in 19th Century Germany." Journal of Urban Economics 59 (3): 370-88. 
Meier, Armando, Lukas Schmid, and Alois Stutzer. 2019. "Rain, emotions and voting for the status quo." European Economic Review 119: 434-51.

Miguel, Edward, and Shanker Satyanath. 2011. "Re-examining economic shocks and civil conflict." American Economic Journal: Applied Economics 3 (4): 228-32.

Miguel, Edward, Shanker Satyanath, and Ernest Sergenti. 2004. "Economic shocks and civil conflict: An instrumental variables approach." Journal of Political Economy 112 (4): $725-53$.

Moreno-Medina, Jonathan. 2021. "Sinning in the Rain: Weather Shocks, Church Attendance and Crime." The Review of Economics and Statistics, 1-46.

Moretti, Enrico. 1998. "Social returns to education and human capital externalities: evidence from cities." Centre for Labour Economics Preprint.

Moretti, Enrico, and Matthew Neidell. 2011. "Pollution, health, and avoidance behavior: Evidence from the ports of Los Angeles.” Journal of Human Resources 46 (1): 154-75.

Muehlenbachs, Lucija, and Mark Cohen. 2014. "The Effect of Inspector Group Size and Familiarity on Enforcement and Deterrence: Evidence from Oil Platforms." IZA Discussion 
Paper 7876.

Mueller, Valerie, and Daniel Osgood. 2009. "Long-term impacts of droughts on labour markets in developing countries: Evidence from Brazil.” Journal of Development Studies 45 (10): 1651-62.

Mueller, Valerie, and Agnes Quisumbing. 2011. "How resilient are labour markets to natural disasters? the case of the 1998 Bangladesh flood." Journal of Development Studies 47 (12): $1954-71$.

Mueller, V., C. Gray, and K. Kosec. 2014. "Heat stress increases long-term human migration in rural Pakistan." Nature Climate Change 4 (3): 182-85.

Mulder, Machiel, and Bert Scholtens. 2013. "The impact of renewable energy on electricity prices in the Netherlands." Renewable Energy 57: 94-100.

Munshi, Kaivan. 2003. "Networks in the modern economy: Mexican migrants in the U.S. Labor market." Quarterly Journal of Economics 118 (2): 549-99.

Nadolnyak, Denis, and Valentina Hartarska. 2012. "Agricultural disaster payments in the southeastern US: Do weather and climate variability matter?" Applied Economics 44 
(33): $4331-42$.

Naudé, Wim. 2010. "The determinants of migration from sub-saharan african countries." Journal of African Economies 19 (3): 330-56.

Nawrotzki, Raphael, Fernando Riosmena, and Lori Hunter. 2013. "Do Rainfall Deficits Predict U.S.-Bound Migration from Rural Mexico? Evidence from the Mexican Census." Population Research and Policy Review 32 (1): 129-58.

Nillesen, Eleonora, and Philip Verwimp. 2011. "Grievance, Commodity Prices and Rainfall: A Village-level Analysis of Rebel Recruitment in Burundi." SSRN 2009 (May 2009).

Nübler, Laura, Karen Austrian, John Maluccio, and Jessie Pinchoff. 2020. "Rainfall shocks, cognitive development and educational attainment among adolescents in a drought-prone region in Kenya." Environment and Development Economics, 1-22.

Oster, Emily. 2004. "Witchcraft, Weather and Economic Growth in Renaissance Europe." Journal of Economic Perspectives 18 (1): 215-28.

Pajaron, Marjorie. 2017. "The role of remittances as a risk-coping mechanism: Evidence from agricultural households in rural Philippines." Asian and Pacific Migration Journal 
$26(1): 3-30$.

Pajaron, Marjorie, and Glacer Vasquez. 2020. "Weathering the storm: Weather shocks and international migrants from the Philippines." Journal of Population Economics.

Papaioannou, Kostadis. 2017. “'Hunger makes a thief of any man': Poverty and crime in British colonial Asia." European Review of Economic History 21 (1): 1-28.

Parham, Paul, and Edwin Michael. 2010. "Modeling the effects of weather and climate change on malaria transmission." Environmental Health Perspectives 118 (5): 620-26.

Paul, Bimal. 2005. "Evidence against disaster-induced migration: The 2004 tornado in north-central Bangladesh." Disasters 29 (4): 370-85.

Paxson, Christina. 1992. "American Economic Association Using Weather Variability to Estimate the Response of Savings to Transitory Income in Thailand." The American Economic Review 82 (1): 15-33.

Peet, Evan. 2020. "Environment and Human Capital: The Effects of Early-Life Exposure to Pollutants in the Philippines." Environment and Development Economics, 1-25.

Pereira, Rogério, and Tatiane de Menezes. 2020. "Does per capita income cause homicide 
rates? An application of an IV spatial model." Regional Science Policy and Practice, no.

September 2019: 1-13.

Persico, Claudia, and Dave Marcotte. 2022. "Air Quality and Suicide." IZA Discussion

Paper, no. 15087.

Persson, Mikael, Anders Sundell, and Richard Öhrvall. 2014. "Does Election Day weather

affect voter turnout? Evidence from Swedish elections." Electoral Studies 33: 335-42.

Pinckney, Jonathan. 2019. “Did the Women's March Work? Re-Evaluating the Political

Efficacy of Protest." 2019 Mobilization Conference, 1-22.

Pipitpukdee, Siwabhorn, Witsanu Attavanich, and Somskaow Bejranonda. 2020. "Climate change impacts on sugarcane production in Thailand." Atmosphere 11 (4): 1-15.

Pitt, Mark, and Wendy Sigle. 1997. "SEASONALITY, WEATHER SHOCKS AND THE TIMING OF BIRTHS AND CHILD MORTALITY." Centre for the Study of African Economies Conference.

Pugatch, Todd, and Dean Yang. 2011. "The Impact of Mexican Immigration on U.S. Labor Markets: Evidence from Migrant Flows Driven by Rainfall Shocks." SSRN. 
Qiu, Yun, Xi Chen, and Wei Shi. 2020. "Impacts of social and economic factors on the transmission of coronavirus disease 2019 (COVID-19) in China." Journal of Population Economics 33 (4): 1127-72.

Rana, Shan. 2013. "The economic causes of terror: evidence from rainfall variation and terrorist attacks in Pakistan." Preprint, 1-57.

Ranson, Matthew. 2014. "Crime, weather, and climate change." Journal of Environmental Economics and Management 67 (3): 274-302.

Rappaport, Jordan. 2007. "Moving to nice weather." Regional Science and Urban Economics $37(3): 375-98$.

Reichhoff, Martin. 2017. "The Effect of Weather on Crime: An Investigation of Weather and Annual Crime Rates." MSc Thesis.

Reuveny, Rafael, and Will Moore. 2009. "Does environmental degradation influence migration? Emigration to developed countries in the late 1980s and 1990s." Social Science Quarterly 90 (3): 461-79.

Ritter, Emily, and Courtenay Conrad. 2016. "Preventing and Responding to Dissent: The 
Observational Challenges of Explaining Strategic Repression." American Political Science

Review 110 (1): 85-99.

Roenneberg, T, and J Aschoff. 1990. "Annual Rhythm of Human Reproduction." Journal of Biological Rhythms 5 (3): 195-239.

Rosenzweig, M. R., and H. P. Binswanger. 1993. "Wealth, Weather Risk and the Composition and Profitability of Agricultural Investments." The Economic Journal 103 (416): $56-78$.

Rosenzweig, Mark, and Oded Stark. 1989. "Consumption Smoothing, Migration, and Marriage : Evidence from Rural India." Journal of Political Economy 97 (4): 905-26.

Rosenzweig, M., and K. Wolpin. 1993. "Credit market constraints, consumption smoothing, and the accumulation of durable production assets in low-income countries: investments in bullocks in India." Journal of Political Economy 101 (2): 223-44.

Rudolph, Lukas. 2020. "Turning out to turn down the EU: the mobilisation of occasional voters and Brexit." Journal of European Public Policy 0 (0): 1-21.

Saeed, Luqman, and Michael Spagat. 2021. "The Impact of Drone Warfare on Suicide 
Bombings in Pakistan." Preprint, 1-33.

Sager, Lutz. 2019. "Estimating the effect of air pollution on road safety using atmospheric temperature inversions." Journal of Environmental Economics and Management 98 (251).

Saldaña-Zorrilla, Sergio, and Krister Sandberg. 2009. "Impact of climate-related disasters on human migration in Mexico: A spatial model." Climatic Change 96 (1): 97-118.

Santeramo, Fabio, and Stephanie Searle. 2019. "Linking soy oil demand from the US Renewable Fuel Standard to palm oil expansion through an analysis on vegetable oil price elasticities." Energy Policy 127 (December 2018): 19-23.

Sarsons, Heather. 2015. "Rainfall and conflict: A cautionary tale." Journal of Development Economics 115: 62-72.

Sayers, Adrian, Kate Tilling, Barbara Boucher, Kate Noonan, and Jon Tobias. 2009. "Predicting ambient ultraviolet from routine meteorological data; its potential use as an instrumental variable for vitamin D status in pregnancy in a longitudinal birth cohort in the UK." International Journal of Epidemiology 38 (6): 1681-88.

Schachner, Ramona. 2014. "Weather shocks' impact on education outcomes in Mongo- 
lia Comparison of Difference-in-Differences Approach and Propensity Score Matching."

Bachelor Thesis.

Schultz, Kenneth, and Justin Mankin. 2019. "Is Temperature Exogenous? The Impact of Civil Conflict on the Instrumental Climate Record in Sub-Saharan Africa." American Journal of Political Science 63 (4): 723-39.

Schultz, T. 2011. "Fertility in Developing Countries." SSRN.

Seo, S. 2019. "Will farmers fully adapt to monsoonal climate change through technological developments? An analysis of rice and livestock production in Thailand." Journal of Agricultural Science 157 (2): 97-108.

Shen, Xinyi, Chenkai Cai, and Hui Li. 2020. "Quantifying socioeconomic activities and weather effects on the global spread of COVID-19 epidemic." Arxiv.

Shifa, Abdulaziz. 2015. "Does Agricultural Growth Cause Manufacturing Growth?" Economica 82: $1107-25$.

Siyi, Liu, Weng Ruoyu, and Yang Daoguang. 2017. "Natural disaster, fiscal pressure and tax avoidance: a typhoon-based study." China Journal of Accounting Studies 5 (4): 468-509. 
Skoufias, Emmanuel, and Katja Vinha. 2012. "Climate variability and child height in rural Mexico." Economics and Human Biology 10 (1): 54-73.

Spencer, Nekeisha, and Eric Strobl. 2019. "Crime Watch: Hurricanes and Illegal Activities." Southern Economic Journal 86 (1): 318-38.

Stokes, Leah. 2016. "Electoral Backlash against Climate Policy: A Natural Experiment on Retrospective Voting and Local Resistance to Public Policy." American Journal of Political Science 60 (4): 958-74.

Strobl, Eric, and Marie Valfort. 2015. "The effect of weather-induced internal migration on local labor markets. Evidence from Uganda." World Bank Economic Review 29 (2): $385-412$.

Swamy, Anand, and Brian Fikkert. 2002. "Estimating the contributions of capital and labor to GDP: An instrumental variable approach." Economic Development and Cultural Change 50 (3): 693-708.

Tack, Jesse, and Matthew Holt. 2016. "The influence of weather extremes on the spatial correlation of corn yields." Climatic Change 134 (1-2): 299-309. 
Tamada, Keiko. 2009. "The Effect of Election Outcomes on the Allocation of Government Spending in Japan." Japanese Economy 36 (1): 3-26.

Tevie, J., A. Bohara, and R. Valdez. 2014. "Examination of the geographical variation in human West Nile virus: A spatial filtering approach.” Epidemiology and Infection 142 (12): $2522-29$.

Thai, Thuan, and Mikko Myrskylä. 2012. "Rainfall shocks, parental behavior and breastfeeding: Evidence from rural Vietnam." Preprint.

Theisen, Ole. 2012. "Climate clashes? weather variability, land pressure, and organized violence in Kenya, 1989-2004." Journal of Peace Research 49 (1): 81-96.

Theisen, Ole, and Helge Holtermann. 2010. "Climate wars." International Security 396 (8690): 79-106.

Thelwall, Mike, and Pardeep Sud. 2022. "Scopus 1900-2020: Growth in articles, abstracts, countries, fields, and journals." Quantitative Science Studies 3 (1): 37-50.

Tione, Sarah, and Stein Holden. 2020. "Can rainfall shocks enhance access to rented land? Evidence from Malawi." Centre for Land Tenure Studies Preprint, Centre for land tenure 
studies working paper, 05 (20).

Tiwari, Sailesh, Hanan Jacoby, and Emmanuel Skoufias. 2017. "Monsoon Babies: Rainfall shocks and child nutrition in Nepal." Economic Development and Cultural Change 65 (2): $167-88$.

Trinh, Trong, Simon Feeny, and Alberto Posso. 2021. "Rainfall shocks and child health: the role of parental mental health." Climate and Development 13 (1): 34-48.

Vahedi, Sajad. 2015. "Children's Skill Formation : The Role of Childhood Exposure to Pollution." Working Paper, 1-39.

Veljanoska, Stefanija. 2018. "Can Land Fragmentation Reduce the Exposure of Rural Households to Weather Variability?" Ecological Economics 154 (May): 42-51.

Ventura-Cots, Meritxell, Ariel Watts, Monica Cruz-Lemini, Neil Shah, Nambi Ndugga, Peter McCann, A. Barritt, et al. 2019. "Colder Weather and Fewer Sunlight Hours Increase Alcohol Consumption and Alcoholic Cirrhosis Worldwide." Hepatology 69 (5): 1916-30.

Viswanathan, Brinda, and K. Kumar. 2015. "Weather, agriculture and rural migration: Evidence from state and district level migration in India." Environment and Development 
Economics 20 (4): 469-92.

Vo, Thang. 2020. "Short-run and Long-run Gasoline Demand Elasticities : A Case Study of Australia." International Energy Journal 20 (September): 299-310.

Völker, Marc, and Hermann Waibel. 2010. "Do rural households extract more forest products in times of crisis? Evidence from the mountainous uplands of Vietnam." Forest Policy and Economics 12 (6): 407-14.

Waldman, Michael, Sean Nicholson, and Nodir Adilov. 2006. "Does Television Cause Autism?" NBER.

Wang, Li, Xianghong Zhou, Minghui Lu, and Zhaocai Cui. 2020. "Impacts of haze weather on tourist arrivals and destination preference: Analysis based on Baidu Index of 73 scenic spots in Beijing, China." Journal of Cleaner Production 273: 122887.

Wasow, Omar. 2020. "Agenda Seeding: How 1960s Black Protests Moved Elites, Public Opinion and Voting." American Political Science Review, 638-59.

Wiwanitkit, Viroj. 2006. "An observation on correlation between rainfall and the prevalence of clinical cases of dengue in Thailand." Journal of Vector Borne Diseases 43 (2): 73-76. 
Wolpin, Kenneth. 1982. "A New Test of the Permanent Income Hypothesis: The Impact of Weather on the Income and Consumption of Farm Households in India." International Economic Review 23 (3): 583.

Xi, Chen, Wei Xie, Xiaoguang Chen, and Pan He. 2022. "Weather Variations, Climate Change, and Demand for in-theater Movie Recreations: Evidence from High-Frequency Movie-Viewing Data in China." SSRN.

Xia, Yuanni, Jos Van Ommeren, Piet Rietveld, and Willem Verhagen. 2013. "Railway infrastructure disturbances and train operator performance: The role of weather." Transportation Research Part D: Transport and Environment 18 (1): 97-102.

Xinye, Zheng, and Chu Wei. 2019. Household energy consumption in china: 2016 report. China Renmin University Press.

Yang, Dean, and Hwa Choi. 2007. "Are remittances insurance? Evidence from rainfall shocks in the Philippines." World Bank Economic Review 21 (2): 219-48.

Zaveri, Esha, Jason Russ, and Richard Damania. 2020. "Rainfall anomalies are a significant driver of cropland expansion." PNAS 117 (19): 10225-33. 
Zhang, Tony. 2016. "Weather effects on social movements: Evidence from Washington, D.C., and New York City, 1960-95." Weather, Climate, and Society 8 (3): 299-311.

Zhang, Xue-mei, Fei-fei Lu, and Dan Xue. 2022. "Does China's carbon emission trading policy improve regional energy efficiency? - an analysis based on quasi-experimental and policy spillover effects." Environmental Science and Pollution Research 29 (14): 21166-83.

Zheng, Siqi, Jianghao Wang, Cong Sun, Xiaonan Zhang, and Matthew Kahn. 2019. "Air pollution lowers Chinese urbanites' expressed happiness on social media." Nature Human Behaviour 3 (3): 237-43.

Zimmermann, Laura. 2020. "Remember when it rained - Schooling responses to shocks in India." World Development 126: 104705. 